\title{
A Compendium of Tyrosine-kinase Inhibitors: Powerful and Efficient Drugs against Cancer
}

\author{
Costa, D. C. S.; Forezi, L. S. M.; Cardoso, M. F. C.; Ribeiro, R. C. B.; Pinto,
}

\author{
A. C.; Ferreira, V. F.; da Silva, F. C.*
}

Rev. Virtual Quim., 2017, 9 (3), 974-1064. Data de publicação na Web: 24 de abril de 2017

http://rvq.sbq.org.br

\section{Um Compêndio de Inibidores de Tirosina Quinase: Fármacos Poderosos e Eficientes contra o Câncer}

Resumo: Os inibidores das enzimas tirosina quinases (ITQs), também conhecidos como "tinibs", têm sido usados como fármacos mais modernos e eficazes no tratamento de diversos tipos de câncer. Este artigo é um compêndio de uma grande série de inibidores de tirosina quinase, recentemente aprovados ou que estão em fase de análise pelo FDA, contendo em cada um deles, relatos como: a primeira síntese química, linha de ação contra o câncer, fase clínica em que se encontram e o preço no mercado.

Palavras-chave: Tinibs; tirosina-quinase; quimioterapia; testes clínicos; câncer.

\begin{abstract}
The inhibitors of the enzymes tyrosine kinase (ITKs), also known by "tinibs", have been used as the most modern and effective tools in the treatment of several types of cancer. This article is a compilation of a huge series of tyrosine kinase inhibitors, recently approved or under clinical trials, containing in each of them information such as: the first chemical synthesis, the mechanism of action against cancer, clinical trials stage and price in the market.
\end{abstract}

Keywords: Tinibs; Tyrosine-kinase; chemotherapy; clinical trials; cancer.

\footnotetext{
* Universidade Federal Fluminense, Departamento de Química Orgânica, Campus do Valonguinho, CEP 24020-150, Niterói-RJ, Brasil.

Mgqofernando@vm.uff.br

DOI: $\underline{10.21577 / 1984-6835.20170063}$
} 


\title{
A Compendium of Tyrosine-kinase Inhibitors: Powerful and Efficient Drugs against Cancer
}

\author{
Dora Cristina S. Costa, ${ }^{a}$ Luana S. M. Forezi, ${ }^{\text {a }}$ Mariana Filomena C. \\ Cardoso, ${ }^{\mathrm{a}}$ Ruan Carlos B. Ribeiro, ${ }^{\mathrm{a}}$ Angelo C. Pinto, ${ }^{+}, \mathrm{b}$ Vitor F. Ferreira, ${ }^{\mathrm{a}}$ \\ Fernando de C. da Silva*,a \\ ${ }^{a}$ Universidade Federal Fluminense, Departamento de Química Orgânica, Campus do \\ Valonguinho, CEP 24020-150, Niterói-RJ, Brasil. \\ b Universidade Federal do Rio de Janeiro, Departamento de Química Orgânica, Instituto de \\ Química, Cidade Universitária, CEP 21941-590, Rio de Janeiro-RJ, Brazil. \\ *gqofernando@vm.uff.br
}

Recebido em 20 de novembro de 2016. Aceito para publicação em 16 de abril de 2017

\section{Introduction}

2. Tinibs Abstracts

3. Conclusions

\section{Introduction}

The synthesis of new drug is an important subject of organic chemistry since it allows the construction of molecules with various levels of complexity. ${ }^{1}$ In order to obtain new prototypes or drug candidates to be introduced in the pharmaceutical market it is necessary to accomplish several steps to get to target compound. Initially, there is a literature search to find the biological target, which allows us to promote rational design, perform the synthesis and find promising new prototype compounds. Afterward, is necessary to carry out studies to know the proper interactions with biological receptors and other active sites, as well as the elucidation of the relationships between their chemical structures and the biological activities. $^{2}$
It is critical that these drug candidates have their mechanisms of action elucidated by experiments in cell cultures, enzymatic tests and human models. The main objective of this phase is to verify how this substance behaves in an organism. In this phase, several protocols are followed in experimental animals and frequently some of them are canceled because they are unsatisfactory. ${ }^{3}$

When these results are shown to be promising, it is therefore necessary to proceed the clinical trials in humans. This stage is composed of three successive phases. Only after all those phases are completed the drug may be released to the market.

The phase 1 is based on testing the safety of the drug for the first time, especially in order to define dosage and side-effects. At this stage, small groups of 20 to 30 healthy volunteers are involved for a minimum of six 
months of testing. After ensuring the safety of the drug candidate, it goes to Phase 2, where the objective is to evaluate the efficacy and safety of the dosage established in the previous phase in a larger number of people, from 70 to 100 volunteers, for a period of testing of nearly one year. ${ }^{3}$

When the drug enters Stage 3, with evidence of drug efficacy, the drug candidate is compared to the best therapy available on the market for the target disease. Usually 100 to 1,000 volunteers are involved, and last phase lasts approximately three years. Generally, the studies of this phase are randomized, that is, the patients are divided into two groups: the control group, which receives the standard treatment and the investigational group, which receives the new treatment. The division between the groups is done in the form of a lottery performed in double or triple blind. ${ }^{3}$

Cancer is the generic name for defining a group of diseases that have in common the disordered growth of abnormal cells that invade tissues and organs and can spread to other parts of the body.

The cancer disease in all of its forms has been poorly understood. It is feared by the population since it can be fatal in most of the cases. The causes of this pathology are varied, however, it is estimated that $80-90 \%$ of cancers are related to the continuous exposure to environmental risk factors such as: infectious organisms, smoking, alcoholism, eating habits, medications, occupational factors, chemical agents and radiation.

Treatment varies according to the type of cancer, and, in many cases, requires the association between different therapeutic resources such as radiation therapy, chemotherapy, surgery or even transplantation. The development of new chemotherapeutics has improved the survival of patients, but there is still a need for the development of new drugs that are more specific, efficient and with fewer side effects.

This disease represents a public health concern due to the high incidence and mortality rate worldwide. According to the World Health Organization (WHO) it is estimated that by 2030, 21.4 million new cases of cancer will occur.

The protein tyrosine-kinases (PTK's) are responsible for the phosphorylation and modulation of the enzymatic activity being related to fundamental processes, such as the cell cycle, proliferation, differentiation, mobility and cell survival or death. ${ }^{4}$

PTK's are classified into protein kinase receptors (RTKs), such as insulin for example, and non-receptors (NRTKs) which are intracellular components, are Src, Jak, Abl, Fak, Fps, Csk, Syk, Pyk2, and Btk. RTKs play an important role not only as key regulators of normal cellular processes, but also in the development and progression of various types of cancer. ${ }^{4}$

Generally, the inhibitors of the enzymes tyrosine kinase (ITK's), also known by "tinibs", compete for the ATP binding site at the catalytic site of various oncogenic tyrosine kinases, have a safe therapeutic profile, and can be combined with other chemotherapies or radiation. ${ }^{4}$

There are currently no fully efficient therapies, but research regarding tyrosine kinase inhibitors (ITK's), targeting the neoangiogenesis of cancer, has shown good results, especially for progression-free survival. ${ }^{5}$

This paper shows a compilation, up to 2016, of a huge series of tyrosine-kinase inhibitors, recently (or nearly) approved, containing in each of them reports such as: reference to the first chemical synthesis, the mode of action against cancer, the stage of the clinical trials and price in the market. 


\section{Tinibs Abstracts}

\section{AC220 (Quizartinib)}

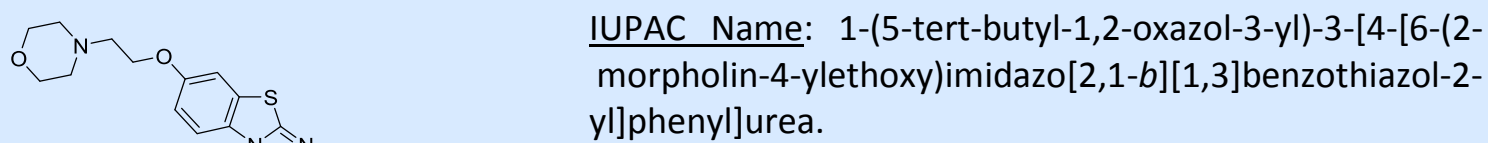
yl]phenyl]urea.

CAS: 950769-58-1.

First Report: Bhagwat et al. from Ambit Biosciences Corporation, in $2007 .{ }^{6}$

Activity: Quizartinib (AC220) is a small molecule receptor tyrosine kinase inhibitor FLT3, also known as CD135 which it has an half maximal inhibitory concentration $\left(\mathrm{IC}_{50}\right)$ of $0.56 \mathrm{nM}$, that is currently under development for the treatment of acute myeloid leukaemia. ${ }^{7,8}$

Clinical Trials: Stage $3 .^{9}$

Storage / Stability: Stable if stored at $-20^{\circ} \mathrm{C}^{10}$

Prices: 5 mg - 230 EUR, 25 mg - 920 EUR, 100 mg - 2760 EUR. $^{11}$

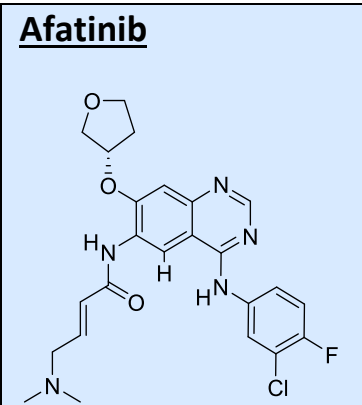

IUPAC Name: (E)-N-[4-(3-chloro-4-fluoroanilino)-7-[(3S)-oxolan-3yl]oxyquinazolin-6-yl]-4-(dimethylamino)but-2-enamide.

CAS: 850140-72-6.

First Report: Soyka et al. from Boehringer Ingelheim International $\mathrm{GmbH}$, in 2005. ${ }^{12}$ the activity of human epidermal growth factor receptor 2 (Her2) and epidermal growth factor receptor (EGFR) kinases. It is a candidate drug against non-small cell lung (NSCL) carcinoma, glioma, and cancers of the breast, prostate, head and neck. ${ }^{13-15}$

Clinical Trials: Stage $4 .^{16}$

Storage / Stability: Stable if stored Store at $-20^{\circ} \mathrm{C}$, keeping the container tightly closed. ${ }^{17}$

Prices: 5 mg - 85 EUR, 25 mg - 340 EUR, 100 mg - 1020 EUR. $^{18}$

\section{Alectinib}

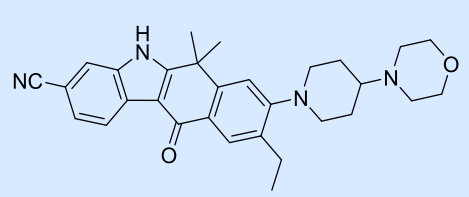

IUPAC Name: 9-ethyl-6,6-dimethyl-8-(4-morpholin-4ylpiperidin-1-yl)-11-oxo-5H-benzo[b]carbazole-3-carbonitrile.

CAS: $1256589-74-8$.

Ltd., in $2010 .^{19}$

First Report: Kinoshita et al. from Chugai Pharmaceutical Co.,

Activity: Alectinib is potent, selective, and orally available ALK inhibitor ( $\mathrm{IC}_{50}$ value of $1.9 \mathrm{nM}$ ) showing preferential antitumour activity against cancers with gene alterations of ALK, such as nonsmall cell lung cancer (NSCLC) cells expressing EML4-ALK fusion and anaplastic large-cell 
lymphoma (ALCL) cells expressing NPM-ALK fusion in vitro and in vivo. It inhibited ALK L1196M, which corresponds to the gatekeeper mutation conferring common resistance to kinase inhibitors and blocked EML4-ALK L1196M-driven cell growth. ${ }^{20,21}$

Clinical Trials: Stage $3 .^{22}$

Storage / Stability: Stable if stored at $-4{ }^{\circ} \mathrm{C}$ for short term (days to weeks) or for long term (months to years) if stored at $-20^{\circ} \mathrm{C}^{23}$

Prices: 5 mg - 120 EUR, 25 mg - 480 EUR, 100 mg - 1440 EUR. $^{24}$

\section{Aminopurvalanol}

$\mathrm{NH}_{2}$
IUPAC Name:
yl]amino]-3-methylbutan-1-ol.<smiles></smiles>

CAS: 220792-57-4.

First Report: Rosania et al. in 1999. ${ }^{25}$

Activity: Aminopurvalanol is a potent cyclin-dependent kinase inhibitor; it has $\mathrm{IC}_{50}$ values of $33 \mathrm{nM}$ for CDK1/cyclin B, $28 \mathrm{nM}$ for CDK2/cyclin E, and 20 $\mathrm{nM}$ for CDK5/p35. Aminopurvalanol-treated cells acquired phenotypic characteristics of differentiated macrophages and underwent cell cycle with 4N DNA content. Affinity chromatography and biochemical reconstitution experiments indicated that it targets cyclindependent kinase 1 (CDK1). This compound showed to be capable of the decreasing of the basal LNCaP human prostate cancer cell proliferation at $3 \mathrm{nM}^{26-28}$

Clinical Trials: No studies in the moment. ${ }^{29}$

Storage / Stability: Stable if stored at $-20^{\circ} \mathrm{C}$, Keeping the container tightly closed in a dry and well-ventilated place. ${ }^{30}$

Prices: 5 mg - 98 EUR, 25 mg - 392 EUR, 100 mg - 1176 EUR. $^{31}$

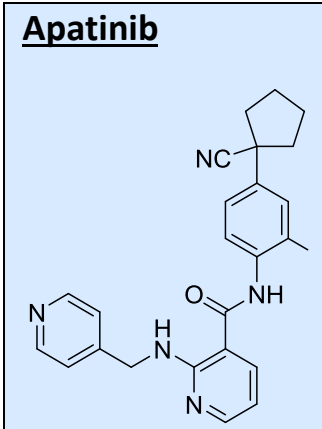

IUPAC Name: $\quad N$-[4-(1-cyanocyclopentyl)phenyl]-2-(pyridin-4ylmethylamino)pyridine-3-carboxamide.

CAS: 1218779-75-9.

First Report: Yuan et al. from Jiangsu Hengrui Medicine, in $2004 .^{32}$

Activity: Apatinib is an orally bioavailable tyrosine kinase inhibitor that selectively inhibits the vascular endothelial growth factor receptor-2 (VEGFR2/KDR) with $\mathrm{IC}_{50}$ value of $2.4 \mathrm{nM}$. Inhibition of this important proangiogenic receptor blocks VEGF-mediated endothelial cell migration and proliferation that in turn reduces new blood vessel formation in tumour tissue. It is being developed as a potential targeted treatment for metastatic gastric carcinoma, metastatic breast cancer and advanced hepatocellular carcinoma. ${ }^{33,34}$

Clinical Trials: Stage $4 .^{35}$

Storage / Stability: Stable up to one week if stored at $4^{\circ} \mathrm{C}$ or six months if stored at $-20^{\circ} \mathrm{C} .{ }^{36}$ Prices: 5 mg - 165 EUR, 25 mg - 660 EUR, 100 mg - 1980 EUR. $^{37}$ 


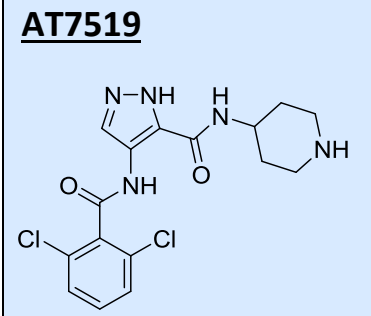

IUPAC Name: 4-[(2,6-dichlorobenzoyl)amino]-N-piperidin-4-yl- $1 \mathrm{H}$ pyrazole-5-carboxamide.

CAS: 844442-38-2.

First Report: Astex Technology Ltd., in 2005. ${ }^{38}$

Activity: AT7519 is a potent inhibitor of several cyclin-dependent kinases (CDKs) that showed potent antiproliferative activity $(40-940 \mathrm{nmol} / \mathrm{L})$ in a panel of human tumour cell lines. Shortterm treatments inhibited phosphorylation of the transcriptional marker RNA polymerase II and caused downregulation of the antiapoptotic protein MCL-1, without affecting the abundance of XIAP or BCL-2. The reduced abundance of the MCL-1 protein level was linked to an increase in cleaved poly(ADP-ribose) polymerase. The mechanism of action was shown to be consistent with the inhibition of CDK1, CDK2 and CDK9 in tumour cell lines. ${ }^{39-42}$ It is now under clinical trials as a potential targeted treatment for metastatic solid neoplasm, lymphoma and chronic lymphocytic leukaemia. ${ }^{43}$

Clinical Trials: Stage 2 completed. ${ }^{44}$

Storage / Stability: Stable if stored Store at $-20^{\circ} \mathrm{C} .^{45}$

Prices: 5 mg - 140 EUR, 25 mg - 560 EUR, 100 mg - 1680 EUR. $^{46}$

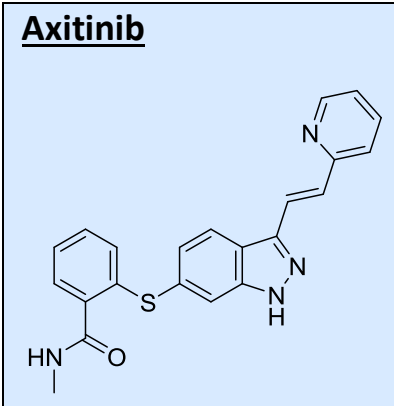

IUPAC Name: $N$-methyl-2-[[3-[(E)-2-pyridin-2-ylethenyl]-1H-indazol6-yl]sulfanyl]benzamide.

CAS: $319460-85-0$.

First Report: Kania et al. from Agouron Pharmaceuticals Inc., in 2001. ${ }^{47}$

Activity: Axitinib is a potent and selective oral inhibitor of vascular endothelial growth factor receptor tyrosine kinases 1, 2, 3. It inhibits cellular autophosphorylation of VEGF receptors (VEGFR) with 100-300 picomolar IC 50 values. Counterscreening across multiple kinase and protein panels showed that it is selective for VEGFRs. Axitinib blocks VEGF-mediated endothelial cell survival, tube formation, and downstream signaling through endothelial nitric oxide synthase, AKT and extracellular signalregulated kinase. It was approved for use in patients with renal cell carcinoma that had failed to respond to a previous treatment. ${ }^{48,49}$

Clinical Trials: Stage $4 .{ }^{50}$

Storage / Stability: Stable if stored at $-4{ }^{\circ} \mathrm{C}$ for short term (days to weeks) or for long term (months to years) if stored at $-20^{\circ} \mathrm{C} .{ }^{51}$

Prices: 25 mg - 52 EUR, 100 mg - 156 EUR, 250 mg - 312 EUR. ${ }^{52}$ 


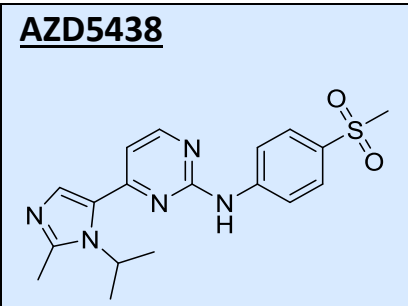

IUPAC Name: 4-(2-methyl-3-propan-2-ylimidazol-4-yl)- $N$-(4methylsulfonylphenyl)pyrimidin-2-amine.

CAS: 602306-29-6.

First Report: Wheeler et al. in $2003 .^{53}$

Activity: AZD5438 is a potent inhibitor of cyclin-dependent kinases (CDKs) 1,2 and 9 (IC $50,16$. 6 , and $20 \mathrm{nmol} / \mathrm{L}$, respectively). It exhibits significant in vitro antiproliferative activity in human tumour cell lines (with $I_{50}$ values ranging from 0.2-1.7 micromol/L), inhibiting the phosphorylation of CDK substrates including $\mathrm{pRb}$, nucleolin, protein phosphatase $1 \mathrm{a}$, and the carboxy-termiinal domain of RNA polymerase II. $\mathrm{n}$ this way, it blocks cell cycle progression in the $\mathrm{G}(2)-\mathrm{M}, \mathrm{S}$ and $\mathrm{G}(1)$ phases. It is currently undergoing clinical trials as an anticancer drug, namely, advanced solid malignancies like as lung, colorectal, breast, prostate, and hematologic tumours. $^{54}$

Clinical Trials: Stage 1 completed. ${ }^{55}$

Storage / Stability: Stable if stored at $-4{ }^{\circ} \mathrm{C}$ for short term (days to weeks) or for long term (months to years) if stored at $-20^{\circ} \mathrm{C} .{ }^{56}$

Prices: 5 mg - 88 EUR, 25 mg - 352 EUR, 100 mg - 1056 EUR. $^{57}$

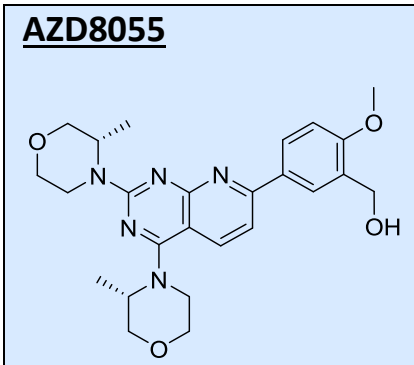

IUPAC Name: [5-[2,4-bis[(3S)-3-methylmorpholin-4-yl]pyrido[2,3d]pyrimidin-7-yl]-2-methoxyphenyl]methanol.

CAS: 1009298-09-2.

First Report: Chresta et al. in $2010 .^{58}$

Activity: AZD8055 is a potent, selective, and orally bioavailable mammalian target of rapamycin kinase inhibitor with in vitro and in vivo antitumour activity. It is an ATP-competitive inhibitor of mTOR kinase activity with an $\mathrm{IC}_{50}$ of $0.8 \mathrm{nmol} / \mathrm{L}$. AZD8055 showed excellent selectivity (approximately 1,000-fold) against all class I phosphatidylinositol 3-kinase (PI3K) isoforms and other members of the PI3K-like kinase family. Moreover, it exhibited no significant activity against a panel of 260 kinases at concentrations of up to 10 micromol/L. AZD8055 inhibits the phosphorylation of mTORC1 substrates p70S6K and 4E-BP1 as well as that of the mTORC2 substrate AKT and downstream proteins. ${ }^{58}$

Clinical Trials: Stage 1 completed. $^{59}$

Storage / Stability: Stable if stored at $-4{ }^{\circ} \mathrm{C}$ for short term (days to weeks) or for long term (months to years) if stored at $-20^{\circ} \mathrm{C} .{ }^{60}$

Prices: 5 mg - 74 EUR, 25 mg - 296 EUR, 100 mg - 888 EUR. ${ }^{61}$ 


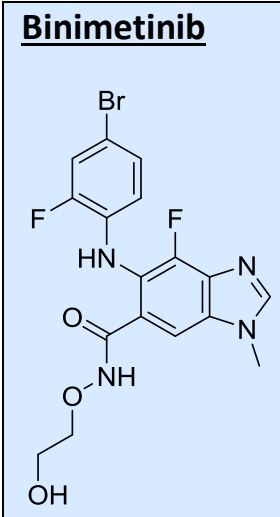

IUPAC Name: 6-(4-bromo-2-fluoroanilino)-7-fluoro- $N$-(2-hydroxyethoxy)-3methylbenzimidazole-5-carboxamide.

CAS: 606143-89-9.

First Report: Wallace et al. from Array BioPharma, Inc, in $2003 .{ }^{62}$

Activity: Binimetinib is a second generation MEK1/2 inhibitor with demonstrated efficacy against BRAF- and RAS-mutant tumours. Binimetinib is an ATP-uncompetitive inhibitor of MEK1/2, with nanomolar activity against purified MEK enzyme $\left(\mathrm{IC}_{50}=12 \mathrm{nM}\right)$, but without any activity on a kinase panel of 220 enzymes at a dose of $10 \mu \mathrm{M}$. It inhibits both basal and induced levels of ERK phosphorylation in numerous cancer cell lines with $\mathrm{IC}_{50}$ 's as low as $5 \mathrm{nM}$. Binimetinib is especially potent at inhibiting the cell proliferation of mutant B-Raf and Ras cell lines such as HT29, Malme-3M, SK-MEL-2, COLO 205, SK-MEL-28 and A375 (IC 50 $_{5}$ from 30-250 $\mathrm{nM}){ }^{63,64}$

Clinical Trials: Stage $3 .^{65}$

Storage / Stability: Stable if stored at $-4{ }^{\circ} \mathrm{C}$ for short term (days to weeks) or for long term (months to years) if stored at $-20^{\circ} \mathrm{C} .66$

Prices: 5 mg - 65 EUR, 25 mg - 195 EUR, 100 mg - 585 EUR. ${ }^{67}$

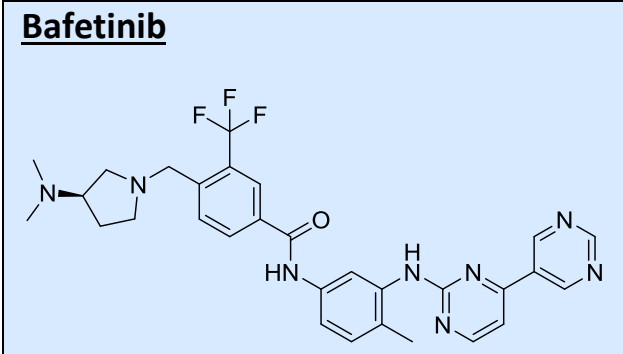

IUPAC Name: 4-[[(3S)-3-(dimethylamino)pyrrolidin-1yl]methyl]- $N$-[4-methyl-3-[(4-pyrimidin-5-ylpyrimidin2-yl)amino]phenyl]-3-(trifluoromethyl)benzamide.

CAS: 859212-16-1.

First Report: Asaki et al. from Nippon Shinyaku Co., Ltd., in $2005 .{ }^{68}$

Activity: Bafetinib is an orally available, dual $B C R / A B L$ and Lyn kinase inhibitor that was developed to treat $B C R / A B L$ positive leukaemias such as chronic myelogenous leukaemia (CML) and Philadelphia-positive acute lymphoblastic leukaemia (AML). It is 25 - to 55 -fold more potent than imatinib in vitro and at least 10-fold more potent in vivo. Bafetinib inhibits 12 of the 13 most frequent imatinib-resistant $B C R-A B L$ isoforms originating from point mutations, but not that bearing the Thr315lle mutation. ${ }^{69,70}$

Clinical Trials: Stage 2 completed. ${ }^{71}$

Storage / Stability: Stable if stored at $-4{ }^{\circ} \mathrm{C}$ for short term (days to weeks) or for long term (months to years) if stored at $-20^{\circ} \mathrm{C}^{72}$

Prices: 5 mg - 194 EUR, 25 mg - 776 EUR, 100 mg - 2328 EUR. $^{73}$ 


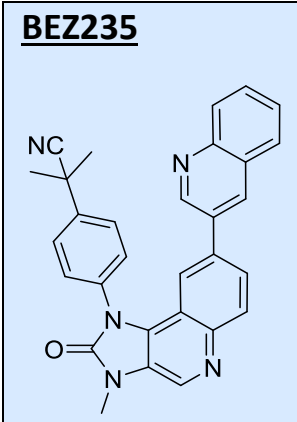

IUPAC Name: 2-methyl-2-[4-(3-methyl-2-oxo-8-quinolin-3-ylimidazo[4,5c]quinolin-1-yl)phenyl]propanenitrile.

CAS: 915019-65-7.

First Report: Garcia-Echeverria et al. from Novartis Ag, in 2006. ${ }^{74}$

Activity: BEZ235 is an imidazo[4,5-c]quinoline derivative that competitively inhibits the PI3K and mTOR kinases, efficiently and selectively preventing dysfunctional activation of the PI3K pathway and thereby inducing $\mathrm{G}(1)$ arrest. It has an $\mathrm{IC}_{50}$ value of $4 \mathrm{nM}$ against the $\mathrm{p} 110 \mathrm{a}$ isoform of $\mathrm{PI} \mathrm{KK}, 75 \mathrm{nM}$ against the $\mathrm{p} 110 \mathrm{~b}$ isoform, $7 \mathrm{nM}$ against the p110d isoform and $5 \mathrm{nM}$ against the p110g isoform. ${ }^{75-77}$ Currently it is under clinical trials for treatment of castration-resistant prostate cancer, inoperable locally advanced breast cancer and also metastatic breast cancer (MBC) ${ }^{78}$

Clinical Trials: Stage 2 completed. ${ }^{79}$

Storage / Stability: Stable if stored at $-4{ }^{\circ} \mathrm{C}$ for short term (days to weeks) or for long term (months to years) if stored at $-20^{\circ} \mathrm{C} .{ }^{80}$

Prices: 25 mg - 70 EUR, 100 mg - 210 EUR, 250 mg - 420 EUR. $^{81}$

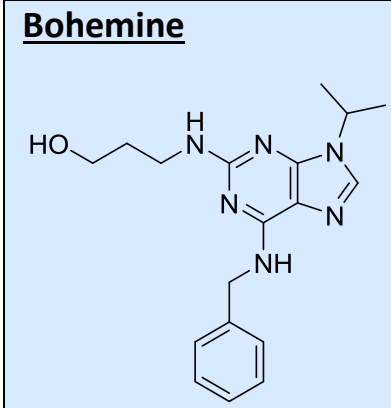

IUPAC Name: 3-[[6-(benzylamino)-9-propan-2-ylpurin-2yl]amino]propan-1-ol.

CAS: 189232-42-6.

First Report: Havlicek et al. in $1997 .^{82}$

Activity: The 2,6,9-trisubstituted purine derivative bohemine is a synthetic inhibitor of cyclin-dependent kinases that was developed from the original hit olomoucine. Bohemine inhibits CDK1 and CDK2 with $I C_{50}$ values of around 1 microM. It also exhibits antitumour activity in vitro, with a mean $\mathrm{IC}_{50}$ value of 27 microM, for CEM T-lymphoblastic leukaemia cell line. ${ }^{83-85}$

Clinical Trials: No studies in the moment. ${ }^{86}$

Storage / Stability: Stable if stored at $-4{ }^{\circ} \mathrm{C}$ for short term (days to weeks) or for long term (months to years) if stored at $-20^{\circ} \mathrm{C} .{ }^{87}$

Prices: 5 mg - 41 EUR, 25 mg - 164 EUR, 100 mg - 492 EUR. ${ }^{88}$

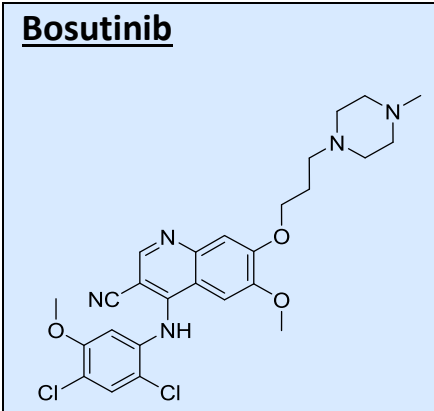

IUPAC Name: 4-(2,4-dichloro-5-methoxyanilino)-6-methoxy-7-[3(4-methylpiperazin-1-yl)propoxy]quinoline-3-carbonitrile.

CAS: $380843-75-4$.

First Report: Boschelli et al. from Wyeth Holdings Corporation, in $2003 .{ }^{89}$

Activity: Bosutinib is a dual inhibitor of the SRC and $A B L$ kinases. It inhibits the activating autophosphorylation of BCR-ABL in CML cells and of $v-A B L$ in fibroblasts. At concentrations that inhibit proliferation in CML cells, this inhibits the phosphorylation of 
cellular proteins such as STAT5. Preclinical studies demonstrated bosutinib to have strong antiproliferative activity in human and murine CML cell lines. It also performed well in clinical trials, exhibiting high clinical efficacy, good tolerability and low toxicity in imatinib-resistant or intolerant CML patients. ${ }^{90-92}$

Clinical Trials: Stage $4 .^{93}$

Storage / Stability: Stable if stored at $-4{ }^{\circ} \mathrm{C}$ for short term (days to weeks) or for long term (months to years) if stored at $-20^{\circ} \mathrm{C} .{ }^{94}$

Prices: 5 mg - 52 EUR, 25 mg - 208 EUR, 100 mg - 624 EUR. ${ }^{95}$

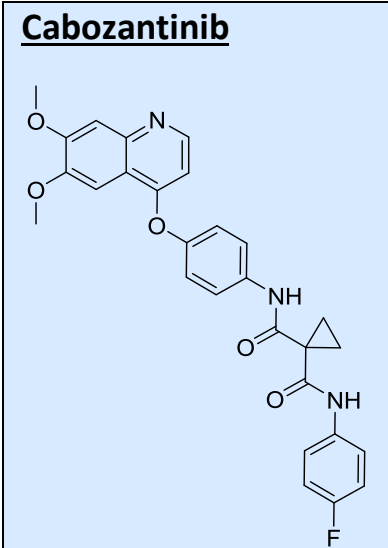

IUPAC Name: 1-N-[4-(6,7-dimethoxyquinolin-4-yl)oxyphenyl]-1-N'-(4fluorophenyl)cyclopropane-1,1-dicarboxamide.

CAS: 849217-68-1.

First Report: Bannen et al. from Exelixis, Inc., in $2005 .^{96}$

Activity: Cabozantinib is a small molecule kinase inhibitor of MET and VEGFR2, as well as a number of other receptor tyrosine kinases that have also been implicated in tumour pathobiology, including RET, KIT, AXL. Treatment with cabozantinib inhibited MET and VEGFR2 phosphorylation and led to significant reductions in cell invasion. ${ }^{97,98}$ It is currently under clinical trials for medullary thyroid cancer, melanoma, prostate cancer, breast cancer, metastatic brain tumour and, also, non-small cell lung cancer treament. ${ }^{99}$

Clinical Trials: Stage $4 .^{100}$

Storage / Stability: Stable if stored at $-4{ }^{\circ} \mathrm{C}$ for short term (days to weeks) or for long term (months to years) if stored at $-20^{\circ} \mathrm{C} .{ }^{101}$

Prices: 5 mg - 140 EUR, 25 mg - 560 EUR, 100 mg - 1680 EUR. ${ }^{102}$

\section{CAL-101 (Idelalisib)}<smiles>CC[C@H](Nc1ncnc2nc[nH]c12)c1nc2cccc(F)c2c(=O)n1-c1ccccc1</smiles>

IUPAC Name: 5-fluoro-3-phenyl-2-[(1S)-1-(7H-purin-6ylamino)propyl]quinazolin-4-one.

CAS: 870281-82-6.

First Report: Fowler et al. from Icos Corporation, in $2005 .{ }^{103}$

Activity: CAL-101 is a potent inhibitor of PI3 kinase with an IC ${ }_{50}$ of $65 \mathrm{nM}$ for the p110d isoform. It blocks constitutive PI3K signaling which disfavours AKT phosphorylation and promotes apoptosis in primary CLL cells ex vivo in a doseand time-dependent fashion. ${ }^{104}$

Clinical Trials: Stage $4 .{ }^{105}$

Storage / Stability: Stable if stored at $-4{ }^{\circ} \mathrm{C}$ for short term (days to weeks) or for long term (months to years) if stored at $-20^{\circ} \mathrm{C} .{ }^{106}$

Prices: 5 mg - 74 EUR, 25 mg - 296 EUR, 100 mg - 888 EUR. ${ }^{107}$ 


\section{CAN508}

N-NH IUPAC Name: 4-[(3,5-diamino-1H-pyrazol-4-yl)hydrazinylidene]cyclohexa-2,5$\mathrm{NH}_{2}$ dien-1-one.<smiles>NNc1ccc(O)cc1</smiles>

CAS: 140651-18-9.

First Report: Krystof et al. in 2006. ${ }^{108}$

Activity: CAN508 was described as a selective inhibitor of transcriptional cyclin-dependent kinase 9 . Its cellular effects include decreased phosphorylation of the C-terminal domain of RNA polymerase II, inhibition of mRNA synthesis, and induction of the tumour suppressor protein $\mathrm{p} 53$, all of which are consistent with inhibition of CDK9. ${ }^{108-112}$

Clinical Trials: No studies in the moment. ${ }^{113}$

Storage / Stability: Stable if stored at $4{ }^{\circ} \mathrm{C} .{ }^{114}$

Prices: 5 mg - 52 EUR, 25 mg - 208 EUR, 100 mg - 624 EUR. ${ }^{115}$

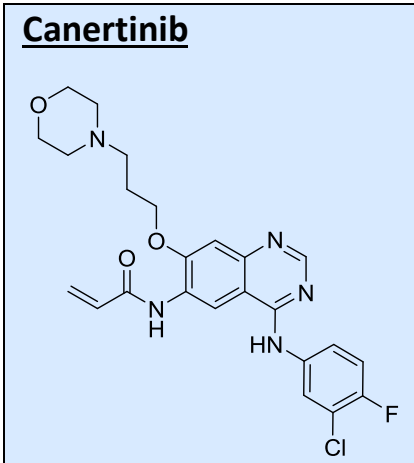

IUPAC Name: $\quad N$-[4-(3-chloro-4-fluoroanilino)-7-(3-morpholin-4ylpropoxy)quinazolin-6-yl]prop-2-enamide.

CAS: 267243-28-7.

First Report: Smaill et al. in 2000. ${ }^{116}$

Activity: Canertinib is an orally available irreversible inhibitor of receptor tyrosine kinases that targets EGFRs. It has $I C_{50}$ values of $0.8,19$ and $7 \mathrm{nM}$ for EGFR, HER-2 and ErbB-4, respectively. Canertinib was beány developed as an anticancer drug, but its development was discontinued. ${ }^{117}$ Now, it is under clinical evaluation for breast and and NSCL carcinoma treatment. ${ }^{118}$

Clinical Trials: Stage 2 completed. ${ }^{119}$

Storage / Stability: Stable if stored at $-4{ }^{\circ} \mathrm{C}$ for short term (days to weeks) or for long term (months to years) if stored at $-20{ }^{\circ} \mathrm{C} .{ }^{120}$

Prices: 5 mg - 52 EUR, 25 mg - 208 EUR, 100 mg - 624 EUR. ${ }^{121}$

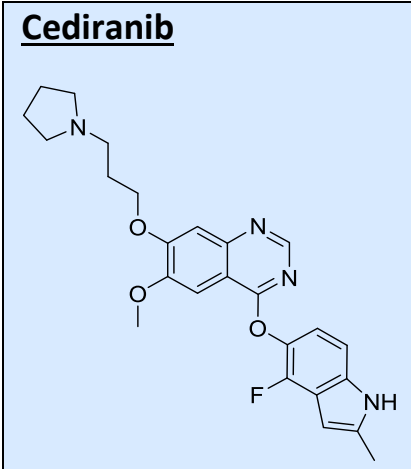

IUPAC Name: 4-[(4-fluoro-2-methyl-1H-indol-5-yl)oxy]-6-methoxy-7(3-pyrrolidin-1-ylpropoxy)quinazoline.

CAS: 288383-20-0.

First Report: Wheeler et al. in $2003 .{ }^{53}$

Activity: Cediranib is a highly potent $\left(\mathrm{IC}_{50}<1 \mathrm{nmol} / \mathrm{L}\right)$ ATPcompetitive inhibitor of KDR tyrosine kinase. Concordant with this activity it inhibits VEGF-stimulated proliferation and KDR phosphorylation in human umbilical vein endothelial cells with $\mathrm{IC}_{50}$ values of 0.4 and $0.5 \mathrm{nmol} / \mathrm{L}$, respectively. In a fibroblast/endothelial cell co-culture model for vessel sprouting, Cediranib also reduced vessel area, length, and branching at subnanomolar 
concentrations. $^{122}$

Clinical Trials: Stage 3 completed. ${ }^{123}$

Storage / Stability: Stable if stored at $-4{ }^{\circ} \mathrm{C}$ for short term (days to weeks) or for long term (months to years) if stored at $-20^{\circ} \mathrm{C}^{124}$

Prices: 5 mg - 140 EUR, 25 mg - 560 EUR, 100 mg - 1680 EUR. ${ }^{125}$

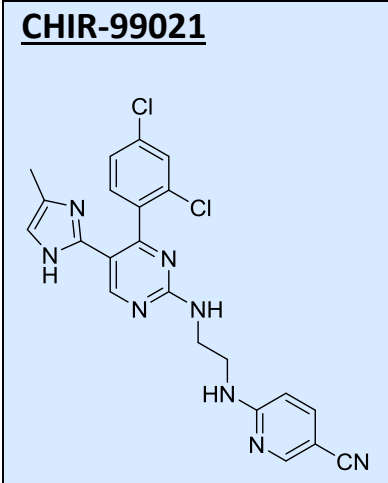

IUPAC Name: 6-[2-[[4-(2,4-dichlorophenyl)-5-(5-methyl-1H-imidazol2-yl)pyrimidin-2-yl]amino]ethylamino]pyridine-3-carbonitrile.

CAS: 252917-06-9.

First Report: MacDougald et al. fromChiron Corporation, in $2002 .{ }^{126}$

Activity: CHIR-99021 is a glycogen synthase kinase 3b (GSK3b) inhibitor with an $\mathrm{IC}_{50}$ value of $7 \mathrm{nM}$. It does not exhibit cross-reactivity against CDKs and is reported to have a 350 -fold selectivity toward GSK3b. CHIR-99021 inhibits cellular proliferation with an IC 50 value of about 10 microM. ${ }^{127}$ It is most effective in solid tumours, such as, pancreatic tumors. ${ }^{128}$

Clinical Trials: No studies in the moment. ${ }^{129}$

Storage / Stability: Stable if stored at $-4{ }^{\circ} \mathrm{C}$ for short term (days to weeks) or for long term (months to years) if stored at $-20^{\circ} \mathrm{C} .{ }^{130}$

Prices: 5 mg - 194 EUR, 25 mg - 776 EUR, 100 mg - 2328 EUR. ${ }^{131}$

\section{CHIR-258}

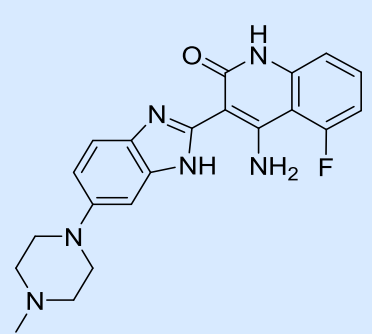

IUPAC Name: (3E)-4-amino-5-fluoro-3-[5-(4-methylpiperazin-1-yl)1,3-dihydrobenzimidazol-2-ylidene]quinolin-2-one.

CAS: 915769-50-5.

First Report: Renhowe et al. from Chiron Corporation, in 2002. ${ }^{132}$

Activity: CHIR-258 is an orally bioavailable, inhibitor of VEGFR-2,

FGFR-1, and PDGFRbeta, with $I_{50}$ values of $<0.1$ microM against these kinases. It is in phase III development for the treatment of renal cell carcinoma, and in phase II development as a treatment for advanced breast cancer, relapsed multiple myeloma and urothelial cancer. ${ }^{133,134}$

Clinical Trials: Stage 3 completed. ${ }^{135}$

Storage / Stability: Stable if stored at $-4{ }^{\circ} \mathrm{C}$ for short term (days to weeks) or for long term (months to years) if stored at $-20^{\circ} \mathrm{C}^{136}$

Prices: 5 mg - 53 EUR, 25 mg - 220 EUR, 100 mg - 660 EUR. ${ }^{137}$

\section{Crizotinib}




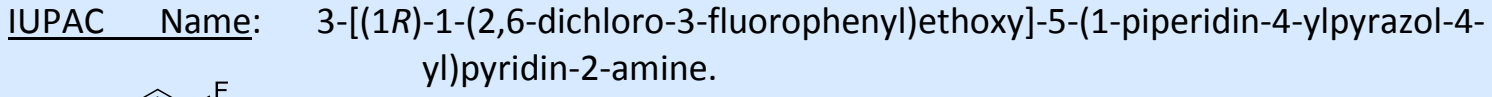
yl)pyridin-2-amine.

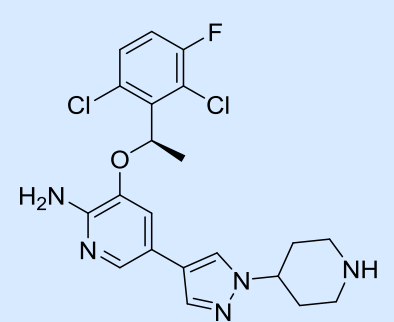

CAS: 877399-52-5.

First Report: Cui et al. from Pfizer Inc., in 2006. ${ }^{138}$

Activity: Crizotinib is an orally bioavailable, ATP-competitive, potent and selective dual inhibitor of the c-MET and ALK kinases. It has been particularly effective against anaplastic large cell lymphoma and non-small cell lung cancer (NSCLC) cell lines harboring ALK translocations that cause the expression of oncogenic ALK fusion proteins. ${ }^{139-142}$

Clinical Trials: Stage $4 .{ }^{143}$

Storage / Stability: Stable if stored at $-4{ }^{\circ} \mathrm{C}$ for short term (days to weeks) or for long term (months to years) if stored at $-20^{\circ} \mathrm{C}^{144}$

Prices: 5 mg - 85 EUR, 25 mg - 340 EUR, 100 mg - 1020 EUR. ${ }^{145}$

\section{$\underline{\text { CVT313 }}$}

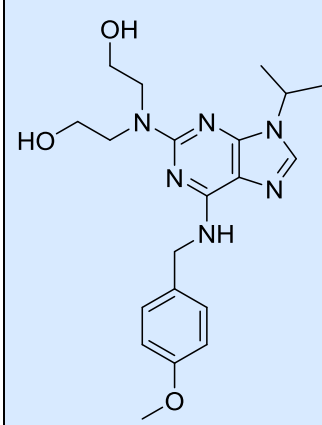

IUPAC Name: 2-[2-hydroxyethyl-[6-[(4-methoxyphenyl)methylamino]-9propan-2-ylpurin-2-yl]amino]ethanol.

CAS: 199986-75-9.

First Report: Brooks et al. in 1997. ${ }^{146}$

Activity: CVT-313 is a potent and selective CDK2 inhibitor with an $\mathrm{IC}_{50}$ of 0.5 microM in vitro. Its $\mathrm{IC}_{50}$ against $\mathrm{CDK} 4$ is 215 microM while those against MAPK, PKA, and PKC are $>1.25 \mathrm{mM}$; it has no effect on other, non-related ATP-dependent serine/threonine kinases. In cells exposed to CVT-313, hyperphosphorylation of the retinoblastoma gene product was inhibited, and progression through the cell cycle was arrested at the G1/S boundary. CVT-313 also inhibits CDC5L. ${ }^{147,148}$

Clinical Trials: No studies in the moment. ${ }^{149}$

Storage / Stability: Stable if stored at $-4{ }^{\circ} \mathrm{C}$ for short term (days to weeks) or for long term (months to years) if stored at $-20^{\circ} \mathrm{C} .{ }^{150}$

Prices: 5 mg - 98 EUR, 25 mg - 392 EUR, 100 mg - 1176 EUR. $^{151}$

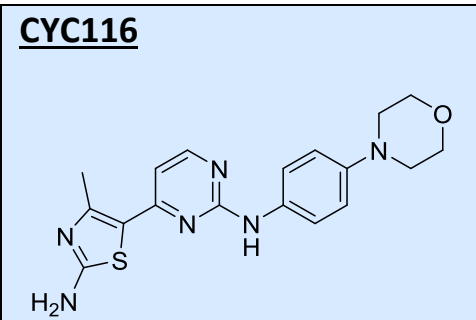

IUPAC Name: 4-methyl-5-[2-(4-morpholin-4-ylanilino)pyrimidin4-yl]-1,3-thiazol-2-amine.

CAS: 693228-63-6.

First Report: Wang et al. in 2010. ${ }^{152}$

Activity: CYC116 is a small molecule inhibitor of aurora kinases $A$ and $B$ with $\mathrm{K}(\mathrm{i})$ values of 8.0 and $9.2 \mathrm{nM}$, respectively, in myelogenous leukaemia cell line MV4-11. Its anticancer effects were shown to emanate from cell death following mitotic failure and increased polyploidy due to cellular inhibition of the aurora kinases. ${ }^{152}$

Clinical Trials: Stage $1 .{ }^{153}$

Rev. Virtual Quim. |Vol 9| |No. 3| |974-1064| 
Storage / Stability: Stable if stored at $-4{ }^{\circ} \mathrm{C}$ for short term (days to weeks) or for long term (months to years) if stored at $-20^{\circ} \mathrm{C} .{ }^{154}$

Prices: 5 mg - 74 EUR, 25 mg - 296 EUR, 100 mg - 888 EUR. ${ }^{155}$

\section{CYT387}<smiles>N#CCNC(=O)c1ccc(-c2ccnc(Nc3ccc(N4CCOCC4)cc3)n2)cc1</smiles>

IUPAC Name: $\quad N$-(cyanomethyl)-4-[2-(4-morpholin-4ylanilino)pyrimidin-4-yl]benzamide.

CAS: 1056634-68-4.

First Report: Burns et al. from Cytopia Research, in $2008 .^{156}$

Activity: CYT387 is a potent inhibitor of the JAK1 and JAK2 kinases $\left(\mathrm{IC}_{50}=11\right.$ and $18 \mathrm{nM}$, respectively) that is significantly less active against other kinases, including JAK3 $\left(\mathrm{IC}_{50}=155\right.$ nM). CYT387 caused growth suppression and apoptosis in JAK2-dependent hematopoietic cell lines, while nonhematopoietic cell lines were unaffected. It is being developed to treat myeloproliferative neoplasms/disorders. ${ }^{157-159}$

Clinical Trials: Stage $3 .^{160}$

Storage / Stability: Stable if stored at $-4{ }^{\circ} \mathrm{C}$ for short term (days to weeks) or for long term (months to years) if stored at $-20^{\circ} \mathrm{C} .{ }^{161}$

Prices: 5 mg - 97 EUR, 25 mg - 388 EUR, 100 mg - 1164 EUR. ${ }^{162}$

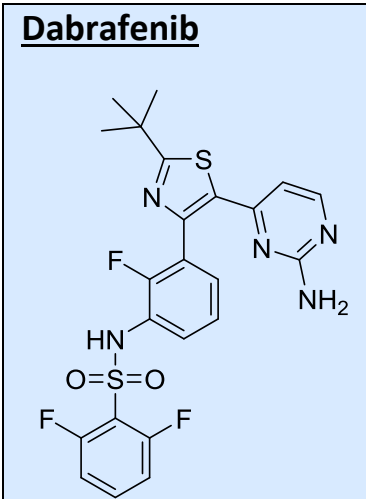

IUPAC Name: $N$-[3-[5-(2-aminopyrimidin-4-yl)-2-tert-butyl-1,3-thiazol4-yl]-2-fluorophenyl]-2,6-difluorobenzenesulfonamide.

CAS: 1195765-45-7.

First Report: Adams et al. from SmithKline Beecham Corporation, in 2009. ${ }^{163}$

Activity: Dabrafenib is the second selective BRAF inhibitor approved for treatment of BRAF-mutated metastatic melanoma. It is a highly potent ATP-competitive inhibitor of BRAF (V600E) and BRAF (V600K) kinases, with $\mathrm{IC}_{50}$ values of 0.6 and $0.5 \mathrm{nM}$, respectively. In contrast, B-Raf and c-Raf display 4- and 6fold weaker sensitivity, respectively. Dabrafenib has been shown to reduce MEK and ERK phosphorylation, induce G1 cell cycle arrest, followed by cell death. In a xenograft model of human melanoma expressing oncogenic BRAF (V600E), it inhibited ERK activation and tumor growth. ${ }^{164-166}$

Clinical Trials: Stage $3 .^{167}$

Storage / Stability: Stable if stored at $-4{ }^{\circ} \mathrm{C}$ for short term (days to weeks) or for long term (months to years) if stored at $-20^{\circ} \mathrm{C} .{ }^{168}$

Prices: 5 mg - 80 EUR, 25 mg - 320 EUR, 100 mg - 660 EUR $^{169}$

\section{Danusertib}




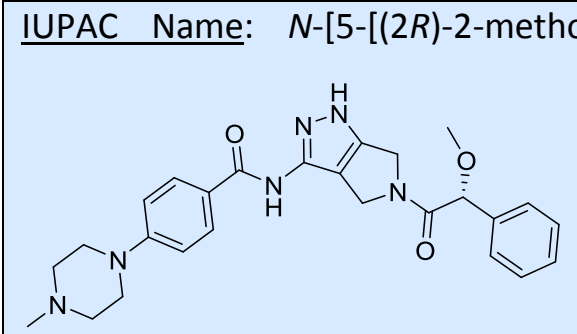

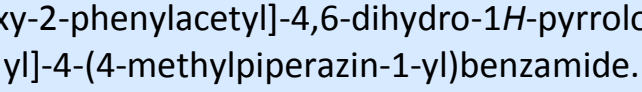

CAS: 827318-97-8.

First Report: Fancelli et al. in 2006. ${ }^{170}$

Activity: Danusertib (PHA-739358) is a small-molecule pan-aurora kinase inhibitor. It also inhibits the kinase activity of wild-type $A B L$ and of several mutants (including T315I) in vitro. ${ }^{171,172}$ It is under clinical trials for treatment of metastatic hormone refractory prostate cancer and multiple myeloma. ${ }^{173}$

Clinical Trials: Stage 2 completed. ${ }^{174}$

Storage / Stability: Stable if stored at $-4{ }^{\circ} \mathrm{C}$ for short term (days to weeks) or for long term (months to years) if stored at $-20^{\circ} \mathrm{C} .{ }^{175}$

Prices: 5 mg - 195 EUR, 25 mg - 780 EUR, 100 mg - 2340 EUR. ${ }^{176}$

\section{Dasatinib}<smiles>Cc1nc(Nc2ncc(C(=O)Nc3c(C)cccc3Cl)s2)cc(N2CCN(CCO)CC2)n1</smiles>

IUPAC Name: $N$-(2-chloro-6-methylphenyl)-2-[[6-[4-(2hydroxyethyl)piperazin-1-yl]-2-methylpyrimidin-4yl]amino]-1,3-thiazole-5-carboxamide.

CAS: 302962-49-8.

First Report: Das et al. from Bristol-Myers Squibb Co., in 2000. ${ }^{177}$

Activity: Dasatinib is a dual SRC/ABL kinase inhibitor with potent antitumor activity, such as, chronic myeloid leukaemia and melanoma. ${ }^{178}$ In addition to inhibiting the wild-type BCR-ABL, dasatinib inhibited 14 of 15 BCR-ABL mutants. It is a potent inhibitor of all members of the SRC family, including C-SRC, LCK, FYN and YES (IC $50<1.1 \mathrm{nmol} / \mathrm{L}) .{ }^{179-182}$

Clinical Trials: Stage 4 completed. ${ }^{183}$

Storage / Stability: Stable if stored at $-4{ }^{\circ} \mathrm{C}$ for short term (days to weeks) or for long term (months to years) if stored at $-20^{\circ} \mathrm{C} .{ }^{184}$

Prices: 25 mg - 103 EUR, 100 mg - 309 EUR, 250 mg - 618 EUR. ${ }^{185}$

\section{Dinaciclib}

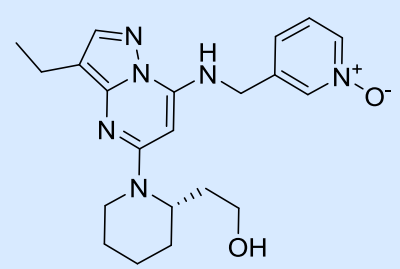

IUPAC Name: 2-[(2S)-1-[3-ethyl-7-[(1-oxidopyridin-1-ium-3yl]ethanol. yl)methylamino]pyrazolo[1,5-a]pyrimidin-5-yl]piperidin-2-

CAS: 779353-01-4.

First Report: Paruch et al. in 2010. ${ }^{186}$

Activity: Dinaciclib inhibits CDK2, CDK5, CDK1, and CDK9 activity in vitro with IC ${ }_{50}$ values of 1,1 , 3 , and $4 \mathrm{nmol} / \mathrm{L}$, respectively. In cell-based assays, it completely suppressed pRB phosphorylation, blocked cellular replication and induced apoptosis. Dinaciclib induced regression of established solid tumors in a range of mouse models following intermittent scheduling of doses below the maximally tolerated level. ${ }^{187,188}$ IT is currently under clinical trials for treatment of chronic lymphocytic leukaemia, advanced or metastatic breast cancer and lymphoma. ${ }^{189}$ 
Clinical Trials: Stage 3 completed. ${ }^{190}$

Storage / Stability: Stable if stored at $-4{ }^{\circ} \mathrm{C}$ for short term (days to weeks) or for long term (months to years) if stored at $-20^{\circ} \mathrm{C} .{ }^{191}$

Prices: 5 mg - 130 EUR, 25 mg - 520 EUR. ${ }^{192}$

\section{Enzastaurin}

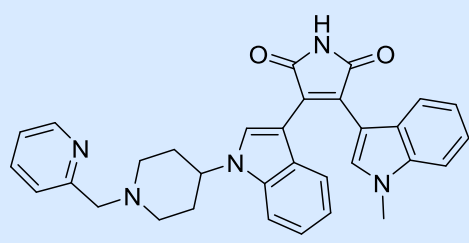

IUPAC Name: 3-(1-methyl-1H-indol-3-yl)-4-(1-(1-(2-pyridinyl methyl)-4-piperidinyl)-1H-indol-3-yl)-1H-pyrrole-2,5-dione.

\section{CAS: 170364-57-5.}

First Report: Teicher et al. in $2002 .{ }^{193}$

Activity: Enzastaurin is an inhibitor of several isoforms of protein kinase $C$, including beta, alpha, gamma and epsilon, with $\mathrm{IC}_{50}$ values of $6,39,83$ and $110 \mathrm{nM}$, respectively. Enzastaurin inhibits tumor growth through several mechanisms: block of tumor cell proliferation, induction of tumor cell apoptosis and inhibition of tumor-induced angiogenesis. ${ }^{194,195}$ It is, at the present, under clinical studies for non Hodgkin lymphoma, glioblastoma, NSCL cancer, breast cancer and prostate cancer treatment. ${ }^{196}$

Clinical Trials: Stage 3 completed. ${ }^{197}$

Storage / Stability: Storage temperature: $2-4{ }^{\circ} \mathrm{C}$ and keep container tightly closed in a dry and well-ventilated place. This product is relatively unstable under normal temperature. ${ }^{198}$

Prices: 5 mg - 62 EUR, 25 mg - 248 EUR, 100 mg - 744 EUR. ${ }^{194}$

\section{Erlotinib Hydrochloride}

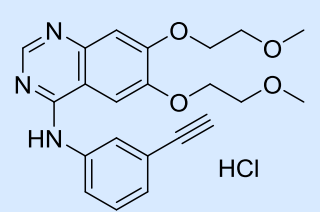

IUPAC Name: $N$-(3-ethynylphenyl)-(6,7-bis(2-methoxyethoxy)quinazolin4-yl)-amine hydrochloride.

CAS: 183319-69-9.

First Report: Moyer et al. in 1997. ${ }^{199}$

Activity: Erlotinib is a low molecular weight, orally active, epidermal growth factor receptor (EGFR) tyrosine kinase inhibitor $\left(\mathrm{IC}_{50}=2 \mathrm{nmol} / \mathrm{L}\right)$. Inhibition of the EGFR tyrosine kinase disrupts of processes involved in cancer growth and development, including cell migration, proliferation, angiogenesis, and apoptosis. Erlotinib is used clinically for the treatment of nonsmall-cell lung cancer (NSCLC). ${ }^{200-202}$

Clinical Trials: Stage 4 completed. ${ }^{203}$

Storage / Stability: Stable store in a cool, dry, well-ventilated area away from incompatible. Stable under normal temperatures and pressures. ${ }^{204}$

Prices: 25 mg - 35 EUR, 100 mg - 103 EUR, 250 mg - 206 EUR. 


\section{Estybon (Rigosertib)}<smiles>COc1cc(OC)c(/C=C/S(=O)(=O)Cc2ccc(OC)c(NCC(=O)ON)c2)c(OC)c1</smiles>

IUPAC Name: $\quad N$-(2-methoxy-5-(((2-(2,4,6-trimethoxyphenyl)ethenyl) sulfonyl)methyl)phenyl)glycine sodium salt.

CAS: 1225497-78-8.

First Report: Premkumar Reddy et al. in 2005. ${ }^{205}$

Activity: Estybon is a non-ATP-competitive inhibitor of protein kinase PLK1 with an IC 50 of $9 \mathrm{nM}^{206,207}$ This TKI is, currently, under clinical trials for the treatment of several cancer types, such as, metastatic pancreatic adenocarcinoma, head and neck neoplasms, acute myelocytic Leukaemia, ovarian cancer and also, acute lymphocytic Leukaemia. ${ }^{208}$

Clinical Trials: Stage 2 completed. ${ }^{209}$

Storage/Stability: Keep container tightly closed in a dry and well-ventilated place. Recommended storage temperature: Store at $-20^{\circ} \mathrm{C}$. Keep in a dry place. ${ }^{210}$

Prices: 5 mg - 194 EUR; 25 mg - 776 EUR; 100 mg - 2328 EUR. $^{207}$

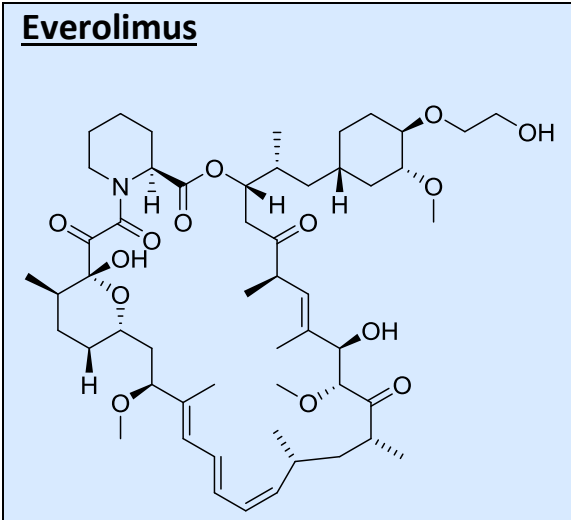

IUPAC Name: Dihydroxy-12-[(2R)-1-[(1S,3R,4R)-4-(2hydroxyethoxy)-3-methoxycyclohexyl]propan-2-yl]-19,30dimethoxy-15,17,21,23,29,35-hexamethyl-11,36-dioxa-4azatricyclo[30.3.1.0-hexatriaconta-16,24,26,28-tetraene2,3,10,14,20-pentone.

CAS: 159351-69-6.

First Report: Reported in $1966 .^{211}$

Activity: Everolimus is a derivative of rapamycin, a drug with immunosuppressant and anti-angiogenic properties. compared to rapamycin, it has structural modifications that confer improved aqueous solubility. Everolimus inhibits the activity of $\mathrm{mTOR}$, an intracellular serine-threonine kinase from phosphatidylinositol 3 kinase/protein kinase B signaling pathway, whose dysregulation leads to increased tumor growth. The inhibition of mTORresults in decreased protein synthesis as well as cell cycle arrest, leading to reduced cell proliferation. ${ }^{211,212}$ And also, it is under clinical trials for the treatment of breast cancer, pancreatic neuroendocrine tumours, hepatocellular carcinoma, metastatic renal cell carcinoma, angiomyolipoma and melanoma. ${ }^{213}$ Clinical Trials: Stage 4 completed. ${ }^{214}$

Storage/Stability: Keep container tightly closed in a dry and well-ventilated place. Recommended storage temperature: $-20^{\circ} \mathrm{C}$. Store under inert gas. ${ }^{215}$

Prices: 5 mg - 70 EUR, 25 mg - 280 EUR, 100 mg - 840 EUR. $^{212}$

\section{$\underline{\text { Fasudil }}$}

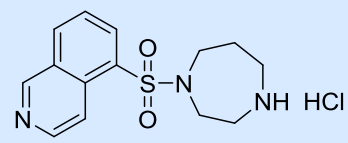

IUPAC

Name:

1-(5-isoquinolinesulfonyl)-homopiperazine hydrochloride; hexahydro-1-(5-isoquinolinylsulfonyl)-1H-1,4-diazepine monohydrochloride.

CAS: 105628-07-7. 
First Report: Uehata et al. in $1997 .^{216}$

Activity: Fasudil is an inhibitor of Rho-associated kinase II with an $\mathrm{IC}_{50}$ value of $1.9 \mu \mathrm{M}$. This drug is marketed in Japan to treat cerebral vasospasm following surgery for subarachnoid hemorrhage and associated cerebral ischemic symptoms. ${ }^{217-219}$

Clinical Trials: Stage $4 .{ }^{220}$

Storage/Stability: Stable store in a cool, dry, well-ventilated area awayfrom incompatible. Stable under normal temperatures and pressures. ${ }^{221}$

Prices: 25 mg - 22 EUR, 100 mg - 65 EUR, 250 mg - 130 EUR. $^{217}$

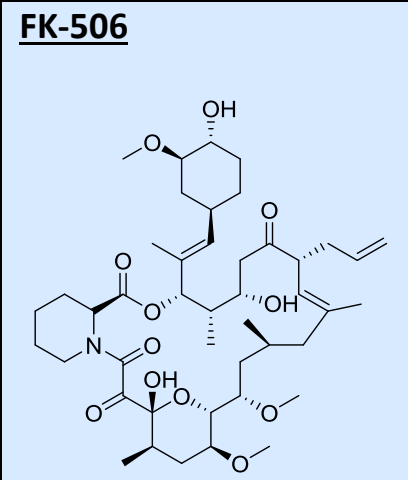

IUPAC Name: $3 S-[3 R[E(1 S, 3 S, 4 S)] \quad, 4 S, 5 R, 8 S, 9 E, 12 R, 14 R, 15 S, 16 R$, $18 S, 19 S, 26 a R-5,6,8,11,12,13,14,15,16,17,18,19,24,25,26,26 a-$ hexadecahydro-5,19-dihydroxy-3-[2-(4-hydroxy-3methoxycyclohexyl)-1-methylethenyl]-14,16-dimethoxy-4,10,12,18tetramethyl-8-(2-propenyl)-15,19-epoxy-3H-pyrido[2,1-c] oxaazacyclotricosine-1,7,20,21(4H,23H)-tetrone

CAS: 104987-11-3

First Report: Toru Kino et al. in 1987.222

Activity: FK-506 is a potent immunosuppressant that is used after allogeneic organ transplantation to reduce the risk of organ rejection. It disrupts signaling events mediated by calcineurin (Ca-dependent phosphatase) in T lymphocytes. Its mechanism of action involves the formation of a molecular complex with the intracellular FK506-binding protein-12 (FKBP12), thereby acquiring the ability to interact with calcineurin and to interfere with its access to and dephosphorylation of various substrates. The knows substrates of calcineurin involved in induced immunosuppression include the nuclear factors of activated T cells (NFAT). 223,224 It is also under clinical evaluation for de treatment for prostate cancer, hepatocellular carcinoma and acute leukaemia. ${ }^{225}$

Clinical Trials: Stage 4 completed. ${ }^{226}$

Storage / Stability: Keep container tightly closed. Keep container in a cool, well-ventilated area. The product is stable. ${ }^{227}$

Prices: 25 mg - 52 EUR, 100 mg - 156 EUR, 250 mg - 312 EUR. $^{223}$

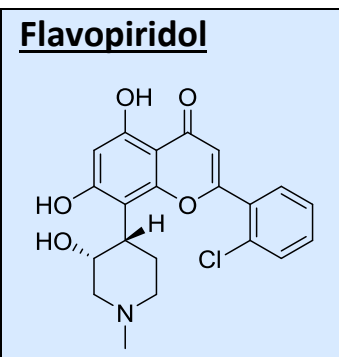

IUPAC Name: 2-(2-chlorophenyl)-5,7-dihydroxy-8-((3S,4R)-3-hydroxy-1methyl-4-piperidyl)chromen-4-one.

CAS: $146426-40-6$.

First Report: Kattige et al. in $1986 .{ }^{228}$

Activity: Flavopiridol was initially identified as an inhibitor of cyclin-dependent kinases 1 and 2. However, its primary target is CDK9, the catalytic component of positive transcription elongation factor $\mathrm{b}$ (P-TEFb). It is currently being tested as an anticancer drug in numerous 
clinical trials, such as prostate cancer, breast cancer, kidney cancer, esophageal cancer, adenocarcinoma of the pancreas, recurrent pancreatic cancer, stage IV pancreatic cancer, liver cancer, lymphoma, leukaemia, ovarian epithelial cancer, sarcoma, melanoma and lymphoma. $229-232$

Clinical Trials: Stage 2 completed. ${ }^{233}$

Storage / Stability: Store in cool place. Keep container tightly closed in a dry, well-ventilated place. Recommended storage temperature $2-8^{\circ} \mathrm{C}$. Store with desiccant. ${ }^{234}$

Prices: 5 mg - 85 EUR, 25 mg - 340 EUR, 100 mg - 1020 EUR. $^{229}$

\section{Foretinib}<smiles>COc1cc2nccc(Oc3ccc(NC(=O)C(C)(C)C(=O)Nc4ccc(F)cc4)cc3F)c2cc1OCCCN1CCOCC1</smiles>

IUPAC Name: $\quad N$-(3-fluoro-4-((6-methoxy-7-(3-(4-morpholinyl) propoxy)-4-quinolinyl)oxy)phenyl)- $N$ '-(4 fluorophenyl)-1,1-cyclo propanedicarboxamide.

CAS: 849217-64-7.

First Report: Bannen et al. in 2003. ${ }^{235}$

Activity: Foretinib is a small-molecule inhibitor of the hepatocyte growth factor (HGF) and vascular endothelial growth factor (VEGF) receptor tyrosine kinases with single-digit nanomolar $\mathrm{IC}_{50}$ values. It also inhibits KIT, FLT-3, PDGFR-beta and TIE-2. Foretinib exerted cytotoxicity against a broad panel of cancer cell lines. It also reduced tumor cell migration, invasion and tumor-induced angiogenesis. Because of these facts, this TKI is under several clinical evaluations, such as, breast cancer, lung cancer, head and neck cancer (HNC), hepatocellular and renal carcinoma ${ }^{236-238}$

Clinical Trials: Stage 2 completed. ${ }^{239}$

Storage / Stability: Storage temperature: $2-4{ }^{\circ} \mathrm{C}$ and keep container tightly closed in a dry and well-ventilated place. This product is relatively unstable under normal temperature. ${ }^{240}$

Prices: 5 mg - 80 EUR, 25 mg - 320 EUR, 100 mg - 960 EUR. ${ }^{236}$

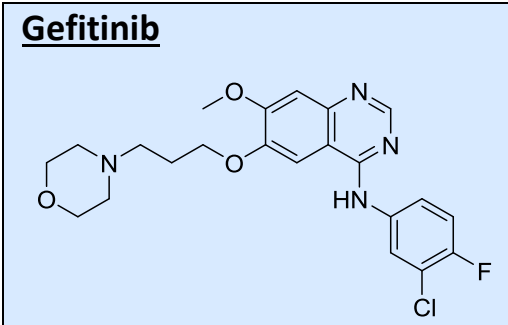

IUPAC Name: N-(3-chloro-4-fluoro-phenyl)-7-methoxy-6-(3morpholin-4-ylpropoxy)quinazolin-4-amine.

CAS: 184475-35-2.

First Report: Lemmon et al. in $1994 .^{241}$

Activity: Gefitinib is a selective inhibitor of the epidermal growth factor receptor (EGFR) tyrosine kinase domain, which is sometimes referred to as HER1 or ERBB-1. Gefitinib blocks signal transduction pathways implicated in the proliferation and survival of cancer cells and other host-dependent processes that promote cancer growth. ${ }^{242,243}$ It is, currently, under advanced clinical trials stage for NSCL Cancer, cancer of the head and neck and melanoma. ${ }^{244}$

Clinical Trials: Stage 4 completed. ${ }^{245}$

Storage / Stability: Store in closed vessels, under $-20^{\circ} \mathrm{C}$. Heat, flames and sparks. ${ }^{246}$ Prices: 5 mg - 52 EUR, 25 mg - 208 EUR, 100 mg - 624 EUR. ${ }^{242}$ 


\section{$\underline{\text { Genistein }}$}<smiles>O=c1c(-c2ccc(O)cc2)coc2cc(O)cc(O)c12</smiles>

IUPAC Name: 4',5,7-trihydroxyisoflavone.

CAS: 446-72-0.

First Report: Akiyama et al. in $1987 .^{247}$

Activity: Genistein is an isoflavone-related natural product. It influences multiple biochemical pathways in cells, including those involved in PPAR activation, the activation of estrogen receptors and topoisomerase activity. In addition, it displays direct antioxidative activity. The molecular mechanism of its anticancer activity is probably related to its ability to inhibit several tyrosine kinases. Genistein treatment inhibited MEKK1 kinase activity when tested by a kinase assay, which demonstrates that genistein inhibits MEKK1 activity, which may be responsible for the decreased phosphorylation of $\mathrm{ljB}$, thereby, resulting in the inactivation of NF-jB. ${ }^{248,249}$ It is, currently, under clinical trials for the treatment of prostate cancer, breast cancer, NSCL Cancer, colorectal cancer, pancreatic cancer, bladder cancer and leukaemia. ${ }^{250}$

Clinical Trials: Stage 3 completed. ${ }^{251}$

Storage / Stability: Keep container dry. Keep in a cool place. Ground all equipment containing material. Carcinogenic, teratogenic or mutagenic materials should be stored in a separate locked safety storage cabinet or room. The product is stable. ${ }^{252}$

Prices: 25 mg - 103EUR, 100 mg - 309 EUR, 250 mg - 618 EUR. $^{248}$

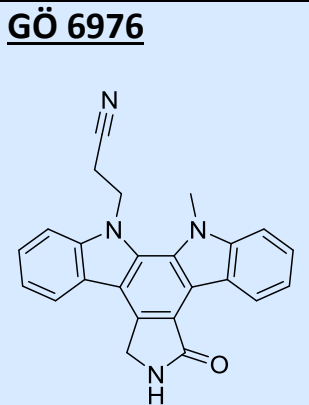

IUPAC Name: 5,6,7,13-tetrahydro-13-methyl-5-oxo-12H-indolo(2,3a)pyrrolo(3,4-c)carbazole-12-propanenitrile.

CAS: 136194-77-9.

First Report: Hartenstein et al. in $1993 .^{253}$

Activity: Gö 6976 inhibits the $\mathrm{Ca}\left({ }^{2+}\right)$-dependent isozymes protein kinase C (PKC) alpha and beta 1 at nanomolar concentrations, using rat brain cells. Kinetic analysis revealed that PKC inhibition by Gö 6976 is competitive with respect to ATP, non-competitive with respect to the protein substrate and mixed type with respect to phosphatidylserine. ${ }^{254,255} \mathrm{GÖ} 6976$ swowed to be capacle of to restore hyperphosphorylated and therefore inactive Rb function in cancer cells, such as T24 urinary bladder carcinoma cells. ${ }^{256}$

Clinical Trials: No studies in the moment. ${ }^{257}$

Storage / Stability: Store in a well closed container. Stable under normal temperatures and pressures. $^{258}$

Prices: 5 mg - 550 EUR, 25 mg - 2200 EUR. ${ }^{254}$

\section{GW2580}

IUPAC Name: 5-((3-methoxy-4-((4-methoxyphenyl)methoxy) phenyl) methyl) -2,4pyrimidinediamine.

CAS: 870483-87-7. 
<smiles>COc1ccc(COc2ccc(Cc3cnc(N)nc3N)cc2OC)cc1</smiles>

First Report: Conway et al. in 2005. ${ }^{259}$

Activity: GW2580 is an orally bioavailable inhibitor of cFMS receptor kinase. It completely inhibited human cFMS kinase in vitro at 0.06 microM. GW2580 selectively inhibited cFMS kinase compared with 186 other kinases in vitro and completely inhibited CSF-1-induced growth of rat monocytes, with an $\mathrm{IC}_{50}$ value of $0.2 \mu \mathrm{M}$. GW2580 at $1 \mu \mathrm{M}$ completely inhibited CSF-1-induced growth of mouse myeloid cells and human monocytes and completely inhibited bone degradation in cultures of human osteoclasts, rat calvaria and rat fetal long bone. ${ }^{259-261}$

Clinical Trials: No studies in the moment. ${ }^{262}$

Storage / Stability: Store in cool place. Keep container tightly closed in a dry, well-ventilated place. Recommended storage temperature: $-20^{\circ} \mathrm{C}^{263}$

Prices: 25 mg - 72 EUR, 100 mg - 216 EUR, 250 mg - 432 EUR. ${ }^{260}$

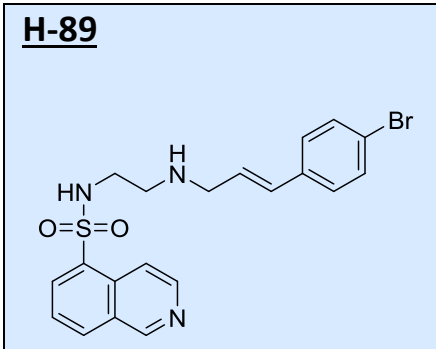
at $1 \mu \mathrm{M}$ (PRKG1, PRKG2, PRKX, ROCK1, ROCK2, MSK1, MSK2, S6K1). IC ${ }_{50}$ values determined for the compound proved that three kinases (MSK1, S6K1 and ROCK2) were inhibited with a potency similar to or greater than that for PKA. ${ }^{265,266}$

Clinical Trials: No studies in the moment. ${ }^{267}$

Storage / Stability: Keep refrigerated (Store below $4{ }^{\circ} \mathrm{C}$ ). Keep container tightly closed. Stable under normal temperatures and pressures. ${ }^{268}$

Prices: 5 mg - 64 EUR, 25 mg - 192 EUR, 100 mg - 576 EUR. ${ }^{265}$

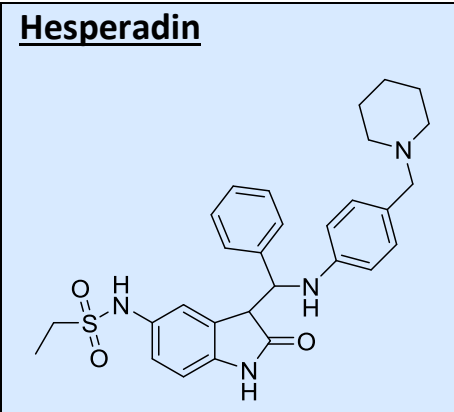

IUPAC Name: $\quad N$-(2,3-dihydro-2-oxo-3-((3Z)-phenyl((4-(1piperidinylmethyl)-phenyl)-amino)methylene)- $1 \mathrm{H}$-indol-5-yl)methanesulfona mide.

CAS: 422513-13-1.

First Report: Walter et al. in 2002. ${ }^{269}$

Activity: Hesperadin is an inhibitor of the Aurora B protein kinase, against which it has an $\mathrm{IC}_{50}$ of $40 \mathrm{nM}$. Mammalian cells treated with Hesperadin enter anaphase with numerous monooriented chromosomes, many of which may have both sister kinetochores attached to one spindle pole (syntelic attachment). Hesperadin causes cells arrested by taxol or monastrol to enter anaphase within $<1 \mathrm{~h}$, whereas cells treated with nocodazole remain arrested for 3-5 $\mathrm{h}^{270,271}$

Clinical Trials: Stage 4 completed. ${ }^{272}$

Storage / Stability: Store in a well closed container. Stable under normal temperatures and

Rev. Virtual Quim. |Vol 9| |No. 3| |974-1064| 
pressures. $^{273}$

Prices: 5 mg - 194 EUR, 25 mg - 776 EUR, 100 mg - 2328 EUR. ${ }^{270}$<smiles>Cc1ccc(NC(=O)c2ccc(CN3CCN(C)CC3)cc2)cc1Nc1nccc(-c2cccnc2)n1</smiles>

Activity: Imatinib is an inhibitor of several tyrosine kinases that is selective for the oncoproteins BCR/ABL, C-Kit and PDGFR. It is used in treating chronic myelogenous leukaemia $(\mathrm{CML})$, gastrointestinal stromal tumors (GISTs) and some other diseases in which these kinases are strongly expressed or unusually active. As one of the first cancer drugs developed using the principles of rational drug design based on an understanding of how cancer cells work, Imatinib is a ground-breaking compound. It was approved in the U.S. in 2001 for the treatment of Philadelphia-chromosome positive $(\mathrm{Ph}+) \mathrm{CML}$ and in 2002 for the treatment of patients with KIT (CD117)-positive unresectable and/or metastatic malignant gastrointestinal stromal tumors (GIST). ${ }^{275,276}$

Clinical Trials: Stage 4 completed. ${ }^{277}$

Storage / Stability: Stable Store in a cool, dry, well-ventilated area away from incompatible. Stable under normal temperatures and pressures. ${ }^{278}$

Prices: 25 mg - 25 EUR, 100 mg - 75 EUR, 250 mg - 150 EUR. ${ }^{275}$

\section{Indirubin}<smiles>O=C1Nc2ccccc2C1=C1Nc2ccccc2C1=O</smiles>

IUPAC Name: 2-(2-oxo-1H-indol-3-ylidene)-1H-indol-3-one.
CAS: 479-41-4.

First Report: Zheng et al. in 1979. ${ }^{279}$

Activity: Indirubin is an inhibitor of cyclin-dependent kinases and GSK3b inhibitor with $\mathrm{IC}_{50}$ values against the two kinase classes of approximately $75 \mathrm{nM}$ and $190 \mathrm{nM}$, respectively. Indirubin was identified as the active ingredient of Danggui Longhui Wan, a mixture of plants that is used in traditional Chinese medicine to treat chronic diseases. ${ }^{280,281}$ It is currently under clinical trials for treatment of childhood acute promyelocytic leukaemia. ${ }^{282}$

Clinical Trials: Stage 4 completed. ${ }^{282}$

Storage / Stability: Keep container tightly closed in a dry and well-ventilated place. Store in refrigerator. Store away from oxidizing agents. Stable under recommended storage conditions. ${ }^{283}$

Prices: 5 mg - 41 EUR, 25 mg - 164 EUR, 100 mg - 492 EUR. $^{280}$ 


\section{Indirubin-3'-monooxime}

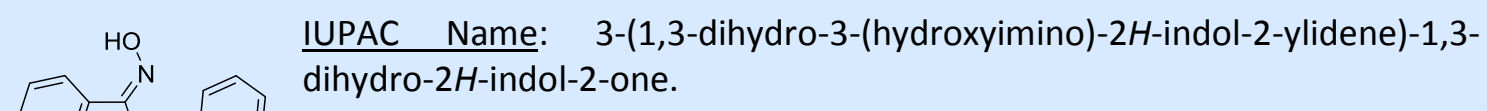<smiles></smiles>

CAS: $160807-49-8$.

First Report: Zheng et al. in 1979. ${ }^{279}$

Activity: Indirubin-3'-monooxime is an inhibitor of GSK3b (IC S0 $\left._{0}=22 \mathrm{nM}\right)$, CDK1 $\left(I C_{50}=180 \mathrm{nM}\right)$ and CDK5 $\left(\mathrm{IC}_{50}=100 \mathrm{nM}\right)$. Treatment with indirubin-3-monooxime caused time-dependent inhibition of cell growth, with the treated cells exhibiting many hallmark features of apoptosis. It has been proved that the treatment with this drug induces cell death and apoptosis in human laryngeal carcinoma cells. ${ }^{284-286}$

Clinical Trials: No studies in the moment. ${ }^{287}$

Storage / Stability: Keep tightly closed. Store at correct temperature. Stable. ${ }^{288}$

Prices: 5 mg - 98 EUR, 25 mg - 392 EUR, 100 mg - 1176 EUR. $^{284}$

\section{Indirubin-5-sulfonic Acid}

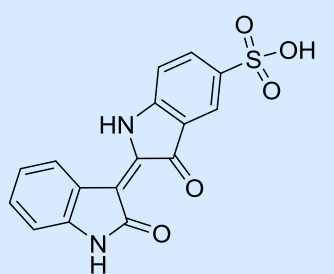

IUPAC Name: 2-(1,2-dihydro-2-oxo-3H-indol-3-ylidene)-2,3-dihydro-3oxo- $1 H$-indole-5-sulfonic acid.

CAS: 864131-82-8.

First Report: Zheng et al. in 1979. ${ }^{279}$

Activity: Indirubin-5-sulfonic acid is an indigoid inhibitor of CDK1/cyclin B $\left(\mathrm{IC}_{50}=55 \mathrm{nM}\right), \mathrm{CDK} 2 /$ cyclin $A\left(\mathrm{IC}_{50}=35 \mathrm{nM}\right), \mathrm{CDK} 2 /$ cyclin $\mathrm{E}\left(\mathrm{IC}_{50}=150 \mathrm{nM}\right)$, CDK4/cyclin D1 $\left(\mathrm{I}_{50}=300 \mathrm{nM}\right), \mathrm{CDK} 5 / \mathrm{p} 35\left(\mathrm{IC} \mathrm{C}_{50}=65 \mathrm{nM}\right)$ and GSK3b $\left(\mathrm{IC}_{50}=280 \mathrm{nM}\right){ }^{289,290}$

Clinical Trials: No studies in the moment. ${ }^{291}$

Storage / Stability: Keep containers tightly closed in a dry, cool, well ventilated. Stable under normal conditions. ${ }^{292}$

Prices: 5 mg - 98 EUR, 25 mg - 392 EUR, 100 mg - 1176 EUR. $^{289}$

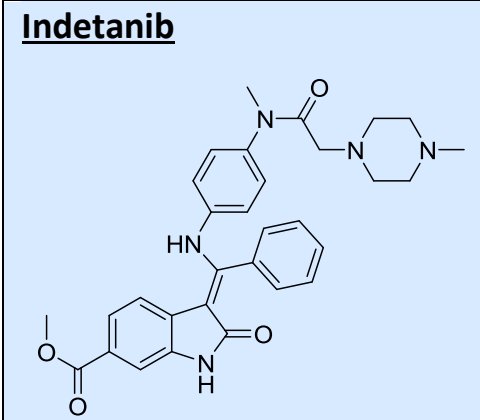

IUPAC Name: Methyl (3Z)-3-\{[(4-\{methyl[(4-methylpiperazin-1yl)acetyl]amino\}phenyl)amino](phenyl)methylidene\}-2-oxo-2,3dihydro- $1 \mathrm{H}$-indole-6-carboxylate.

CAS: 656247-17-5.

First Report: Hilberg et al. in 2008. ${ }^{293}$

Activity: Intedanib is a kinase inhibitor blocking VEGFR, PDGFR and FGFR receptors, developed for the treatment of several malignancies and idiopathic pulmonary fibrosis. Intedanib also significantly decreased blood vessel area in treated tumours. The sustained inhibition of VEGFR phosphorylation, the fast in vivo clearance and clinical efficacy against a broad range of malignancies appear to be the major advantages of intedanib. Furthermore, the existing data suggest an excellent safety profile. As of 2012, intedanib undergoes several phase III trials for the treatment of NSCLC and ovarian cancer. ${ }^{294,295}$ 
Clinical Trials: Stage 3 completed. ${ }^{296}$

Storage / Stability: Store in a well closed container. Stable under normal temperatures and pressures. $^{297}$

Prices: 5 mg - 80 EUR, 25 mg - 320 EUR, 100 mg - 960 EUR. $^{294}$

\section{JNJ-7706621}

IUPAC Name: 4-((5-amino-1-(2,6-difluorobenzoyl)-1H-1,2,4-triazol-3yl)amino)benzenesulfonamide.

CAS: 443797-96-4.

First Report: Emanuel et al. in 2005. ${ }^{298}$

Activity: JNJ-7706621 is a potent cell cycle inhibitor that targets several cyclin-dependent kinases (CDK) and Aurora kinases. It has $\mathrm{IC}_{50}$ values of 9 and $11 \mathrm{nM}$ for CDK1/Cyclin $\mathrm{B}$ and aurora $A$, respectively, and blocked the growth of several different types of tumour cell in vitro (such as HeLa cells, A375 melanoma human tumour and retinoblastoma cells) ten times more effectively than it inhibited the growth of normal human cells. At low concentrations, JNJ7706621 slowed cell growth; at high concentrations, it was cytotoxic. Flow cytometric analysis of cellular DNA content showed that JNJ-7706621 delayed progression through G1 and arrested the cell cycle in the G2-M phase. Additional cellular effects due to Aurora kinase inhibition included endoreduplication and inhibition of histone $\mathrm{H} 3$ phosphorylation. ${ }^{298-300}$

Clinical Trials: No studies in the moment. ${ }^{301}$

Storage / Stability: Storage temperature: $2-4{ }^{\circ} \mathrm{C}$ and keep container tightly closed in a dry and well-ventilated place. This product is relatively unstable under normal temperature. ${ }^{302}$

Prices: 5 mg - 230 EUR, 25 mg - 920 EUR, 100 mg - 2760 EUR. ${ }^{299}$

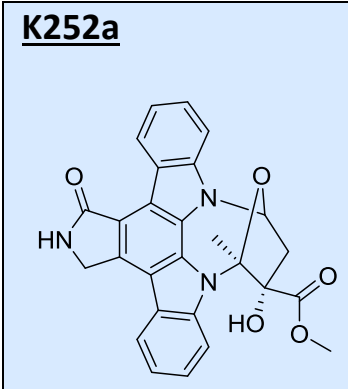

IUPAC Name: $(9 S-(9 \alpha, 10 \beta, 12 \alpha))-2,3,9,10,11,12$-hexahydro-10-hydroxy10-(methoxycarbonyl)-9-methyl-9,12-epoxy-1H-diindolo[1,2,3fg:3',2',1'-kl]pyrrolo[3,4-i][1,6]benzodiazocin-1-one.

CAS: 99533-80-9.

First Report: Kase et al. in $1986 .^{303}$

Activity: $\mathrm{K} 252 \mathrm{a}$ is an alkaloid related to staurosporin, but isolated from Nocardiopisis $s p$. soil fungi. It is potent inhibitor of multiple serine/threonine protein kinases ( $\mathrm{IC}_{50}$ 's of 10 to $30 \mathrm{nM}$ ), including $\mathrm{Ca} 2+/$ calmodulin-dependent protein kinase II, protein kinase A, protein kinase $C$ and protein kinase $G .{ }^{304,305}$ This inhibitor is associated to the reducing of the proliferation of in GTL-16 gastric carcinoma cells $(100 \mathrm{nM})$, and cause reversion in NIH3T3 fibroblasts transformed by the oncogenic form of the receptor, TprMet (75 nM). K252a inhibits Met autophosphorylation in cultured cells and in immunoprecipitates and prevents activation of its downstream effectors MAPKinase and Akt. Interestingly, K252a seems to be more effective at inhibiting the mutated form of Met (M1268T) found in papillary carcinoma of the kidney than the wild type receptor. Pretreatment of both Tpr-Met-transformed NIH3T3 fibroblasts and of GTL-16 gastric carcinoma cells with K252a results in loss of their ability to form lung metastases in nude mice upon injection into the caudal vein. ${ }^{306}$ 
Clinical Trials: No studies in the moment. ${ }^{307}$

Storage / Stability: Keep container tightlyclosed. Stable. ${ }^{308}$

Prices: 5 mg - 208 EUR, 25 mg - 832 EUR, 100 mg - 2496 EUR. ${ }^{304}$

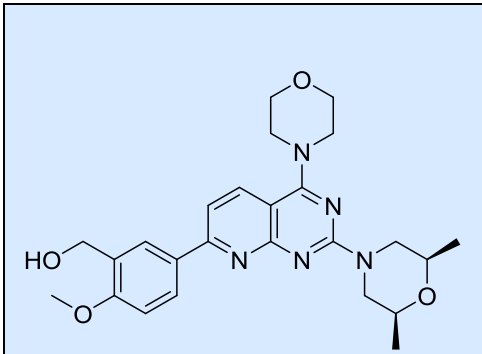

\section{$\underline{\text { KU0063794 }}$}

IUPAC Name: 5-(2-((2R,6S)-2,6-dimethyl-4-morpholinyl)-4-(4morpholinyl)pyrido(2,3-d)pyrimidin-7-yl)-2methoxybenzenemethanol.

CAS: 938440-64-3.

First Report: García-Martínez et al. in 2009. ${ }^{309}$

Activity: KU0063794 is selective inhibitor of mammalian target of rapamycin (mTOR) with an $\mathrm{IC}_{50}$ value of $10 \mathrm{nM}$. It displays no activity against PI3-kinase or 76 other kinases tested. It inhibits the activation of AKT, S6K and SGK, but not RSK. Treatment of cells suppresses their growth and induces $\mathrm{G} 1$ cell cycle arrest in vitro. ${ }^{309,310}$

Clinical Trials: No studies in the moment. ${ }^{311}$

Storage / Stability: Store in a well closed container. Stable under normal temperatures and pressures. $^{312}$

Prices: 5 mg - 121 EUR, 25 mg - 484 EUR, 100 mg - 1452 EUR. ${ }^{310}$

\section{Lapatinib Ditosylate}

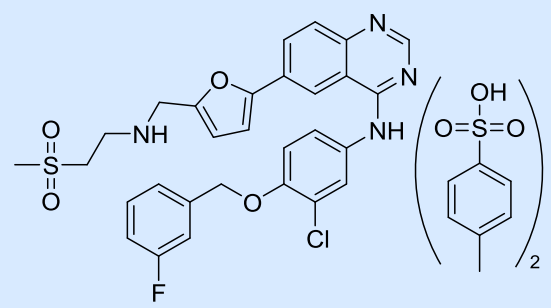

IUPAC Name: $N$-(3-chloro-4-((3-fluorophenyl)methoxy) phenyl)-6-(5-(((2-(methylsulfonyl) ethyl)amino)methyl)-2furanyl)-4-quinazolinamine bis(4methylbenzenesulfonate) monohydrate.

CAS: $388082-78-8$.

First Report: Carter et al. in 1999. ${ }^{313}$

Activity: Lapatinib is an orally available small molecule that targets the tyrosine activity of the erbB1 and erbB2 (Her2) receptors. It is used to treat breast cancers and other solid tumours. ${ }^{314,315}$

Clinical Trials: Stage 4 completed. ${ }^{316}$

Storage / Stability: Storage temperature: $2-4{ }^{\circ} \mathrm{C}$ and keep container tightly closed in a dry and well-ventilated place. This product is relatively unstable under normal temperature. ${ }^{317}$

Prices: 25 mg - 103 EUR, 100 mg - 309 EUR, 250 mg - 618 EUR. $^{314}$

\section{Lestaurtinib}

IUPAC Name: (5S,6S,8R)-6-hydroxy-6-(hydroxymethyl)-5-methyl-7,8,14,15-tetrahydro-5H-16oxa-4b,8a,14-triaza-5,8-methanodibenzo[b,h] cycloocta[jkl]cyclopenta[e]-as-indacen-13(6H)one.

CAS: $111358-88-4$.

First Report: George et al. in 1999. ${ }^{318}$ 


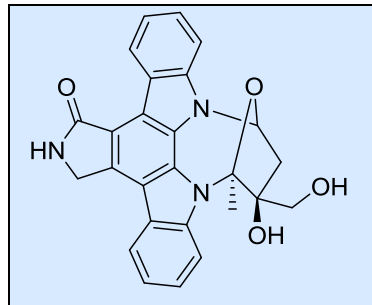

Activity: Lestaurtinib is a multi-targeted tyrosine kinase inhibitor. In preclinical studies, it was shown to inhibit FLT3 at nanomolar concentrations, prompting its rapid development as a potential agent for treating AML. Phase I studies have shown it to be an active agent, particularly when used in combination with cytotoxic drugs. It is currently undergoing Phase II and Phase III studies in patients with FLT3-ITD AML. ${ }^{319,320}$

Clinical Trials: Stage 2 completed. ${ }^{321}$

Storage / Stability: Keep container tightly closed in a dry and well-ventilated place. Recommended storage temperature: $-20^{\circ} \mathrm{C}$. Keep in a dry place. Stable under recommended storage conditions. ${ }^{322}$

Prices: 5 mg - 220 EUR, 25 mg - 880 EUR, 100 mg - 2640 EUR. $^{319}$

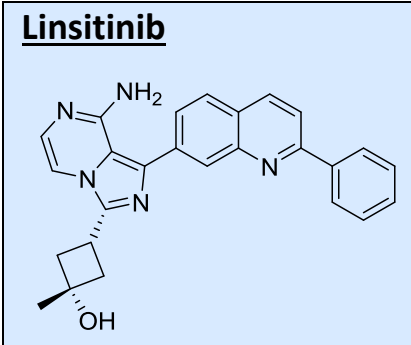

IUPAC Name: cis-3-(8-amino-1-(2-phenyl-7-quinolinyl)imidazo (1,5a)pyrazin-3-yl)-1-methylcyclobutanol.

CAS: 867160-71-2.

First Report: Arnold et al. in $2005 .^{323}$

Activity: Linsitinib has been developed as a small-molecule inhibitor of IGF-1R and IR kinases, with $\mathrm{IC}_{5} 0$ values of $35 \mathrm{nM}$ and $75 \mathrm{nM}$, respectively. Linsitinib potently and selectively inhibits autophosphorylation of both human IGF-1R and IR in cells, displays in vitro antiproliferative effects in a variety of tumour cell lines and robust in vivo anti-tumour efficacy in a xenograft model. It undergoes clinical trials as a drug against several cancer types including adrenocortical, lung and ovarian carcinomas. ${ }^{324-326}$

Clinical Trials: Stage 3 completed. ${ }^{327}$

Storage / Stability: Store in a well closed container. Stable under normal temperatures and pressures. $^{328}$

Prices: 5 mg - 85 EUR, 25 mg - 340 EUR, 100 mg - 1020 EUR. ${ }^{324}$

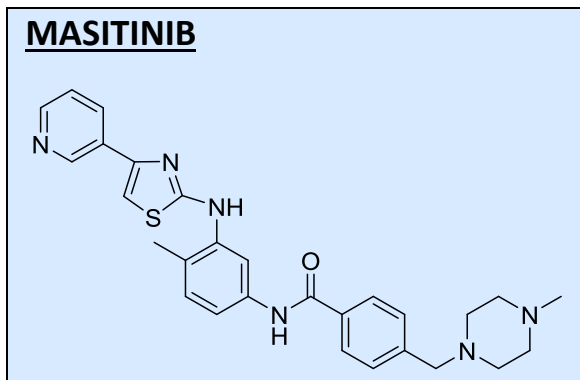

IUPAC Name: 4-((4-methyl-1-piperazinyl)methyl)-N-(4methyl-3-((4-(3-pyridinyl)-2thiazolyl)amino)phenyl)benzamide.

CAS: 790299-79-5.

First Report: Developed by AB Science, S.A. (France). ${ }^{329}$

Activity: Masitinib is a tyrosine kinase inhibitor that targets KIT with an $\mathrm{IC}_{50}$ value of $200 \mathrm{nM}$. Masitinib also potently inhibited recombinant PDGFR and the intracellular kinase Lyn. In contrast, it was a weak inhibitor of ABL and c-FMS and was inactive against a variety of other tyrosine and serine/threonine kinases. Kinetic analyses suggest that its mode of binding is different from that of imatinib; it also proved to be a stronger inhibitor of degranulation, cytokine production, and bone marrow mast cell migration than imatinib. It has been approved as a veterinary medicine for the treatment of mast cell 
Costa, D. C. S. et al.

tumours in dogs. ${ }^{329,330}$

Clinical Trials: Stage 2 completed. ${ }^{331}$

Storage / Stability: Storage temperature: $2-4{ }^{\circ} \mathrm{C}$ and keep container tightly closed in a dry and well-ventilated place. This product is relatively unstable under normal temperature. ${ }^{332}$

Prices: 25 mg - 172 EUR, 100 mg - 516 EUR, 250 mg - 1032 EUR. ${ }^{330}$

\section{MLN8054}

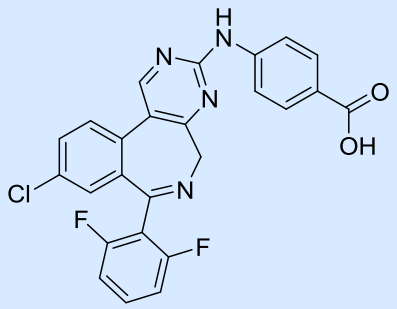

IUPAC Name: 4-((9-chloro-7-(2,6-difluorophenyl)-5H-pyrimido (5,4d)(2)benzazepin-2-yl)amino)benzoic acid.

CAS: 869363-13-3.

First Report: Manfredi et al. in 2007. ${ }^{333}$

Activity: MLN8054 is an orally bioavailable, potent and selective inhibitor of the protein kinase Aurora A. MLN8054 inhibits AURKA activity with an IC 50 of $4 \mathrm{nM}$ (its IC $\mathrm{C}_{50}$ for AURKB is $170 \mathrm{nM}$ ). MLN8054 treatment results in $\mathrm{G} 2 / \mathrm{M}$ cell cycle arrest, spindle defects and cell death in many tumour cell lines..$^{334,335}$

Clinical Trials: Stage 1 terminated. ${ }^{336}$

Storage / Stability: Store in a well closed container. Stable under normal temperatures and pressures. $^{337}$

Prices: 5 mg - 194 EUR, 25 mg - 776 EUR, 100 mg - 2328 EUR. $^{334}$

\section{Motesanib}<smiles>CC1(C)CNc2cc(NC(=O)c3cccnc3NCc3ccncc3)ccc21</smiles>

IUPAC Name: $N$-(2,3-dihydro-3,3-dimethyl-1H-indol-6-yl)-2-((4pyridinylmethyl)amino)-3-pyridinecarboxamide.

CAS: 857876-30-3.

First Report: Askew et al. in 2005. ${ }^{338}$

Activity: Motesanib is an oral multikinase inhibitor that selectively targets the vascular endothelial growth factor (VEGFR), platelet-derived growth factor (PDGFR) and kit receptors, potently inhibits angiogenesis and induces regression in tumour xenografts. ${ }^{339,340}$

Clinical Trials: Stage 3 terminated. ${ }^{341}$

Storage / Stability: Keep container tightly sealed in cool, well-ventilated area. Keep away from direct sunlight and sources of ignition. Recommended storage temperature: Store at $-20^{\circ} \mathrm{C}$. Stable under recommended storage conditions. ${ }^{342}$

Prices: 5 mg - 194 EUR, 25 mg - 776 EUR, 100 mg - 2328 EUR. $^{339}$

\section{Neratinib}

IUPAC Name: (2E)-N-[4-[[3-chloro-4-[(pyridin-2-yl)methoxy]phenyl]amino]-3-cyano-7ethoxyquinolin-6-yl]-4-(dimethylamino)but-2-enamide.

CAS: 698387-09-6.

First Report: Hilberg et al. in $2004 .^{343}$ 


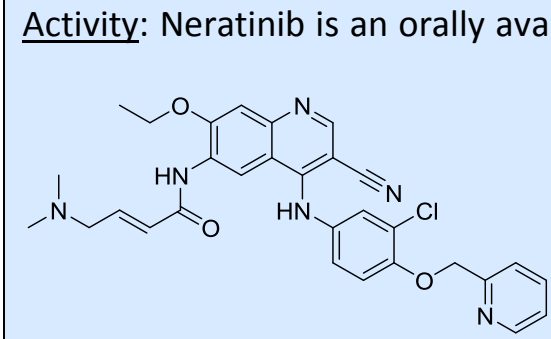

able tyrosine kinase inhibitor with $\mathrm{IC}_{50}$ values of $59 \mathrm{nM}$ and $92 \mathrm{nM}$ for HER2 and EGFR, respectively. In contrast to other tyrosine kinase inhibitors that are ATP-competitors, Neratinib binds to the HER2 receptor irreversibly, forming a covalent bond with a cysteine residue in the ATP-binding pocket. Treatment of cells with neratinib inhibits mitogenic signal transduction events and induces arrest during the $\mathrm{G} 1 / \mathrm{S}$ phase transition of the cell cycle. ${ }^{344,345}$ This drug is under clinical trials to the treatment of bladder cancer, breast cancer, colorectal cancer, HER2-mutant NSCL cancer, lymphoma, leukaemia, and glioblastoma. ${ }^{346}$

Storage / Stability: Stable if stored at $-20^{\circ} \mathrm{C}^{347}$

Clinical Trials: Stage $3 .^{348}$

Prices: 5 mg - 176 EUR; 25 mg - 704 EUR; 100 mg - 2112 EUR. $^{349}$

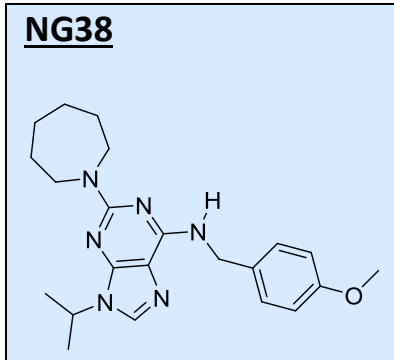

IUPAC Name: 9-isopropyl-N-(4-methoxybenzyl)-2-(perhydroazepin-1yl)-9H-purin-6-amine.

CAS: 244030-38-4.

\section{First Report: Ann M. Lacy in $1965 .^{350}$}

Activity: NG38 is an estrogen sulfotransferase (EST) inhibitor identified (wich function is related to kinase CDK2) from a trisubstituted purine library. It has an $\mathrm{IC}_{50}$ of $500 \mathrm{nM}$ against the purified enzyme. EST catalyzes the transfer of a sulfuryl group to estrogens in the cytosol, solubilizing them to maintain hormone homeostasis. Unusually high levels of estrogen sulfate are found in breast tumour cells and EST is therefore considered to be a potential drug target. ${ }^{351}$

Storage / Stability: Stable if stored in original container and avoiding direct sunlight and water contact. Do not apply physical shock to container. Store in a secure, dry and temperate area. Keep the container closed when not in use. ${ }^{352}$

Clinical Trials: Stage 4 completed. ${ }^{353}$

Prices: 5 mg - 98 EUR; 25 mg - 392 EUR; 100 mg - 1176 EUR. $^{349}$

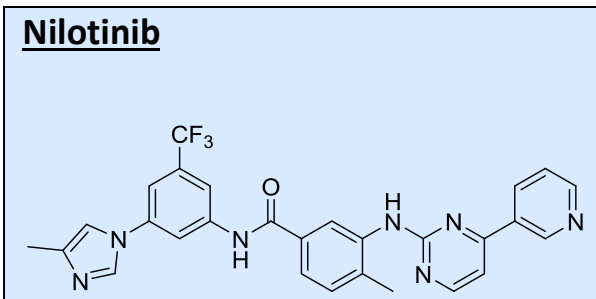

IUPAC Name: 4-methyl-3-[(4-(3-pyridinyl)-2-

pyrimidinyl)amino]- $\mathrm{N}$-[5-(4-methyl-1H-imidazol-1-yl)-3-

(trifluoromethyl)phenyl]benzamide.

CAS: $641571-10-0$.

First Report: Breitenstein et al. in 2004 ${ }^{354}$

Activity: Nilotinib is a potent inhibitor of the BCR/ABL protein kinase that was developed as a drug against Philadelphia chromosome positive chronic myeloid and acute lymphoblastic leukaemias. Nilotinib is approximately 20 times more potent than imatinib, and this translates into improved inhibitory activity against most of the common BCR-ABL mutations. ${ }^{355,356}$ 
Storage / Stability: Stable if stored at $-20^{\circ} \mathrm{C}^{357}$

Clinical Trials: Stage 4 completed $^{358}$

Prices: 25 mg - 103 EUR; 100 mg - 309 EUR; 250 mg - 618 EUR. $^{349}$<smiles>O=C(c1cc(Cc2n[nH]c(=O)c3ccccc23)ccc1F)N1CCN(C(=O)C2CC2)CC1</smiles>

IUPAC Name: 1-(cyclopropylcarbonyl)-4-(5-((3,4-dihydro-4-oxo-1phthalazinyl)methyl)-2-fluorobenzoyl)piperazine

CAS: 763113-22-0.

First Report: Martin et al. in $2004^{359}$

Activity: Olaparib is a single digit nanomolar inhibitor of poly(adenosine diphosphate-ribose) polymerase (PARP), an enzyme that is involved in DNA damage repair. It exhibits $I C_{50}$ values of 5 and $1 \mathrm{nM}$ for PARP-1 and PARP-2, respectively, and is being developed as a drug for BRCA1and BRCA2-defective cancers. ${ }^{360-362}$

Storage / Stability: Stable if stored at $-20^{\circ} \mathrm{C}^{363}$

Clinical Trials: Stage $4 .{ }^{364}$

Prices: 5 mg - 52 EUR; 25 mg - 208 EUR; 100 mg - 624 EUR. ${ }^{349}$

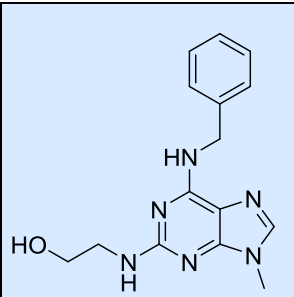

\section{Olomoucine}

IUPAC Name: 2-(2'-hydroxyethylamino)-9-methyl-6-(benzylamino)purine;6(benzylamino)-2-(2-hydroxyethylamino)-9-methylpurine.

CAS: 101622-51-9.

First Report: Charles et al. in $1986 .{ }^{365}$

Activity: Olomoucine was one of the first selective inhibitors of cyclin-dependent kinases (CDKs) to be discovered. It competes with ATP for binding to the kinase active site, as demonstrated by the structure of a co-crystal with human CDK2. It was discovered by screening a library of 2,6,9-trisubstituted purines. Studies on olomoucine analogues resulted in the identification of the much more potent inhibitor roscovitine. ${ }^{366,367}$ It inhibits the proliferation of human HL-60 leukaemia cells and HeLa cervical carcinoma. ${ }^{368}$

Storage / Stability: Stable if stored at $-20^{\circ} \mathrm{C}^{369}$

Clinical Trials: No Studies in the moment. ${ }^{370}$

Prices: 5 mg - 41 EUR; 25 mg - 164 EUR; 100 mg - 492 EUR. $^{349}$

\section{Olomoucine II}

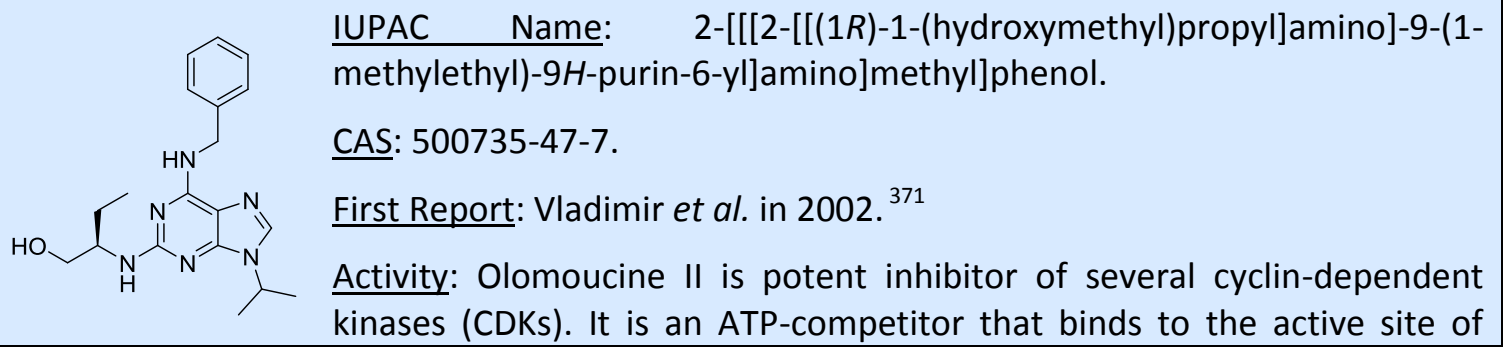


CDK2, as demonstrated by the analysis of co-crystal structures. In addition to its inhibition of the main cell cycle-regulating kinase CDK2, olomoucine II also binds to CDK7 and CDK9, which play important roles in regulating RNA transcription. It has been shown to have in vitro anticancer activity against a panel of tumour cell lines. ${ }^{371,372}$

Storage / Stability: Stable if stored at $-20^{\circ} \mathrm{C}$, under desiccating conditions. Under these conditions, the product can be stored for up to 12 months. ${ }^{373}$

Clinical Trials: No studies in the moment. ${ }^{374}$

Prices: 5 mg - 98 EUR; 25 mg - 392 EUR; 100 mg - 1176 EUR. $^{349}$

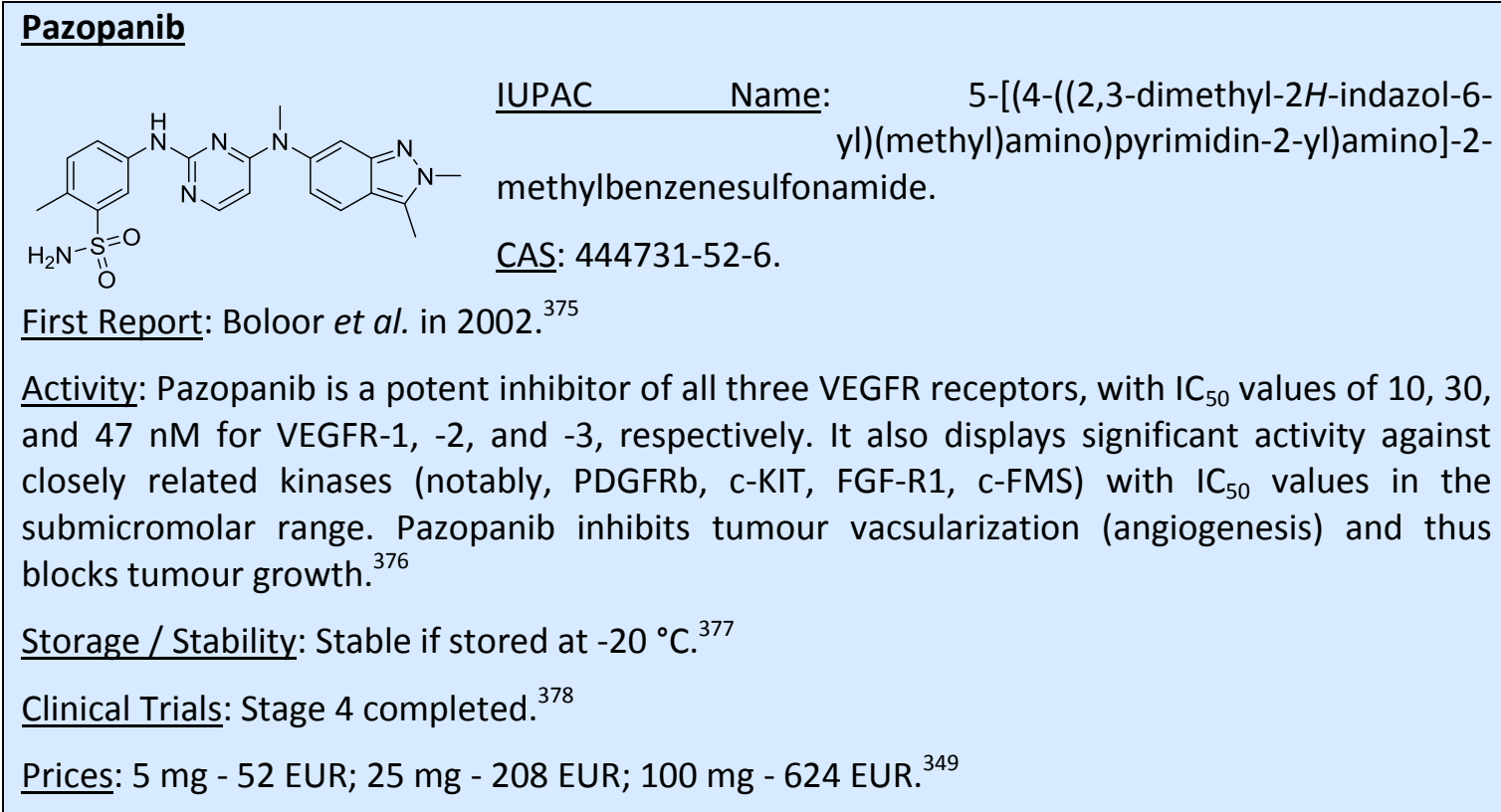

\section{PD-0332991}

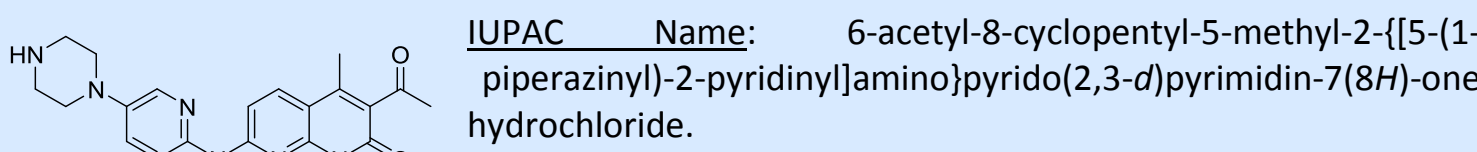

CAS: 827022-32-2.

First Report: Eck et al. in $2005^{379}$

Activity: PD0332991 is a highly specific inhibitor of cyclin-dependent kinase 4 (CDK4, IC $C_{50}=11$ $\mathrm{nM})$ and CDK6 $\left(\mathrm{IC}_{50}=16 \mathrm{nmol} / \mathrm{L}\right)$ that is inactive against other CDKs. It is a potent antiproliferative agent against retinoblastoma $(\mathrm{Rb})$-positive tumour cells in vitro, inducing $\mathrm{G} 1$ arrest with a concomitant reduction in the extent of phosphorylation of the pRb protein at Ser780 and Ser795. ${ }^{380,381}$

Storage / Stability: Stable if stored at $-20^{\circ} \mathrm{C}^{382}$

Clinical Trials: Stage $4 .^{383}$

Prices: 5 mg - 139 EUR; 25 mg - 556 EUR; 100 mg - 1668 EUR. $^{349}$ 
<smiles>CCOc1cc2ncc(C)c(Nc3ccc(F)c(Cl)c3)c2cc1NC(=O)/C=C/CN(C)C</smiles>

IUPAC Name: (2E)-N-\{4-[(3-chloro-4-fluorophenyl)amino]-3cyano-7-ethoxy-6-quinolinyl-4-(dimethylamino)-2-butenamide\}.

CAS: 257933-82-7.

First Report: Torrance et al. in 2000. ${ }^{384}$

Activity: Pelitinib is an irreversible inhibitor of epidermal growth factor receptor (EGFR) tyrosine kinase in clinical trials. It inhibits EGF-induced phosphorylation of EGF-R and the growth of tumours that overexpress EGF-R in animal models. ${ }^{385}$ It is now under clinical trials to the treatment of NSCL carcinoma and colorectal neoplasms. ${ }^{386}$

Storage / Stability: Stable if stored at $-20{ }^{\circ} \mathrm{C}^{387}$

Clinical Trials: Stage 2 completed. ${ }^{388}$

Prices: 5 mg - 176 EUR; 25 mg - 704 EUR; 100 mg - 2112 EUR. $^{349}$<smiles>CCCCCCCCCCCCCCCCCOP(=O)(O)OC1CCN(C)CC1</smiles>

IUPAC Name: (1,1-dimethylpiperidin-1-ium-4-yl) octadecyl phosphate; 4-[(hydroxy(octadecyloxy)phosphinyl)oxy]-1,1-dimethylpiperidinium inner salt.

CAS: $157716-52-4$.

First Report: Noessner et al. in $1994 .^{389}$

Activity: Perifosine is an oral AKT (protein kinase B, PKB) inhibitor that is currently being tested in clinical trials for the treatment of colon cancer, prostate cancer, renal cancer, ovarian cancer, breast cancer, pancreatic cancer, gastrointestinal stromal tumours, kidney cancer, leukaemia, lymphoma, brain tumour and melanoma. Unlike most kinase inhibitors, which target the adenosine triphosphate-binding region, perifosine targets the pleckstrin homology domain of AKT, thereby preventing its translocation to the plasma membrane. Perifosine exerts both AKT-dependent and AKT-independent effects. ${ }^{390-392}$

Storage / Stability: Stable if stored $-20^{\circ} \mathrm{C} .{ }^{393}$

Clinical Trials: Stage 3 completed. ${ }^{394}$

Prices: 5 mg - 148 EUR; 25 mg - 592 EUR; 100 mg - 1776 EUR. ${ }^{349}$

\section{PHA-680632}

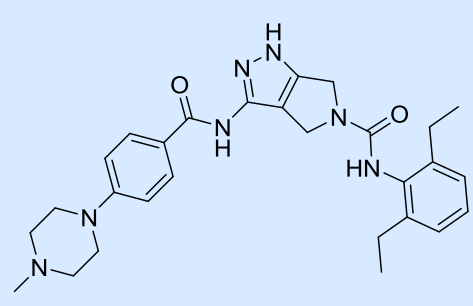

IUPAC Name: $\quad N$-(2,6-diethylphenyl)-4,6-dihydro-3-((4-(4methyl-1-piperazinyl)benzoyl)amino)pyrrolo(3,4-c)pyrazole$5(1 H)$-carboxamide.

CAS: 398493-79-3.

First Report: Fancelli et al. in 2005. ${ }^{395}$

Activity: PHA-680632 is a highly selective Aurora kinase inhibitor and an anticancer drug candidate. Its $I C_{50}$ values against Aurora kinases $A, B$ and $C$ are 27, 135 and $120 \mathrm{nM}$, respectively, and it potently inhibits Histone $\mathrm{H} 3$ phosphorylation at Ser10. PHA-680632 is active against a wide range of cancer cell lines (HeLa cells, HL60 cells, HCT116 
cells, U2OS cells) and shows significant tumour growth inhibition in different animal tumour models (HL60 human acute myelogenous leukaemia xenograft, A2780 human ovarian carcinoma model, HCT116 colon carcinoma xenograft). ${ }^{396}$

Storage / Stability: Stable if the container was kept tightly sealed in cool, well-ventilated area and away from direct sunlight or sources of ignition; at $-20^{\circ} \mathrm{C} .{ }^{397}$

Clinical Trials: No studies in the moment. ${ }^{398}$

Prices: 5 mg - 194 EUR; 25 mg - 776 EUR; 100 mg - 2328 EUR. $^{349}$

\section{Pictilisib}

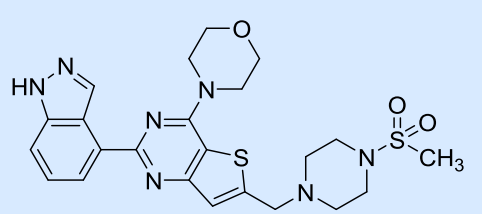

IUPAC Name: 2-(1H-indazol-4-yl)-6-((4-(methylsulfonyl)-1piperazinyl)methyl)-4-(4-morpholinyl)thieno(3,2-d)pyrimidine.

CAS: 957054-30-7.

First Report: Chuckowree et al. in $2007 .{ }^{399}$

Activity: Pictilisib, formerly known as GDC-0941, is a potent, selective, orally bioavailable inhibitor of PI3K. It inhibits PI3K isoform p110 alpha with a single digit nanomolar $\mathrm{IC}_{50}$ value. The compound exhibits in vitro antiproliferative properties with submicromolar potency in PTEN-negative cells and clear PI3K pathway modulation. It is currently being evaluated in human clinical trials for the treatment of cancer, such as, breast cancer, NSCL cancer, nonHodgkin's lymphoma and glioblastoma. ${ }^{400,401}$

Storage / Stability: Stable is stored at $+4{ }^{\circ} \mathrm{C}$, for up to 12 months. ${ }^{402}$

Clinical Trials: Stage 2 completed $^{403}$

Prices: 5 mg - 52 EUR; 25 mg - 208 EUR; 100 mg - 624 EUR. $^{349}$

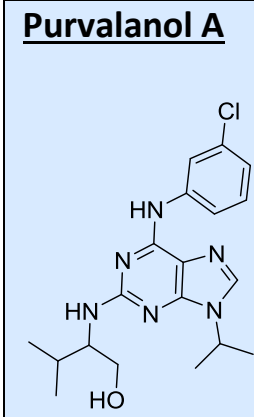

IUPAC Name: (2R)-2-[[6-[(3-chlorophenyl)amino]-9-propan-2-ylpurin-2yl]amino]-3-methylbutan-1-ol.

CAS: 212844-53-6.

First Report: Gray et al. in $1998 .{ }^{404}$

Activity: Purvalanol $A$ is cyclin-dependent kinase inhibitor with $\mathrm{IC}_{50}$ values of 4, 70, 850 and $75 \mathrm{nM}$ for CDK1, CDK2, CDK4 and CDK5, respectively. It is a strong inducer of cell cycle arrest during the G2-M phase, and a potent suppressor of the anchorage-independent growth of c-SRC-transformed cells. It also effectively suppressed the growth of human colon cancer HT29 and SW480 cells that express oncogenic SRC. ${ }^{404,405}$

Storage / Stability: Stable as a solid or solutions if stored at $-20{ }^{\circ} \mathrm{C} .{ }^{406}$

Clinical Trials: No studies in the moment. ${ }^{407}$

Prices: 5 mg - 98 EUR; 25 mg - 164 EUR; 100 mg - 492 EUR. $^{349}$ 


\section{Quercetin}<smiles></smiles>

IUPAC Name: $\quad 3,3^{\prime}, 4$ ',5,7-pentahydroxyflavone;

First Report: Fountain et al. in $1948 .^{408}$

Activity: Quercetin is a natural compound with flavonoid structure. Quercetin appears to have many potential beneficial effects on human health, including antioxidant, anticancer, gastroprotective, antiinfective, antiinflammatory and many more. Quercetin is known PI3K and PKC inhibitor. ${ }^{409}$ It is currently being evaluated in human clinical trials for the treatment of cancer, such as, colorectal cancer, kidney cancer, pancreatic ductal adenocarcinoma and follicular lymphoma. ${ }^{410}$

Storage / Stability: Stable if stored $-20^{\circ} \mathrm{C} .{ }^{411}$

Clinical Trials: Stage 4 completed. ${ }^{412}$

Prices: 5 mg - 156 EUR; 25 mg - 624 EUR; 100 mg - 1872 EUR. ${ }^{349}$

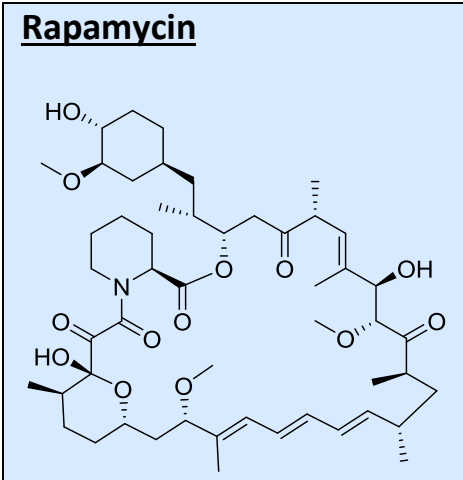

IUPAC Name:

23,27-epoxy-3H-pyrido(2,1-

c)(1,4)oxaazacyclohentriacontine.

CAS: 53123-88-9.

First Report: Vezina et al. in $1975 .{ }^{413}$

Activity: Rapamycin is an immunosuppressant used to prevent rejection in organ transplantation. Due to its antiproliferative properties, it is also being tested as an anticancer drug. Rapamycin is a bacterial product that inhibits the mTOR kinase by associating with its intracellular receptor FKBP12; the FKBP12-rapamycin complex binds directly to mTOR. ${ }^{414}$ It is currently being evaluated in human clinical trials for the treatment of several kinds of cancer such as, estrogen receptor positive advanced breast cancer, large cell carcinoma, skin cancer resulting of kidney transplantation, progressive gastrointestinal stromal tumour, non-Hodgkin's lymphoma, renal cell carcinoma and melanoma. ${ }^{415}$

Storage / Stability: Stable if stored $-20^{\circ} \mathrm{C}{ }^{416}$

Clinical Trials: Stage 4 completed. ${ }^{417}$

Prices: 5 mg - 103 EUR; 25 mg - 412 EUR; 100 mg - 1236 EUR. $^{349}$

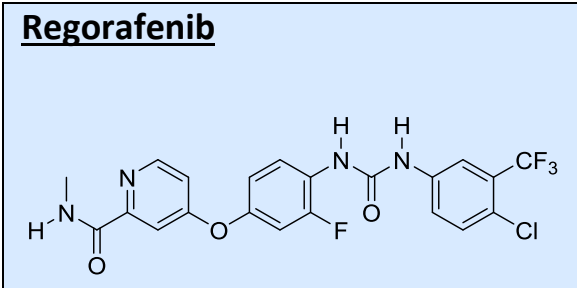

IUPAC Name: 4-(4-(\{(4-chloro-3(trifluoromethyl)phenyl)carbamoyl\}amino)-3fluorophenoxy)- $\mathrm{N}$-methylpyridine-2-carboxamide.

CAS: 755037-03-7.

First Report: Wilhelm et al. in $2004{ }^{418}$

Activity: Regorafenib is an orally available multi-kinase inhibitor that targets several receptor tyrosine kinases, with IC $\mathrm{C}_{50}$ values of 17,40 and $69 \mathrm{nM}$ for c-KIT, VEGFR2, B-RAF. It is currently 
being studied in the treatment of multiple tumour types, such as, colorectal neoplasms, gastrointestinal stromal tumours, urothelial cancer and melanoma. ${ }^{419,420}$

Storage / Stability: Stable if stored $-20^{\circ} \mathrm{C}^{421}$

Clinical Trials: Stage $4 .{ }^{422}$

Prices: 5 mg - 148 EUR; 25 mg - 592 EUR; 100 mg - 1776 EUR. $^{349}$

\section{$\underline{(R / S) \text {-Roscovitine }}$}

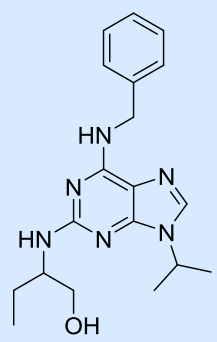

IUPAC Name: 2-[(9-(1-methylethyl)-6-[(phenylmethyl)amino]-9H-purin-2yl)amino]-1-butanol.

CAS: $186692-44-4$.

First Report: Meijer et al. in $1997{ }^{423}$

Activity: Roscovitine is a highly efficient and selective inhibitor of certain cyclindependent kinases, including CDK2, CDK5, CDK7 and CDK9. It reversibly halts the cell cycle and DNA synthesis in several model systems and inhibits proliferation in various mammalian cell lines with an average $\mathrm{IC}_{50}$ of 16 microM. ${ }^{424}$

Storage / Stability: Stable is kept in a well-closed container at $-20^{\circ} \mathrm{C}$ until 2 years. ${ }^{425,426}$

Clinical Trials: Stage $2 .{ }^{427}$

Prices: 5 mg - 41 EUR; 25 mg - 164 EUR; 100 mg - 492 EUR. $^{349}$

\section{(R)-Roscovitine}<smiles>CCC(O)Nc1nc(NCc2ccccc2)c2ncn(C(C)C)c2n1</smiles>

IUPAC Name: 2-(R)-[[9-(1-methylethyl)-6-[(phenylmethyl)amino]-9H-purin-2yl]amino]-1-butanol.

CAS: $186692-46-6$.

First Report: Meijer et al. in $1997 .{ }^{423}$

Activity: Roscovitine is a highly efficient and selective inhibitor of certain cyclindependent kinases, including CDK2, CDK5, CDK7 and CDK9. It reversibly halts the cell cycle and DNA synthesis in several model systems and inhibits proliferation in various mammalian cell lines with an average $I_{50}$ of 16 microM. ${ }^{424}$

Storage / Stability: Stable if stored at $-20^{\circ} \mathrm{C} .{ }^{428}$

Clinical Trials: Stage $2 .{ }^{429}$

Prices: 5 mg - 41 EUR; 25 mg - 164 EUR; 100 mg - 492 EUR. ${ }^{349}$

(S)-roscovitine
IUPAC Name: (2S)-2-((9-(1-methylethyl)-6-((phenylmethyl)amino)-9H-purin-2-
yl)amino)-1-butanol.
Activity: Roscovitine is a highly efficient and selective inhibitor of certain cyclin-


dependent kinases, including CDK2, CDK5, CDK7 and CDK9. In addition to its anticancer activities (and in contrast to the $\mathrm{R}$ isomer), $\mathrm{S}$-roscovitine is being studied as a potential neuroprotectant for stroke because it can cross the blood brain barrier. In the brain, its inhibition of CDK5 blocks hypoxia-induced apoptosis in neurons. ${ }^{424}$

Storage / Stability: Stable for at least 2 years after receipt when stored at $-20^{\circ} \mathrm{C} .{ }^{431}$

Clinical Trials: Stage $2 .^{432}$

Prices: 5 mg - 41 EUR; 25 mg - 164 EUR; 100 mg - 492 EUR. $^{349}$

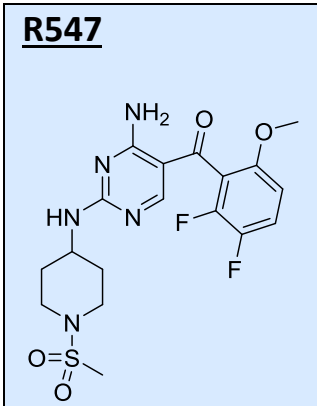

$$
\text { IUPAC Name: (4-amino-2-((1-methylsulfonylpiperidin-4- }
$$
yl)amino)pyrimidin-5-yl)(2,3-difluoro-6-methoxyphenyl)methanone.

CAS: 741713-40-6.

First Report: DePinto et al. in $2006 .{ }^{433}$

Activity: R547 is a CDK inhibitor ( $\mathrm{Ki}=1,3$, and $1 \mathrm{nM}$ for CDK1, CDK2, and CDK4, respectively) with excellent in vitro cellular potency that inhibits the growth of various human tumour cell lines (HCT116 cells, H460a cells, MDA-MB-435 cells, DU145 cells, LOX cells and A549 cells). Its growth-inhibitory activity is characterized by cell cycle blockage in the $G(1)$ and $G(2)$ phases, reduced phosphorylation of the cellular retinoblastoma protein, and induction of apoptosis. ${ }^{433}$

Storage/Stability: Stable if the container was kept tightly closed in a dry and well-ventilated place, at $-20^{\circ} \mathrm{C} .{ }^{434}$

Clinical Trials: Stage 1 completed. ${ }^{435}$

Prices: 5 mg - 647 EUR; 25 mg - 2558 EUR; 100 mg - 7764 EUR. $^{349}$

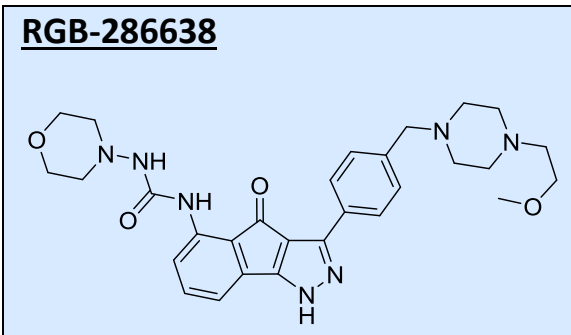

IUPAC Name: $N$-(1,4-dihydro-3-(4-((4-(2-methoxyethyl)-1piperazinyl)methyl)phenyl)-4-oxoindeno(1,2-c)pyrazol-5yl)- $N$ '-4-morpholinylurea.

CAS: 784210-88-4.

First Report: Caligiuri et al. in $2006 .{ }^{436}$

Activity: RGB-286638 is a cyclin-dependent kinase inhibitor with $I_{50}$ values of $1,2,3$ and 44 $\mathrm{nM}$ for CDK9, CDK1, CDK2, and CDK4, respectively. It has been shown to inhibit cell cycle progression in cancer cells by targeting CDKs, and was found to induce apoptosis. In a range of pre-clinical models of solid and hematological tumours, RGB-286638 treatment resulted in tumour regression and increased survival. ${ }^{437}$

Storage / Stability: Stable if stored -20 C. $^{438}$ |

Clinical Trials: Stage $1 .^{439}$

Prices: 5 mg - 185 EUR; 25 mg - 745 EUR; 100 mg - 2220 EUR. $^{349}$ 


\section{Ruxolitinib}<smiles>N#CCC(C1CCCC1)n1cc(-c2ncnc3[nH]ccc23)cn1</smiles>

IUPAC Name: (3R)-3-cyclopentyl-3-[4-(7H-pyrrolo[2,3-d]pyrimidin-4yl)pyrazol-1-yl]propanenitrilbeta.

CAS: 941678-49-5.

First Report: Rodgers et al. in 2007. ${ }^{440}$

Activity: Ruxolitinib is a selective orally bioavailable JAK1/JAK2 inhibitor with nanomolar potency against JAK1 (5.9 $\mathrm{nM})$ and JAK2 (5.7 nM). It inhibits the proliferation of JAK2V617Fpositive cells. In a mouse model of JAK2V617F-positive MPN, it markedly reduced splenomegaly and circulating levels of inflammatory cytokines and preferentially eliminated neoplastic cells. This significantly increased survival without myelo- or immunosuppression. ${ }^{441}$

Storage / Stability: Stable if stored $-20{ }^{\circ} \mathrm{C}^{442}$

Clinical Trials: Stage $4 .^{443}$

Prices: 5 mg - 185 EUR; 25 mg - 745 EUR; 100 mg - 2220 EUR. $^{349}$

\section{$\underline{\text { Saracatinib }}$}<smiles>CN1CCN(CCOc2cc(OC3CCOCC3)c3c(Nc4c(Cl)ccc5c4OCO5)ncnc3c2)CC1</smiles>

IUPAC Name: N-(5-chloro-1,3-benzodioxol-4-yl)-7-(2-(4-methyl-1quinazolinamine. piperazinyl)ethoxy)-5-((tetrahydro-2h-pyran-4-yl)oxy)-4-

CAS: 379231-04-6.

First Report: Hennequin et al. in 2001 . $^{444}$

Activity: Saracatinib inhibits c-SRC and ABL at low nanomolar concentrations and exhibited high selectivity for these two enzymes against a range of kinases. It has excellent pharmacokinetic properties and is currently undergoing clinical evaluation as a possible anticancer drug, such as, hormone-resistant prostate cancer, breast cancer, ovarian cancer, fallopian tube cancer, primary peritoneal cancer, pancreatic cancer, osteosarcoma, colorectal cancer and NSCL cancer. ${ }^{445,446}$

Storage / Stability: Stable if stored $-20^{\circ} \mathrm{C} .{ }^{447}$

Clinical Trials: Stage 3 completed. ${ }^{448}$

Prices: 5 mg - 52 EUR; 25 mg - 208 EUR; 100 mg - 624 EUR. $^{349}$

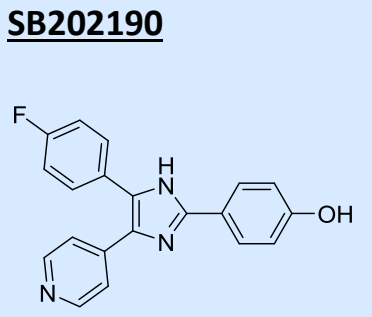

IUPAC Name: 4-(4-fluorophenyl)-2-(4-hydroxyphenyl)-5-(4-pyridyl)$1 H$-imidazole.

CAS: $152121-30-7$.

First Report: Leroy et al. in $1993 .^{449}$

Activity: SB202190 is an inhibitor of the p38 mitogen-activated protein (MAP) kinases that regulate signal transduction in response to environmental stress. It inhibits SAPK2a and SAPK $2 b$ (p38 beta2) with $I_{50}$ values of $50 \mathrm{nM}$ and $100 \mathrm{nM}$, respectively. It also targets BRAF and cRAF kinases. In cells, SB202190 induces cell death, with typical apoptotic features such as nucleus condensation, caspase activation and intranucleosomal DNA fragmentation. These 
Costa, D. C. S. et al.

results were obtained using HeLa, Sh-SY5Y, WM1617, WM793 cells. ${ }^{450,451}$

Storage / Stability: Stable if storage $-20^{\circ} \mathrm{C} .{ }^{452}$

Clinical Trials: No studies in the moment. ${ }^{453}$

Prices: 5 mg - 52 EUR; 25 mg - 208 EUR; 100 mg - 624 EUR. $^{349}$

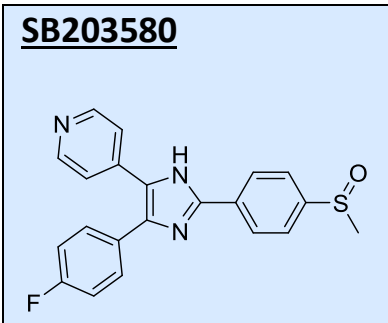

IUPAC Name: 4-(4-fluorophenyl)-2-(4-methylsulfinylphenyl)-5-(4pyridyl)- $1 H$-imidazole.

CAS: 152121-47-6.

First Report: Leroy et al. in $1993 .{ }^{449}$

Activity: SB203580 is an inhibitor of the p38 mitogen-activated protein (MAP) kinases, selectively inhibiting SAPK2a and SAPK2b (p38 beta2) with $\mathrm{IC}_{50}$ values of $50 \mathrm{nM}$ and $500 \mathrm{nM}$, respectively. ${ }^{454}$ It was originally prepared as inflammatory cytokine synthesis inhibitor, but recently a study showed that with $50 \mu \mathrm{g} / \mathrm{mL}$ of SB203580, the proliferation of esophageal were significantly inhibited. ${ }^{455}$

Storage / Stability: Stable if stored $-20^{\circ} \mathrm{C} .{ }^{456}$

Clinical Trials: No studies in the moment. ${ }^{457}$

Prices: 5 mg - 60 EUR; 25 mg - 120 EUR; 100 mg - 360 EUR. $^{349}$

\section{SCH900776}

(1)

IUPAC Name: 6-bromo-3-(1-methyl-1H-pyrazol-4-yl)-5-(3R)-3piperidinylpyrazolo(1,5-a)pyrimidin-7-amine.

CAS: 891494-63-6.

First Report: Guz et al. in $2006 .^{458}$

Activity: SCH900776 is a potent and selective inhibitor of check-point kinase 1 (CHK1) with IC $\mathrm{IC}_{50}$ value of $3 \mathrm{nM}$. Sensitivity of CHK2 is 500 fold lower (IC $\mathrm{C}_{50}$ value of $\left.1500 \mathrm{nM}\right)$. Consistently with its kinase inhibitory activity, SCH900776 abrogates cell-cycle arrest induced by SN38. It interacts synergistically with DNA antimetabolite agents in vitro and in vivo to selectively induce double strand DNA breaks and cell death in tumour cells. ${ }^{459}$

Storage / Stability: Stable if stored at $-20^{\circ} \mathrm{C} .{ }^{460}$

Clinical Trials: Stage 2 completed. ${ }^{461}$

Prices: 5 mg - 160 EUR; 25 mg - 640 EUR; 100 mg - 1920 EUR. $^{349}$

\section{Selumetinib}

IUPAC Name: 5-((4-bromo-2-chlorophenyl)amino)-4-fluoro- $\mathrm{N}$-(2-hydroxyethoxy)-1-methyl-1Hbenzimidazole-6-carboxamide.

CAS: 606143-52-6.

First Report: was invented by Array BioPharma Inc. (Nasdaq: ARRY) and licensed to AstraZeneca, in $2016 .{ }^{462}$ 
Activity: Selumetinib is a potent and selective MEK1/2 ATP-uncompetitive inhibitor with<smiles>Cn1cnc2c(F)c(Nc3ccc(Br)cc3Cl)c(C(=O)NOCCO)cc21</smiles>
nanomolar $\mathrm{IC}_{50}$ values. It is highly active in both in vitro and in vivo tumour models. This compound is currently being investigated in clinical trials as a cancer drug, such as, differentiated thyroid cancer, locally advanced or metastatic NSCL Cancer Stage IIIb - IV, uveal melanoma, pancreatic cancer and breast cancer ${ }^{463,464}$

Storage / Stability: Stable is stored at $-20^{\circ} \mathrm{C} .{ }^{465}$

Clinical Trials: Stage $3 .^{466}$

Prices: 25 mg - 55 EUR; 100 mg - 220 EUR; 250 mg - 440 EUR. ${ }^{349}$

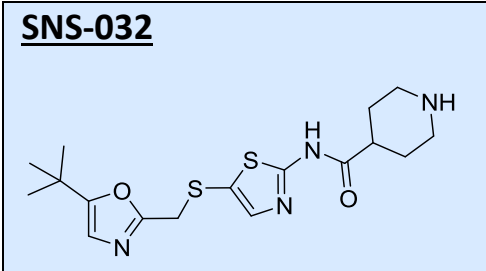

IUPAC Name: $N$-(5-((5-tert-butyl-1,3-oxazol-2-yl)methylsulfanyl)1,3-thiazol-2-yl)piperidine-4-carboxamide.

CAS: $345627-80-7$.

$2005 .{ }^{467}$

First Report: was licensed from Bristol-Myers Squibb (BMS) in

Activity: SNS-032 is a potent and selective inhibitor of cyclin-dependent kinases (CDKs) with $\mathrm{IC}_{50}$ values of 4, 62 and $38 \mathrm{nM}$ for CDK9, CDK2/cyclin A and CDK7/Cyclin $\mathrm{H}$, respectively. Its antiproliferative activity was established in an A2780 cellular cytotoxicity assay, in which it showed an $\mathrm{IC}_{50}$ value of $95 \mathrm{nM}{ }^{468}$ This compound is currently being investigated in clinical trials for the treatment for B-lymphoid malignancies, chronic lymphocytic leukaemia, mantle cell lymphoma and multiple myeloma. ${ }^{469}$

Storage / Stability: Stable if stored at $-20^{\circ} \mathrm{C} .4^{470}$

Clinical Trials: Stage 2 completed. ${ }^{471}$

Prices: 5 mg - 140 EUR; 25 mg - 560 EUR; 100 mg - 1680 EUR. $^{349}$

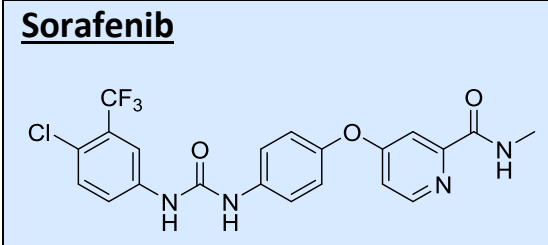

IUPAC

Name:

4-[4-[[4-chloro-3-

(trifluoromethyl)phenyl]carbamoylamino]phenoxy]- $\mathrm{N}$ methyl-pyridine-2-carboxamide.

CAS: 475207-59-1.

First Report: Riedl et al. in 2000. ${ }^{472}$

Activity: Sorafenib is a biarylurea derivative that selectively targets several receptor tyrosine kinases and Raf kinases. It has IC 50 values of $6,22,38 \mathrm{nM}$ for Raf-1, wt BRAF and V599E mutant BRAF. It has been approved for use in the treatment of advanced renal cancer and hepatocellular carcinoma. ${ }^{473}$

Storage / Stability: Stable if stored at $-20^{\circ} \mathrm{C} .{ }^{474}$

Clinical Trials: Stage 4 completed. ${ }^{475}$

Prices: 5 mg - 85 EUR; 25 mg - 340 EUR; 100 mg - 1020 EUR. $^{349}$ 


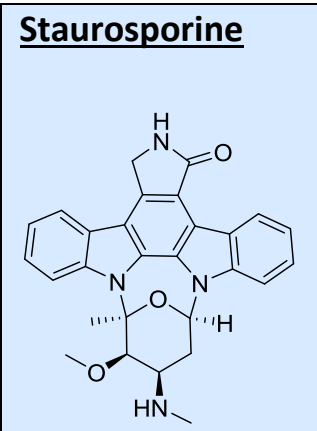

IUPAC Name: $\quad(9 S, 10 R, 11 R, 13 R)-2,3,10,11,12,13-$ Hexahydro10-methoxy-9-methyl-11-(methylamino)-9,13-epoxy-1H,9H-diindolo[1,2,3gh:3',2',1'-Im]pyrrolo[3,4-j][1,7]benzodiazonin-1-one.

\section{CAS: 62996-74-1}

First Report: Omura et al. in $1977 .{ }^{476}$

Activity: Staurosporine is a microbial alkaloid that was originally found to inhibit phospholipid/ $\mathrm{Ca}^{2+}$ dependent protein kinase (protein kinase $\mathrm{C}$ ) in low nanomolar concentrations. Later it was proved that staurosporin is potent non-selective inhibitor of many protein kinases. It displays strong cytotoxic and proapoptotic activity in many cultured cells. ${ }^{477}$

Storage / Stability: Stable if stored at $-20^{\circ} \mathrm{C} .{ }^{478}$

Clinical Trials: Stage $3 .^{479}$

Prices: 5 mg - 142 EUR; 25 mg - 568 EUR; 100 mg - 1704 EUR. ${ }^{349}$

\section{$\underline{\text { Sunitinib }}$}<smiles></smiles>

IUPAC Name: $N$-(2-diethylaminoethyl)-5-[(Z)-(5-fluoro-2-oxo- $1 \mathrm{H}$ indol-3-ylidene)methyl]-2,4-dimethyl-1H-pyrrole-3-carboxamide.

CAS: 341031-54-7.

First Report: was discovered at SUGEN/Pharmacia (which was acquired by Pfizer in 2003) in 2000. ${ }^{480}$

Activity: Sunitinib is a small molecule receptor tyrosine kinase inhibitor with direct antitumour as well as antiangiogenic activity. It targets the vascular endothelial growth factor (VEGF), platelet-derived growth factor (PDGF), KIT, and FLT3 receptor tyrosine kinases, and has Ki values of 9 and $8 \mathrm{nM}$ for FLK-1 and PDGFR, respectively. Sunitinib has been approved for use in the treatment of kidney cancer, gastrointestinal stromal tumours and pancreatic neuroendocrine tumours. ${ }^{481}$

Storage / Stability: Stable if the container was kept tightly closed in a dry and well-ventilated place. ${ }^{482}$

Clinical Trials: Stage 4 completed $^{483}$

Prices: 25 mg - 43 EUR; 100 mg - 129 EUR; 250 mg - 258 EUR. ${ }^{349}$

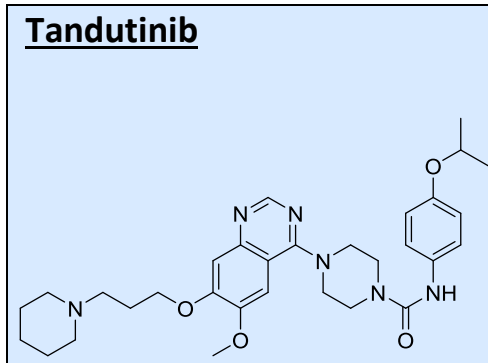

IUPAC Name: 4-[6-methoxy-7-[3-(1-piperidinyl)propoxy]-4piperazinecarboxamide. quinazolinyl]- $\mathrm{N}$-[4-(1-methylethoxy)phenyl]-1-

CAS: 387867-13-2.

First Report: Yu et al. in $2001 .^{484}$

Activity: It is an orally active small-molecule tyrosine kinase inhibitor that targets the kinase insert domain receptor (KDR; VEGFR-2) and the FMS-related tyrosine kinase 4 (FLT4; VEGFR-3). Treatment with telatinib inhibits angiogenesis and cellular proliferation in tumours in which 
these receptors are upregulated. At this time, it is under clinical evaluation to the treatment for prostate cancer, renal cell carcinoma, glioblastoma, gliosarcoma, anaplastic astrocytoma, anaplastic oligodendroglioma, adult brain tumour and myelogenous leukaemia. ${ }^{485-487}$

Clinical Trials: Stage 2 completed. ${ }^{488}$

Storage / Stability: Stable if stored in a tightly closed container, in a dry and well-ventilated place, at $-20{ }^{\circ} \mathrm{C} .{ }^{489}$

Prices: 25 mg - 85 EUR, 100 mg - 255 EUR, 250 mg - 510 EUR. $^{490}$

\section{Telatinib}<smiles>CNC(=O)c1cc(COc2nnc(Nc3ccc(Cl)cc3)c3ccoc23)ccn1</smiles>

IUPAC Name: 4-((4-((4-chlorophenyl)amino)furo[2,3-d]pyridazin7-yl)oxy)methyl)- $N$-methylpicolinamide.

CAS: $332012-40-5$.

First Report: Dumas et al. from Bayer Corporation, in $2001{ }^{491}$

Activity: It is an orally active small-molecule tyrosine kinase inhibitor that targets the kinase insert domain receptor (KDR; VEGFR-2) and the FMS-related tyrosine kinase 4 (FLT4; VEGFR-3). Telatinib inhibits angiogenesis and cellular proliferation in tumours in which these receptors are upregulated, such as, colorectal cancer, ovarian cancer, adreanal cancer, esophageal cancer and soft tissue sarcoma. ${ }^{492}$

Clinical Trials: Stage 1 completed. ${ }^{493}$

Storage / Stability: Stable if stored in a tightly closed container, in a dry and well-ventilated place, at $-20{ }^{\circ} \mathrm{C} .{ }^{494}$

Prices: 5 mg - 194 EUR, 25 mg - 776 EUR, 100 mg - 2328 EUR. ${ }^{490}$

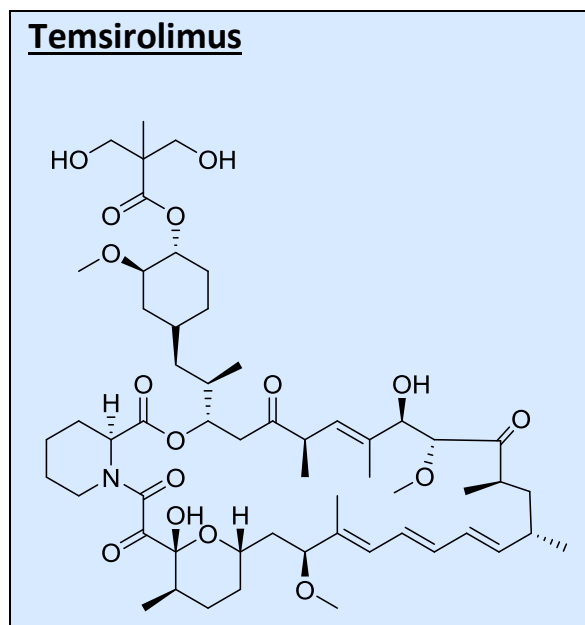

IUPAC

Name:

$1 R, 2 R, 4 S)-4-\{(2 R)-2-$

$[(3 S, 6 R, 7 E, 9 R, 10 R, 12 R, 14 S, 15 E, 17 E, 19 E, 21 S, 23 S, 26 R, 27 R$,

34aS)-9,27-dihydroxy-10,21-dimethoxy-6,8,12,14,20,26-

hexamethyl-1,5,11,28,29-pentaoxo-

$1,4,5,6,9,10,11,12,13,14,21,22,23,24,25,26,27,28,29,31,3$

2,33,34,34a-tetracosahydro-3H-23,27-epoxypyrido[2,1c] [1,4]oxazacyclohentriacontin-3-yl]propyl\}-2methoxycyclohexyl3-hydroxy-2-(hydroxymethyl)-2methylpropanoate.

CAS: 162635-04-3.

First Report: Wyeth Pharmaceuticals, Inc. in 2000. ${ }^{495}$

Activity: It is a water-soluble synthetic rapamycin ester that has been developed for both oral and intravenous applications. Like rapamycin, temsirolimus is an inhibitor of the protein kinase mTOR, which is important for the synthesis of proteins that regulate proliferation and thus for cellular growth and survival. Inhibition of mTOR abrogates pathway-mediated cellular transcription and translation, leading to cell cycle arrest, antiangiogenesis and apoptosis. Temsirolimus has significant in vitro antitumour effects against a number of cancer cell lines and has demonstrated in vivo cytostatic activity in xenograft models. Patients receiving 
temsirolimus alone achieved longer survival than those receiving interferon alone or temsirolimus plus interferon in a randomized phase III trial. It has been approved as a drug for the treatment of renal cell carcinoma. ${ }^{496,497}$

Clinical Trials: Stage 4 completed. ${ }^{498}$

Storage / Stability: Stable if stored in a tightly closed container, in a dry and well-ventilated place, at $-20{ }^{\circ} \mathrm{C} .{ }^{499}$

Prices: 5 mg - 56 EUR, 25 mg - 224 EUR, 100 mg - 672 EUR. $^{490}$

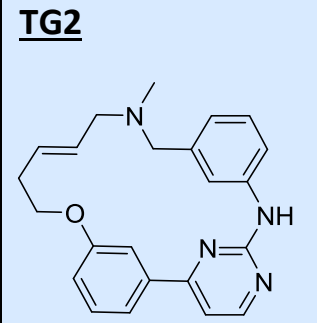

in $2008 .^{500}$ $\underline{\text { IUPAC }}$

Name:

(16E)-14-methyl-20-oxa-5,7,14,26-

tetraazatetracyclo[19.3.1.1(2,6).1(8,12)]heptacosa1(25),2(26),3,5,8(27),9,11,16,21,23-decaene.

CAS: 937270-47-8.

First Report: discovered by S*BIO and licensed to Tragara Pharmaceuticals

Activity: It is a novel pyrimidine-based multi-kinase inhibitor that inhibits CDKs 1, 2, 7 and 9 together with JAK2 and FLT3; IC 50 values are 13, 73, and $56 \mathrm{nM}$ for CDK2, JAK2 and FLT3, respectively. TG02 is cytotoxic in a broad range of tumour cell lines, inducing G1 cell cycle arrest, both the intrinsic and extrinsic pathways of apoptosis, depletion of XIAP and the key multiple myeloma survival protein MCL-1. It is currently undergoing clinical trials in advanced leukaemias and multiple myeloma. ${ }^{501}$

Clinical Trials: Stage $1^{502}$

Storage / Stability: Stable if stored in a tightly closed container, in a dry and well-ventilated place, away from direct sunlight at $-20{ }^{\circ} \mathrm{C} .{ }^{503}$

Prices: 5 mg - 280 EUR, 25 mg - 1120 EUR, 100 mg - 3360 EUR. ${ }^{490}$

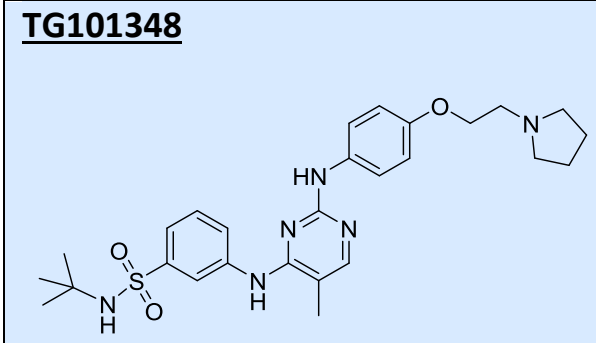

Activity: It is a potent and selective ATP-competitive JAK2 inhibitor with an $\mathrm{IC}_{50}$ of $3 \mathrm{nM}$; it is active also towards the JAK2 V617F mutant. TG101348 also inhibits the FLT3 and Ret kinases with $\mathrm{IC}_{50}$ values of 15 and $48 \mathrm{nM}$, respectively. It exhibits significantly less activity against other tyrosine kinases, including JAK3 ( $\left.\mathrm{IC}_{50}=169 \mathrm{nM}\right)$. In treated cells, it blocks downstream cellular signalling (JAK-STAT), suppressing proliferation and inducing apoptosis. It is currently being developed for the treatment of patients with myeloproliferative diseases including myelofibrosis. $^{504,505}$

Clinical Trials: Stage 2 completed. ${ }^{506}$

Storage / Stability: Stable if stored in a tightly closed container, in a dry and well-ventilated place, away from direct sunlight, at $-20{ }^{\circ} \mathrm{C} .{ }^{507}$ 
Prices: 5 mg - 140 EUR, 25 mg - 560 EUR, 100 mg - 1680 EUR. ${ }^{490}$

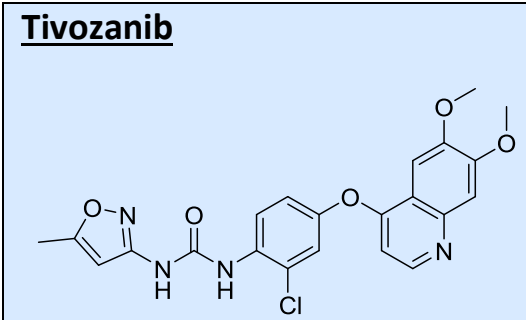

IUPAC Name: $\quad N$-\{2-chloro-4-[(6,7-dimethoxy-4quinolinyl)oxy]phenyl\}-N'-(5-methyl-3-isoxazole-yl)urea.

CAS: $475108-18-0$.

First Report: AVEO Pharmaceuticals, in $2008 .^{508}$

Activity: It is an orally active, ATP-competitive inhibitor of VEGFR tyrosine kinase developed for the potential treatment of cancer. Tivozanib inhibits activation of VEGFR-1, VEGFR-2 and VEGFR-3 at picomolar concentrations. In preclinical studies, tivozanib produced a significant inhibition of tumour growth and angiogenesis in several different animal models, such as, colorectal cancer, renal cancer, pancreatic cancer, NSCL cancer, esophageal cancer and melanoma. ${ }^{509}$

Clinical Trials: Stage 3 completed. ${ }^{510}$

Storage / Stability: Stable if stored in a tightly closed container, in a dry and well-ventilated place, away from direct sunlight at $-20^{\circ} \mathrm{C} .^{511}$

Prices: 5 mg - 80 EUR, 25 mg - 320 EUR, 100 mg - 960 EUR. ${ }^{490}$

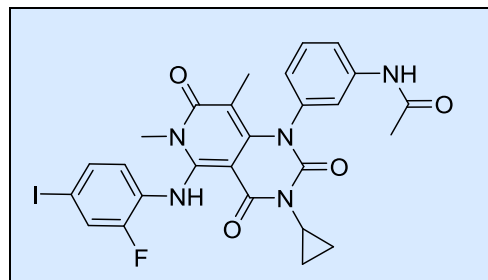

\section{Trametinib}

IUPAC Name: $\quad N$-(3-(3-cyclopropyl-5-(2-fluoro-4iodophenylamino)-6,8-dimethyl-2,4,7-trioxo-3,4,6,7tetrahydropyrido[4,3-d]pyrimidin-1(2H)-yl)phenyl)acetamide.

CAS: 871700-17-3.

First Report: Abe et al. in 2011. ${ }^{512}$

Activity: It is a potent and selective allosteric inhibitor of the MEK1 and MEK2 kinases with strong antitumour activity. Trametinib inhibits prevents Raf-dependent MEK phosphorylation (S217 for MEK1), producing prolonged p-ERK1/2 inhibition. Cell growth inhibition is significant in most tumour lines with mutant BRAF or Ras. It undergoes trials in patients with metastatic BRAF-mutant melanoma. ${ }^{513,514}$

Clinical Trials: Stage $4 .{ }^{515}$

Storage / Stability: Stable if stored in a tightly closed container, in a dry and well-ventilated place, away from direct sunlight and sources of ignition at $-20^{\circ} \mathrm{C}^{516}$

Prices: 5 mg - 85 EUR, 25 mg - 340 EUR, 100 mg - 1020 EUR. $^{490}$

\section{Tyrphostin AG 490}<smiles>N#C/C(=C\c1ccc(O)c(O)c1)C(=O)NCc1ccccc1</smiles>

IUPAC Name: 2-cyano-3-(3,4-dihydroxyphenyl)- $N$-(benzyl)-2propenamide-2-cyano-3-(3,4-dihydroxyphenyl)- $\mathrm{N}$-(phenylmethyl)2-propenamide.

CAS: 134036-52-5.

First Report: Gazit et al. in $1991 .^{517}$ 
Activity: AG-490 potently inhibits the kinase activities of JAK2 and JAK3. Inhibition of JAK-2 activity by AG-490 selectively blocks leukaemic cell growth in vitro and in vivo by inducing programmed cell death (acute lymphoblastic leukaemia), with no deleterious effect on normal haematopoiesis. AG490 also suppresses cell proliferation and induces apoptosis in IL-6dependent multiple myeloma cell lines. AG-490 inhibits JAK3-dependent activation of STAT5a/b and downstream signal transduction and cellular proliferation of antigen-activated human T cells. ${ }^{518}$

Clinical Trials: No studies in the moment. ${ }^{519}$

Storage / Stability: Stable if stored in a tightly closed container, in a dry and well-ventilated place at $-20^{\circ} \mathrm{C}^{520}$

Prices: 5 mg - 52 EUR, 25 mg - 208 EUR, 100 mg - 624 EUR. ${ }^{490}$

\section{Tyrphostin AG 1478}<smiles>COc1cc2ncnc(Nc3cccc(Cl)c3)c2cc1OC</smiles>

IUPAC Name: $N$-(3-chlorophenyl)-6,7-dimethoxy-4-quinazolinamine.

CAS: 175178-82-2.

First Report: Barker from Zeneca Ltd. in $1993 .^{521}$

Activity: It is a specific inhibitor of the EGF-receptor tyrosine kinase (ERBB1) activity with an $\mathrm{IC}_{50}$ of about $3 \mathrm{nM}$ in vitro. It is also very active against L858R and L861Q EGFR mutants. According to in vitro gene profiling, it displays moderate activity also against ERBB2 (HER2) and ERBB4 (HER4) receptors, LYNA and LYNB. AG1478 has very weak activity on PDGF and HER2-NEU kinases (I $5_{50}$ values over 100 microM), in human myeloma cells. ${ }^{522,523}$

Clinical Trials: No studies in the moment. ${ }^{524}$

Storage / Stability: Stable if stored, as supplied at $-20^{\circ} \mathrm{C}$. Upon solubilization, apportion into working aliquots and store at $-20^{\circ} \mathrm{C}$. Avoid repeated freeze/thaw cycles. Solutions are stable at $-20^{\circ} \mathrm{C}$ for up to three months. ${ }^{525}$

Prices: 5 mg - 52 EUR, 25 mg - 208 EUR, 100 mg - 624 EUR. ${ }^{490}$

\section{$\underline{\text { U0126 }}$}

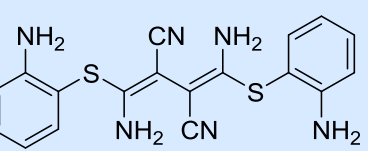

IUPAC

Name:

1,4-diamino-2,3-dicyano-1,4-bis(2aminophenylthio)butadiene.

First Report: W. J. Middleton et al. in $1958 .^{526}$

Activity: U0126 was originally found to functionally antagonize AP-1 transcriptional activity via non-competitive inhibition of the dual specificity kinases MEK with an $\mathrm{IC}_{50}$ of $70 \mathrm{nM}$ for MEK1 and $60 \mathrm{nM}$ for MEK2. Later, U0126 was reported to inhibit MKK1, and five-fold less potently also SAPK2a/p38, PRAK and PKB alpha. ${ }^{527,528}$ It is currently being clinical evaluated as a anticancer drug for lung cancer, multiple myeloma, fallopian tube carcinoma, primary peritoneal carcinoma and recurrent ovarian carcinoma. ${ }^{529}$

Clinical Trials: Stage $3 .^{530}$

Storage / Stability: Stable if stored, as supplied, at room temperature for up to one year and in solution at $-20^{\circ} \mathrm{C}$ for up to three months. ${ }^{531}$ 
Prices: 5 mg - 52 EUR, 25 mg - 208 EUR, 100 mg - 624 EUR. ${ }^{532}$

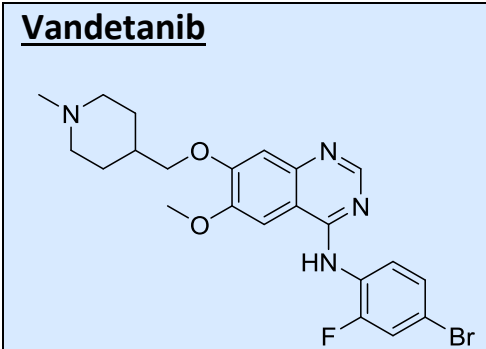

IUPAC Name: $\mathrm{N}$-(4-bromo-2-fluorophenyl)-6-methoxy-7-((1methylpiperidin-4-yl)methoxy)quinazolin-4-amine.

CAS: 443913-73-3.

Activity: It is a tyrosine kinase inhibitor that targets the VEGFR $\left(I C_{50}=40 \mathrm{nM}\right)$ and EGFR $\left(I C_{50}=\right.$ $500 \mathrm{nM}$ ) receptors. It is a potent in vitro inhibitor of VEGFA-stimulated endothelial cell proliferation $\left(\mathrm{IC}_{50}=60 \mathrm{nM}\right)$ and has been demonstrated to selectively inhibit VEGF signalling in vivo in a growth factor-induced hypotension rat model. ${ }^{533,534}$ It is currently being clinical evaluated as a cancer drug for invasive breast cancer, differentiated thyroid cancer, prostate cancer, gastric cancer, lung cancer, colorectal cancer, thyroid cancer, HNC and breast cancer. ${ }^{535}$

Clinical Trials: Stage $4 .{ }^{536}$

Storage / Stability: Stable if stored in a tightly closed container, in a dry and well-ventilated place, away from direct sunlight and sources of ignition at $-20{ }^{\circ} \mathrm{C} .{ }^{537}$

Prices: 25 mg - 103 EUR, 100 mg - 309 EUR, 250 mg - 618 EUR. $^{538}$

\section{Vatalanib (dihydrochloride)}

$\mathrm{Cl}$
IUPAC Name: $N$-(4-chlorophenyl)-4-(pyridin-4-ylmethyl)phthalazin-1-amine
dihydoride. dihydrochloride.

$\underbrace{1}_{1}$

First Report: Department of Oncology Research of Novartis Pharmaceuticals, in collaboration with the Institute of Molecular Medicine (Tumour Biology Center) in $2000 .^{539}$

Activity: It is a potent inhibitor of vascular endothelial growth factor (VEGF) receptor tyrosine kinases, active in the submicromolar range. It also inhibits other class III kinases, such as the platelet-derived growth factor (PDGF) receptor beta tyrosine kinase, c-KIT, and c-FMS, but at higher concentrations. It is not active against kinases from other receptor families, such as epidermal growth factor receptor, fibroblast growth factor receptor-1, c-MET, and TIE-2, or intracellular kinases such as C-SRC, c-ABL and protein kinase C-alpha. ${ }^{539,540} \mathrm{It}$ is currently being clinical evaluation for breast cancer, prostate cancer, pancreatic cancer, kidney cancer, NSCl cancer and pleural mesothelioma, ovarian cancer, endometrial cancer, cervical cancer, fallopian tube cancer, peritoneal cancer, brain and central nervous system tumours and leukaemia treament. ${ }^{541}$

Clinical Trials: Stage 3 completed. ${ }^{542}$

Storage / Stability: Stable if stored in a tightly closed container, in a dry and well-ventilated place at $-20^{\circ} \mathrm{C}^{543}$

Prices: 25 mg - 88 EUR, 100 mg - 264 EUR, 250 mg - 528 EUR. $^{538}$ 
<smiles>COc1ccc(-c2cnc(N)c(NC(=O)c3ccccc3)n2)cc1</smiles>

IUPAC Name: (methylsulfonyl)phenyl]- $N$-phenyl-2-pyrazinecarboxamide.

CAS: 1232410-49-9.

First Report: Reaper et al. in 2011. ${ }^{544}$

Activity: VE-821 was described as a potent and selective inhibitor of protein kinase ATR. The compound acts as an ATP competitor with $\mathrm{IC}_{50}$ value of $50 \mathrm{nM}$ for ATR at 50 microM ATP. It exhibited no significant activity against a panel of 50 kinases. A VE-821 significantly enhanced the sensitivity of pancreatic cancer cells to radiation. ATR inhibition by VE-821 led to suppression of radiation-induced G2/M arrest in cancer cells and reduced cancer cell survival, accompanied by increased DNA damage and inhibition of homologous recombination repair. Growth arrest induced by ATR inhibition in normal cells is reversible and VE-821 does not induce cytotoxicity in normal cells. ${ }^{545-547}$

Clinical Trials: Stage $4 .{ }^{548}$

Storage / Stability: Stable if stored in a tightly closed container, in a dry and well-ventilated place, away from direct sunlight and sources of ignition at $-20{ }^{\circ} \mathrm{C} .{ }^{549}$

Prices: 5 mg - 85 EUR, 25 mg - 199 EUR, 100 mg - 599 EUR. ${ }^{538}$ 


\section{$\underline{\mathrm{VX}-680}$}<smiles>Cc1cc(Nc2cc(N3CCN(C)CC3)nc(Sc3ccc(NC(=O)C4CC4)cc3)n2)n[nH]1</smiles>

IUPAC Name: $N$-(4-(4-(5-methyl-1H-pyrazol-3-ylamino)-6-(4methylpiperazin-1-yl)pyrimidin-2ylthio)phenyl)cyclopropanecarboxamide.

CAS: 639089-54-6.

First Report: Vertex's Oxford in 2002. ${ }^{555}$

Activity: It is a highly potent and selective small-molecule inhibitor of Aurora kinases. In addition, it has activity against BCR-ABL, including the T315I BCR-ABL mutant. It also, blocks cell-cycle progression and induces apoptosis in a diverse range of human tumour types both in vitro and in vivo. ${ }^{556,557,558}$ This compound is currently being evaluated for the treatment of colorectal cancer, NSCL carcinoma and leukaemia. ${ }^{559}$

Clinical Trials: Stage 2 completed. ${ }^{560}$

Storage / Stability: Keep container tightly sealed in cool, in well-ventilated area. Keep away from direct sunlight and sources of ignition. Recommended storage temperature: Store at -20 ${ }^{\circ} \mathrm{C} .{ }^{561}$

Prices: 5 mg - 62 EUR, 25 mg - 248 EUR, 100 mg - 744 EUR. ${ }^{538}$

\section{$\underline{\mathrm{VX}-702}$}<smiles>NC(=O)c1cnc(N(C(N)=O)c2c(F)cccc2F)nc1-c1ccc(F)cc1F</smiles>

IUPAC Name: 1-(5-carbamoyl-6-(2,4-difluorophenyl)pyridin-2-yl)-1(2,6-difluorophenyl)urea.

CAS: 745833-23-2.

First Report: Vertex Pharmaceuticals Inc, in collaboration with Kissei Pharmaceutical Co Ltd, in 2003. ${ }^{562}$

Activity: VX-702 is a p38 MAPK inhibitor, which shows activity against prostate cancer cells PC3 and Du145 and breast cancer cells MDA-MB-231. ${ }^{563}$

Clinical Trials: Stage 2 completed. ${ }^{564}$

Storage / Stability: Stable in the unopened package. The powder is stable for 1 year (at $4{ }^{\circ} \mathrm{C}$ desiccated) and in DMSO solution (at $-20^{\circ} \mathrm{C}$ ) is stable for 6 months. ${ }^{565}$

Prices: 5 mg - 62 EUR, 25 mg - 248 EUR, 100 mg - 744 EUR. ${ }^{538}$

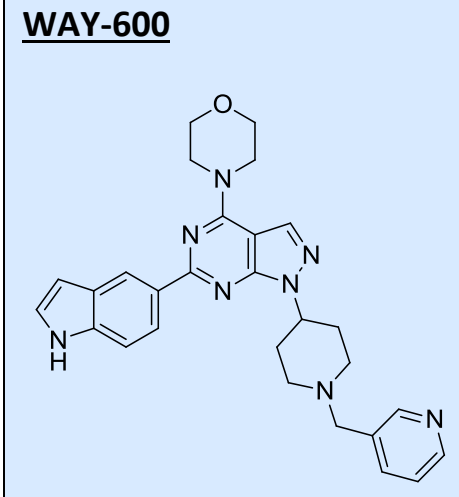

IUPAC

Name:

4-[6-(1H-indol-5-yl)-1-[1-(pyridin-3-

yl]morpholine.

ylmethyl)piperidin-4-yl]pyrazolo[3,4-d]pyrimidin-4-

CAS: 1062159-35-6.

First Report: Zask et al. in $2008 .^{566}$

Activity: It is a single digit nanomolar inhibitor of the mTOR kinases, with significant selectivity for these enzymes over phosphatidylinositol 3-kinase (PI3K) isofoms (>100-fold). WAY600 inhibited the activity of proteins downstream of AKT and the proliferation of diverse 
cancer cell lines. These effects correlated with a strong $\mathrm{G}(1)$ cell cycle arrest in both rapamycinsensitive and rapamycin-resistant cells, selective induction of apoptosis, repression of global protein synthesis and down-regulation of angiogenic factors. ${ }^{567}$ It is currently being evaluated for the treatment of metastatic colorectal cancer, breast cancer, lung cancer, prostate cancer, esophageal cancer, pancreatic cancer, peritoneal cavity cancer, squamous neck carcinoma of the head and neck cancer (SCCHN), lymphoma, leumkemia, melanoma, osteosarcoma and retinoblastoma. ${ }^{568}$

Clinical Trials: Stage 4 completed. ${ }^{569}$

Storage / Stability: Keep container tightly sealed in cool, well-ventilated area. Keep away from direct sunlight and sources of ignition. Recommended storage temperature: Store at $-20{ }^{\circ} \mathrm{C} .{ }^{570}$

Prices: 5 mg - 284 EUR, 25 mg - 1136 EUR, 100 mg - 3408 EUR. $^{571}$

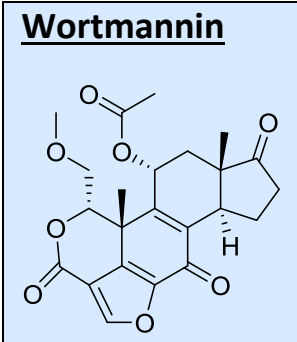

IUPAC Name: (1S,6bR,9aS,11R,11bR)11-(acetyloxy)-1,6b,7,8,9a,10,11,11boctahydro-1-(methoxymethyl)-9a,11bdimethyl-3H-furo[4,3,2de]indeno[4,5,-H]-2-H]-2-benzopyran-3,6,9-trione.

CAS: 19545-26-7.

First Report: Isolated from Penicillium wortmanmii Klöcker by Norris's Group, in $1957^{572}$ and characterized by Yeboah's group, in $1972 .^{573}$

Activity: It is a fungal metabolite that has been shown to act as a selective inhibitor of phosphoinositide 3-kinases with $\mathrm{IC}_{50}$ values in low nanomolar range. It has been shown that wortmannin binds irreversibly in proximity to the substrate-binding site of PI3K. Wortmannin inhibits also the ataxia telangiectasia gene (ATM)-related DNA-dependent protein kinase (DNAPKcs). ${ }^{574,575}$ The exposing of KNS-62 and Colo-699 lung cancer cells to wortmannin the proliferation was inhibited in correlation to concentration in vitro. In vivo the blocking of PI3K by wortmannin prior to xenotransplantation caused a significant delay in the growth of subcutaneously induced tumours. Systemic wortmannin administration increased mean survival after intrapulmonary xenotransplantation of human NSCL cancer significantly by $38 \%$ and $47 \%{ }^{576}$

Clinical Trials: Stage 4 completed. ${ }^{577}$

Storage / Stability: Store in cool, well-ventilated area. Keep away from direct sunlight. Keep container tightly sealed until ready for use. Recommended storage temperature: Desiccate at $20^{\circ} \mathrm{C}^{578}$

Prices: 5 mg - 84 EUR, 25 mg - 336 EUR, 100 mg - 1008 EUR. $^{571}$

\section{WYE-125132}

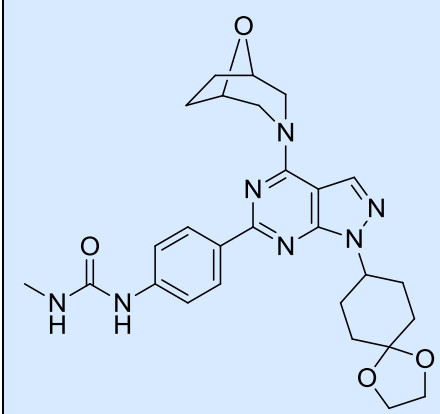

IUPAC Name: 1-[4-[1-(1,4-dioxaspiro[4.5]decan-8-yl)-4-(8-oxa-3azabicyclo[3.2.1]octan-3-yl)pyrazolo[3,4-d]pyrimidin-6-yl]phenyl]3-methylurea.

CAS: 1144068-46-1.

First Report: Ker Yu et al. in 2010. ${ }^{579}$

Activity It is a highly potent (subnanomolar), ATP-competitive, and specific mTOR kinase inhibitor. WYE-132 inhibited mTORC1 
and mTORC2 in diverse cancer models in vitro and in vivo. Compared to the rapalog temsirolimus/CCI-779, WYE-132 is a significantly more potent inhibitor of cancer cell growth and survival, protein synthesis, cell growth, bioenergetic metabolism and adaptation to hypoxia. ${ }^{579,580}$

Clinical Trials: Stage 4 completed. ${ }^{581}$

Storage / Stability: Store at room temperature. The product can be stored for up to 12 months. ${ }^{582}$

Prices: 5 mg - 284 EUR; 25 mg - 1136 EUR; 100 mg - 3408 EUR. $^{571}$

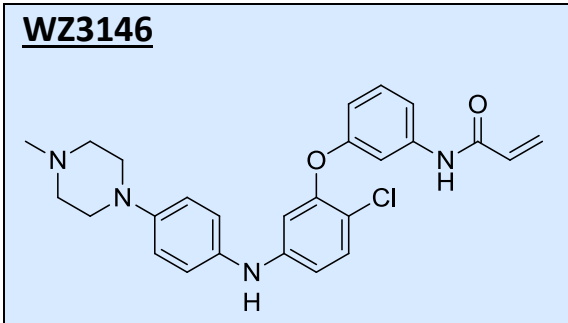

IUPAC Name: N-(3-(5-chloro-2-(4-(4-methylpiperazin-1yl)phenylamino)pyrimidin-4-yloxy)phenyl)acrylamide.

CAS: $1214265-56-1$.

First Report: Wenjun Zhou et al. in $2009 .{ }^{583}$

Activity: Similar to WZ8040. ${ }^{583}$

Clinical Trials: No studies in the moment. ${ }^{584}$

Storage / Stability: Storage in dry ambient and in absent of light. If stored to $0-4{ }^{\circ} \mathrm{C}$ is stable for several days to weeks; if stored at $-20^{\circ} \mathrm{C}$ remained stable for a period of several months to years. $^{585}$

Prices: 5 mg - 194 EUR; 25 mg - 776 EUR; 100 mg - 2328 EUR. $^{571}$

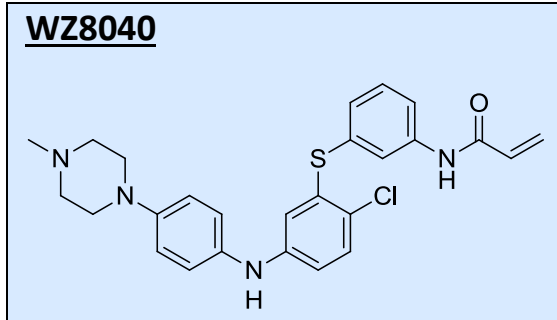

IUPAC Name: $\mathrm{N}$-(3-(5-chloro-2-(4-(4-methylpiperazin-1yl)phenylamino)pyrimidin-4-ylthio)phenyl)acrylamide.

CAS: 1214265-57-2.

First Report: Wenjun Zhou et al. in 2009. ${ }^{583}$

Activity: It is an irreversible inhibitor of EGFR receptor kinase mutants carrying a mutation in an active site gatekeeper residue (T790M), which is detected in $50 \%$ of patients exhibiting resistance to gefitinib or erlotinib. WZ8040 is much less potent against wild-type EGFR kinase. ${ }^{583}$

Clinical Trials: Pre-clinical Stage. ${ }^{583}$

Storage / Stability: Stable if stored in cold place (up to one week at $4{ }^{\circ} \mathrm{C}$ or six months at $-20^{\circ} \mathrm{C}$ ) and kept the container tightly closed in a dry and well-ventilated place. Containers which are opened must be carefully resealed and kept upright to prevent leakage. ${ }^{586}$

Prices: 5 mg - 194 EUR; 25 mg - 776 EUR; 100 mg - 2328 EUR. $^{571}$ 


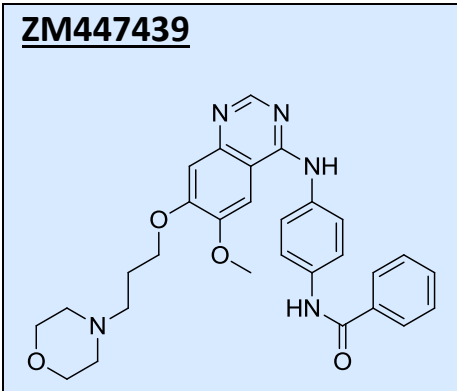

IUPAC Name: $N$-[4-[[6-methoxy-7-[3-(4-morpholinyl)propoxy]-4uinazolinyl]amino]phenyl]benzamide.

CAS: 331771-20-1.

First Report: Claire Ditchfield et al. in $2003 .^{587}$

Activity: It is a selective ATP-competitive inhibitor of Aurora B kinase in vitro. ZM447439 has a higher over a range of other kinases including CDK1 and PLK1, when analysed in HCT-116 colorectal cancer cells. Inhibits cell division and displays selective toxicity towards proliferating tumour cells versus nondividing cells. ${ }^{588}$

Storage / Stability: Stable if, stored in cool, well-ventilated area. Keeping away from direct sunlight, in a container tightly sealed until ready for use. After opening, keep the flash at the dissector conditions. ${ }^{589}$

Clinical Trials: Stage 1.

Prices: 5 mg - 103 EUR; 25 mg - 412 EUR; 100 mg - 1236 EUR. $^{590}$

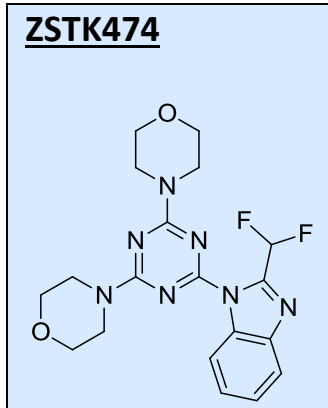

IUPAC Name: 2-(2-difluoromethylbenzimidazol-1-yl)-4,6-dimorpholino1,3,5-triazine.

CAS: 475110-96-4.

First Report: Shin-ichi Yaguchi et al. from Zenyaku Kogyo Co., Ltd.'s research laboratory in $1997 .{ }^{591}$

Activity: is a potent inhibitor of all four isoforms of class I PI 3-kinase. It has shown strong antitumour activity against human cancer xenografts (in mice by arresting cell growth) ${ }^{592,593}$ In addition, it was able to inhibit osteoclast formation and collagen-induced arthritis in a mouse model. ${ }^{594}$ It has higher selectivity over the other classes of PI3K and protein kinases. Until now, it not shown any type of toxicity to vital organs.

Storage / Stability: Stable if in powder form storage at $-20^{\circ} \mathrm{C}$ (years) and DMSO solution at $4{ }^{\circ} \mathrm{C}$ (months). ${ }^{595}$

Clinical Trials: Stage 1 completed. ${ }^{596}$

Prices: Manufactured and distributed only in small amounts: 60 EUR; 100 mg - 180 EUR; 250 mg - 360 EUR. ${ }^{590}$

\section{Conclusions}

This article presented a huge compilation of tyrosine kinase inhibitors, recently approved or under clinical trials, containing important informations that can be used for as a starting point for many medicinal chemists who wish to enter this area. 


\section{References}

${ }^{1}$ Menegatti, R.; Fraga, C. A. M.; Barreiro, E. J. A importância da síntese de fármacos. Cadernos Temáticos de Química Nova na Escola 2001, 3. [Link]

${ }^{2}$ Silverman, R. B. The organic Chemistry of drug design and drug action. Academic Press, San Diego, 1992.

3 Sociedade Brasileira de Profissionais em Pesquisa Clínica. Available in: <http://www.sbppc.org.br/portal/index.php?option=com content\&task=view\&id=14\&ltemid= 37>. Accessed in: May $5^{\text {th }} 2016$.

${ }^{4}$ Avila, C. M.; Romeiro, N. C. Proteínas Tirosinas Quinases: Desafios do Desenvolvimento de Fármacos para a Terapia do Câncer. Revista Virtual de Química 2010, 2, 59. [CrossRef]

${ }^{5}$ a) Katoh, H.; Yamashita, K.; Enomoto, T.; Watanabe, M. Classification and General Considerations of Thyroid Cancer. Annals Clinical Pathology 2015, 3, 1045; [Link] b) Laursen, R.; Wehland, M.; Kopp S.; Pietsch, J.; Infanger, M.; Grosse, J.; Grimm, D. Effects and Role of Multikinase Inhibitors in Thyroid Cancer. Current Pharmaceutical Design 2016, In Press. [CrossRef] [PubMed]

${ }^{6}$ Bhagwat, S.; Chao, Q.; Grotzfeld, R. M.; Patel, H. K.; Sprankle, K. G.; USA. PCT/US2007/006613 2007. (WO 2007109120 A2).

${ }^{7}$ Zarrinkar, P. P.; Gunawardane, R. N.; Cramer, M. D.; Gardner, M. F.; Brigham, D.; Belli, B.; Karaman, M. W.; Pratz, K. W.; Pallares, G.; Chao, Q.; Sprankle, K. G.; Patel, H. K.; Levis, M.; Armstrong, R. C.; James, J.; Bhagwat, S. S. AC220 is a uniquely potent and selective inhibitor of FLT3 for the treatment of acute myeloid leukemia (AML). Blood 2009, 114, 2984. [CrossRef] [PubMed]

${ }^{8}$ Chao, Q.; Sprankle, K. G.; Grotzfeld, R. M.; Lai A. G.; Carter, T. A.; Velasco, A. M.; Gunawardane, R. N.; Cramer, M. D.; Gardner, M. F.; James, J.; Zarrinkar, P. P.; Patel, H. K.; Bhagwat, S. S. Identification of $N$-(5-tert-butyl-isoxazol-3-yl)- $N^{\prime}-\{4-[7-(2-$ morpholin-4-ylethoxy)imidazo[2,1- $b][1,3]$ benzothiazol-2-yl]phenyl\}urea dihydrochloride (AC220), a uniquely potent, selective, and efficacious FMS-like tyrosine kinase-3 (FLT3) inhibitor. Journal of Medicinal Chemistry 2009, 52, 7808. [CrossRef] [PubMed]

${ }^{9}$ Clinical Trials.gov's website - A service of the U.S. National Institutes of Health. Available at: $<$ https://clinicaltrials.gov/ct2/results?term=AC220\&Search=Search>. Accessed in: September $25^{\text {th }} 2016$.

10 Selleckchem.com website. Available $<$ http://www.selleckchem.com/msds/MSDS_S1526.pdf>. Accessed in September $25^{\text {th }} 2016$.

11 Tinib-Tools website. Available at: <http://www.tinib-tools.com/products_A.html\#A008>. Accessed in September $25^{\text {th }} 2016$.

${ }^{12}$ Soyka, R.; Rall, W.; Schnaubelt, J.; Sieger, P.; Kulinna, C.; Germany, 2005. (US 20050085495 A1)

${ }^{13}$ Schütze, C.; Dörfler, A.; Eicheler, W.; Zips, D.; Hering, S.; Solca, F.; Baumann, M.; Krause, M. Combination of EGFR/HER2 tyrosine kinase inhibition by BIBW 2992 and BIBW 2669 with irradiation in FaDu human squamous cell carcinoma. Strahlenther Onkologie 2007, 183, 256. [CrossRef] [PubMed]

${ }^{14}$ Li, D.; Ambrogio, L.; Shimamura, T.; Kubo, S.; Takahashi, M.; Chirieac, L. R.; Padera, R. F.; Shapiro, G. I,: Baum, A.; Himmelsbach, F.; Rettig, W. J.; Meyerson, M.; Solca, F.; Greulich, H.; Wong, K. K. BIBW2992, an irreversible EGFR/HER2 inhibitor highly effective in preclinical lung cancer models. Oncogene 2008, 27, 4702. [CrossRef] [PubMed]

15 Ioannou, N.; Dalgleish, A.G.; Seddon, A.M.; Mackintosh, D.; Guertler, U.; Solca, F.; Modjtahedi, H. Anti-tumour activity of afatinib, an irreversible ErbB family blocker, in human pancreatic tumour cells. British Journal of Cancer 2011, 105, 1554. [CrossRef] [PubMed] 
${ }^{16}$ Clinical Trials.gov's website - A service of the U.S. National Institutes of Health. Available at: $<$ https://clinicaltrials.gov/ct2/results?term=Afatinib\&Search=Search $>$. Accessed in: September $25^{\text {th }} 2016$.

17 Apollo Scientific Limited website - safety data sheet of Afatinib. Available at: http://www.apolloscientific.co.uk/downloads/msds/BIFK0010 msds.pdf>. Accessed in: September $25^{\text {th }} 2016$.

18 Tinib-Tools website. Available at: <http://www.tinib-tools.com/product A010.html>. Accessed in: September $25^{\text {th }} 2016$.

${ }^{19}$ Kinoshita, K.; Aso, K.; Furuichi, N.; Ito, T.; Kawada, H.; Ishii, N.; Sakamoto, H.; Ho, W. S.; Park, M. J.; Ono, Y.; Japan, 2010. (JP 4588121 B1 20101124).

${ }^{20}$ Sakamoto, H.; Tsukaguchi, T.; Hiroshima, S.; Kodama, T.; Kobayashi, T.; Fukami, T.A., Oikawa, N.; Tsukuda, T.; Ishii, N.; Aoki, Y. CH5424802, a selective ALK inhibitor capable of blocking the resistant gatekeeper mutant. Cancer Cell 2011, 19, 679. [CrossRef] [PubMed]

${ }^{21}$ Kinoshita, K.; Asoh, K.; Furuichi, N.; Ito, T.; Kawada, H.; Hara, S.; Ohwada, J.; Miyagi, T.; Kobayashi, T.; Takanashi, K.; Tsukaguchi, T.; Sakamoto, H.; Tsukuda, T.; Oikawa, N. Design and synthesis of a highly selective, orally active and potent anaplastic lymphoma kinase inhibitor (CH5424802). Bioorganic \& Medicinal Chemistry 2012, 20, 1271. [CrossRef] [PubMed]

${ }^{22}$ Clinical Trials.gov's website - A service of the U.S. National Institutes of Health. Available at: $<$ https://clinicaltrials.gov/ct2/results?term=Alectinib\&Search=Search>. Accessed in: September $25^{\text {th }} 2016$.

${ }^{23}$ MedKoo Biosciences's website - Leading supplier of anticancer chemical reagents and kinase inhibitors. Available at: 〈http://www.medkoo.com/products/8915>. Accessed in: September $25^{\text {th }} 2016$.

24 Tinib-Tools website. Available at: <http://www.tinib-tools.com/product A174.html $>$. Accessed in: September $25^{\text {th }} 2016$.

${ }^{25}$ Rosania, G. R.; Merlie, J. Jr.; Gray, N.; Chang, Y. T.; Schultz, P. G.; Heald, R. A. A cyclindependent kinase inhibitor inducing cancer cell differentiation: Biochemical identification using Xenopus egg extracts. Proceedings of the National Academy of Sciences of the United States of America 1999, 96, 4797. [CrossRef] [PubMed]

${ }^{26}$ Rosania, G. R.; Merlie, J. Jr.; Gray, N.; Chang, Y. T.; Schultz, P. G.; Heald, R. A cyclindependent kinase inhibitor inducing cancer cell differentiation: biochemical identification using Xenopus egg extracts. Journal of Medicinal Chemistry 2006, 49, 3826. [CrossRef] [PubMed]

${ }^{27} \mathrm{X}$-ray structure of human CDK6-V cyclin with the inhibitor aminopurvalanol $2 \mathrm{~F} 2 \mathrm{C}$.

${ }^{28}$ Rivest, P.; Renaud, M.; Sanderson, J. T. Proliferative and androgenic effects of indirubin derivatives in LNCaP human prostate cancer cells at sub-apoptotic concentrations. ChemicoBiological Interactions 2011, 189, 177. [Crossref] [PubMed]

${ }^{29}$ Clinical Trials.gov's website - A service of the U.S. National Institutes of Health. Available at: $<$ https://clinicaltrials.gov/ct2/results?term=AMINOPURVALANOL\&Search=Search $>$. Accessed in: September $29^{\text {th }} 2016$.

30 Biovision's website. Available: $<$ http://www.biovision.com/manuals/2205 MSDS.pdf?osCsid=9o1ple0f1q79uffhc91uij8nd4>. Accessed in: September $25^{\text {th }} 2016$.

${ }^{31}$ Tinib-Tools website. Available at: <http://tinib-tools.com/product A011.html>. Accessed in: September $26^{\text {th }} 2016$.

${ }^{32}$ Yuan, K.; Sun, P.; Zhou, Y.; Chen, Y.; Chen, G. P.; China, 2010 (WO 2010031266 A1)

${ }^{33}$ Mi, Y. J.; Liang, Y. J,; Huang, H. B.; Zhao, H. Y.; Wu, C. P.; Wang, F.; Tao, L. Y.; Zhang, C. Z.; Dai,

C. L.; Tiwari, A. K.; Ma, X. X.; To, K. K.; Ambudkar, S. V.; Chen, Z. S.; Fu, L. W. Apatinib 
(YN968D1) reverses multidrug resistance by inhibiting the efflux function of multiple ATPbinding cassette transporters. Cancer Research 2010, 70, 7981. [CrossRef] [PubMed]

${ }^{34}$ Tian, S.; Quan, H.; Xie, C.; Guo, H.; Lü, F.; Xu, Y.; Li, J.; Lou, L. YN968D1 is a novel and selective inhibitor of vascular endothelial growth factor receptor-2 tyrosine kinase with potent activity in vitro and in vivo. Cancer Science 2011, 102, 1374. [CrossRef] [PubMed]

${ }^{35}$ Clinical Trials.gov's website - A service of the U.S. National Institutes of Health. Available at: $<$ https://clinicaltrials.gov/ct2/results?term=Apatinib+\&Search=Search>. Accessed in: September $25^{\text {th }} 2016$.

36 Ebiochemichals's website. Available at: <http://www.ebiochemicals.com/Wiki/Qceb000023488 MSDS 1.html>. Accessed in: September $25^{\text {th }} 2016$.

37 Tinib-Tools website. Available at: <http://www.tinib-tools.com/product A111.html>. Accessed in: September $25^{\text {th }} 2016$.

${ }^{38}$ Astex's website. Available: <http://astx.com/pipeline/products/clinical\#at7519>. Accessed in: September $25^{\text {th }} 2016$.

${ }^{39}$ Wyatt, P. G.; Woodhead, A. J.; Berdini, V.; Boulstridge, J. A.; Carr, M. G.; Cross, D. M.; Davis, D. J.; Devine, L. A.; Early, T. R.; Feltell, R. E.; Lewis, E. J.; McMenamin, R. L.; Navarro, E. F.; O'Brien, M. A.; O'Reilly, M.; Reule, M.; Saxty, G.; Seavers, L. C.; Smith, D. M.; Squires, M. S.; Trewartha, G.; Walker, M. T.; Woolford, A. J. Identification of N-(4-piperidinyl)-4-(2,6dichlorobenzoylamino)-1H-pyrazole-3-carboxamide (AT7519), a novel cyclin dependent kinase inhibitor using fragment-based X-ray crystallography and structure based drug design. Journal of Medicinal Chemistry 2008, 51, 4986. [CrossRef] [PubMed]

${ }^{40}$ Squires, M. S.; Feltell, R. E.; Wallis, N. G.; Lewis, E. J.; Smith, D. M.; Cross, D. M.; Lyons, J. F.; Thompson, N. T. Biological characterization of AT7519, a small-molecule inhibitor of cyclindependent kinases, in human tumor cell lines. Molecular Cancer Therapeutics 2009, 8, 324. [CrossRef] [PubMed]

${ }^{41}$ Santo, L.; Vallet, S.; Hideshima, T.; Cirstea, D.; Ikeda, H.; Pozzi, S.; Patel, K.; Okawa, Y.; Gorgun, G.; Perrone, G.; Calabrese, E.; Yule, M.; Squires, M.; Ladetto, M.; Boccadoro, M.; Richardson, P. G.; Munshi, N. C.; Anderson, K. C.; Raje, N. AT7519, A novel small molecule multi-cyclin-dependent kinase inhibitor, induces apoptosis in multiple myeloma via GSK-3beta activation and RNA polymerase II inhibition. Oncogene 2010, 29, 2325. [CrossRef] [PubMed]

${ }^{42}$ PDB Structure of its co-crystal with CDK2: 2VTQ

${ }^{43}$ Clinical Trials.gov's website - A service of the U.S. National Institutes of Health. Available at: $<$ https://clinicaltrials.gov/ct2/results?term $=A T+7519 \&$ type $=\& r$ slt=\&recr=\&age $v=\& g n d r=\& c o n$ $\mathrm{d}=$ cancer\&intr=\&titles=\&outc=\&spons=\&lead=\&id=\&state1=\&cntry1=\&state2=\&cntry2=\&state 3=\&cntry3=\&locn=\&rcv s=\&rcv e=\&lup s=\&lup e=>. Accessed in: February $2^{\text {nd }} 2017$.

${ }^{44}$ Clinical Trials.gov's website - A service of the U.S. National Institutes of Health. Available at: $<$ https://clinicaltrials.gov/ct2/results?term=AT7519\&Search=Search>. Accessed in: September $25^{\text {th }} 2016$.

45 Selleckchem.com website. Available $<$ http://www.selleckchem.com/msds/MSDS S1524.pdf $>$. Accessed in: September $25^{\text {th }} 2016$.

46 Tinib-Tools website. Available at: <http://www.tinib-tools.com/product A012.html>. Accessed in: September $25^{\text {th }} 2016$.

${ }^{47}$ Kania, R. S.; Bender, S. L.; Borchardt, A. J.; Braganza, J. F.; Cripps, S. J.; Hua, Y.; Johnson, M. D.; Johnson, T. O Jr.; Luu, H. T.; Palmer, C. L.; Reich, S. H.; Tempczyk-russell, A. M.; Teng, M.; Thomas, C.; Varney, M. D.; Wallace, M. B.; USA. PCT/US2001/0018263 2001, (WO 2001002369 A2). 
${ }^{48}$ Hu-Lowe, D. D.; Zou, H. Y.; Grazzini, M.L.; Hallin, M. E.; Wickman, G. R.; Amundson, K.; Chen, J. H.; Rewolinski, D. A.; Yamazaki, S.; Wu, E. Y.; McTigue, M. A.; Murray, B. W.; Kania, R. S.; O'Connor, P.; Shalinsky, D. R.; Bender, S. L. Nonclinical antiangiogenesis and antitumor activities of axitinib (AG-013736), an oral, potent, and selective inhibitor of vascular endothelial growth factor receptor tyrosine kinases 1, 2, 3. Clinical Cancer Research 2008, 14, 7272. [CrossRef] [PubMed]

${ }^{49}$ Bhargava, P.; Robinson, M. O. Development of second-generation VEGFR tyrosine kinase inhibitors: current status. Current Oncology Reports 2011, 13, 103. [CrossRef] [PubMed]

${ }^{50}$ Clinical Trials.gov's website - A service of the U.S. National Institutes of Health. Available at: $<$ https://clinicaltrials.gov/ct2/results?term=Axitinib\&Search=Search>. Accessed in: September $25^{\text {th }} 2016$.

${ }^{51}$ MedKoo Biosciences's website - Leading supplier of anticancer chemical reagents and kinase inhibitors. Available at: <http://www.medkoo.com/products/4585>. Accessed in: September $25^{\text {th }} 2016$.

52 Tinib-Tools website. Available at: <http://www.tinib-tools.com/product A013.html>. Accessed in: September $25^{\text {th }} 2016$.

${ }^{53}$ Wheeler, C.; Stephens, T.; Byth, K.; Greenb, T.; Wedge, S.; Blakey, D.; Hughes, A. Novel approaches in oncology at AstraZeneca. European Journal of Cancer Supplements 2003, 1, 3. [CrossRef]

${ }^{54}$ Byth, K. F.; Thomas, A.; Hughes, G.; Forder, C.; McGregor, A.; Geh, C.; Oakes, S.; Green, C.; Walker, M.; Newcombe, N.; Green, S.; Growcott, J.; Barker, A.; Wilkinson, R. W. AZD5438, a potent oral inhibitor of cyclin-dependent kinases 1, 2, and 9, leads to pharmacodynamic changes and potent antitumor effects in human tumor xenografts. Molecular Cancer Therapeutics 2009, 8, 1856. [CrossRef] [PubMed]

${ }^{55}$ Clinical Trials.gov's website - A service of the U.S. National Institutes of Health. Available at: $<$ https://clinicaltrials.gov/ct2/results?term=AZD5438\&Search=Search>. Accessed in: September $25^{\text {th }} 2016$.

${ }^{56}$ MedKoo Biosciences's website - Leading supplier of anticancer chemical reagents and kinase inhibitors. Available at: <http://www.medkoo.com/products/5272>. Accessed in: September $25^{\text {th }} 2016$.

57 Tinib-Tools website. Available at: <http://www.tinib-tools.com/product A014.html>. Accessed in: September $25^{\text {th }} 2016$.

${ }^{58}$ Chresta, C. M.; Davies, B. R.; Hickson, I.; Harding, T.; Cosulich, S.; Critchlow, S. E.; Vincent, J. P.; Ellston, R.; Jones, D.; Sini, P.; James, D.; Howard, Z.; Dudley, P.; Hughes, G.; Smith, L.; Maguire, S.; Hummersone, M.; Malagu, K.; Menear, K.; Jenkins, R.; Jacobsen, M.; Smith, G. C.; Guichard, S.; Pass, M. AZD8055 Is a Potent, Selective, and Orally Bioavailable ATP-Competitive Mammalian Target of Rapamycin Kinase Inhibitor with In vitro and In vivo Antitumor Activity. Cancer Research 2010, 70, 268. [CrossRef] [PubMed]

${ }^{59}$ Clinical Trials.gov's website - A service of the U.S. National Institutes of Health. Available at: $<$ https://clinicaltrials.gov/ct2/results?term=AZD8055\&Search=Search>. Accessed in: September $25^{\text {th }} 2016$.

${ }^{60}$ MedKoo Biosciences's website - Leading supplier of anticancer chemical reagents and kinase inhibitors. Available at: <http://www.medkoo.com/products/5279>. Accessed in: September $25^{\text {th }} 2016$.

${ }^{61}$ Tinib-Tools website. Available at: $<$ http://www.tinib-tools.com/product A015.html $>$.

${ }^{62}$ Wallace, E. M.; Lyssikatos, J. P.; Hurley, B. T.; Marlow, A. L.; USA, 2003. (WO 2003077914 A1).

${ }^{63}$ Array Biopharma's website. Available: $<$ www.arraybiopharma.com $>$. Accessed in: September $25^{\text {th }} 2016$. 
${ }^{64}$ Küsters-Vandevelde, H. V.; Willemsen, A. E.; Groenen, P. J.; Küsters, B.; Lammens, M.; Wesseling, P.; Djafarihamedani, M.; Rijntjes, J.; Delye, H.; Willemsen, M. A.; van Herpen, C. M.; Blokx, W. A. Experimental treatment of NRAS-mutated neurocutaneous melanocytosis with MEK162, a MEK-inhibitor. Acta Neuropathologica Communications 2014, 2, 41. [CrossRef] [PubMed]

${ }^{65}$ Clinical Trials.gov's website - A service of the U.S. National Institutes of Health. Available at: $<$ https://clinicaltrials.gov/ct2/results/refine?term=Binimetinib $>$. Accessed in: September $25^{\text {th }}$ 2016.

${ }^{66}$ MedKoo Biosciences's website - Leading supplier of anticancer chemical reagents and kinase inhibitors. Available at: <http://www.medkoo.com/products/5624>. Accessed in: September $25^{\text {th }} 2016$.

67 Tinib-Tools website. Available at: <http://www.tinib-tools.com/product B175.html>. Accessed in: September $25^{\text {th }} 2016$.

${ }^{68}$ Asaki, T.; Sugiyama, Y.; Segawa, J.; Japan, 2005. (WO 2005063709 A1).

${ }^{69}$ Kimura, S.; Naito, H.; Segawa, H.; Kuroda, J.; Yuasa, T.; Sato, K.; Yokota, A.; Kamitsuji, Y.; Kawata, E.; Ashihara, E.; Nakaya, Y.; Naruoka, H.; Wakayama, T.; Nasu, K.; Asaki, T.; Niwa, T.; Hirabayashi, K.; Maekawa, T. NS-187, a potent and selective dual Bcr-Abl/Lyn tyrosine kinase inhibitor, is a novel agent for imatinib-resistant leukemia. Blood 2005, 106, 3948. [CrossRef] [PubMed]

${ }^{70}$ Santos, F. P.; Kantarjian, H.; Cortes, J.; Quintas-Cardama, A. Bafetinib, a dual Bcr-Abl/Lyn tyrosine kinase inhibitor for the potential treatment of leukemia. Current Opinion Investigation Drugs 2010, 11, 1450. [PubMed]

${ }^{71}$ Clinical Trials.gov's website - A service of the U.S. National Institutes of Health. Available at: $<$ https://clinicaltrials.gov/ct2/results?term=Bafetinib\&Search=Search>. Accessed in: September $25^{\text {th }} 2016$.

${ }^{72}$ MedKoo Biosciences's website - Leading supplier of anticancer chemical reagents and kinase inhibitors. Available at: <http://www.medkoo.com/products/5285>. Accessed in: September $25^{\text {th }} 2016$.

73 Tinib-Tools website. Available at: <http://www.tinib-tools.com/product B096.html >. Accessed in: September $25^{\text {th }} 2016$.

${ }^{74}$ Garcia-Echeverria, C.; Stauffer, F.; Furet, P.; Switz, 2006. (WO 2006122806 A2).

${ }^{75}$ Maira, S. M.; Stauffer, F.; Brueggen, J.; Furet, P.; Schnell, C.; Fritsch, C.; Brachmann, S.; Chène, P.; De Pover, A.; Schoemaker, K.; Fabbro, D.; Gabriel, D.; Simonen, M.; Murphy, L.; Finan, P.; Sellers, W.; García-Echeverría, C. Identification and characterization of NVP-BEZ235, a new orally available dual phosphatidylinositol 3-kinase/mammalian target of rapamycin inhibitor with potent in vivo antitumor activity. Molecular Cancer Therapeutics 2008, 7, 1851. [CrossRef] [PubMed]

${ }^{76}$ Serra, V.; Markman, B.; Scaltriti, M.; Eichhorn, P. J.; Valero, V.; Guzman, M.; Botero, M. L.; Llonch, E.; Atzori, F.; Di Cosimo, S.; Maira, M.; Garcia-Echeverria, C.; Parra, J. L.; Arribas, J.; Baselga, J. NVP-BEZ235, a dual PI3K/mTOR inhibitor, prevents PI3K signaling and inhibits the growth of cancer cells with activating PI3K mutations. Cancer Research 2008; 68, 8022. [CrossRef] [PubMed]

${ }^{77}$ Eichhorn, P. J.; Gili, M.; Scaltriti, M.; Serra, V.; Guzman, M.; Nijkamp, W.; Beijersbergen, R. L.; Valero, V.; Seoane, J.; Bernards, R.; Baselga, J. Phosphatidylinositol 3-kinase hyperactivation results in lapatinib resistance that is reversed by the $\mathrm{mTOR} /$ phosphatidylinositol 3-kinase inhibitor NVP-BEZ235. Cancer Research 2008, 68, 9221. [CrossRef] [PubMed]

${ }^{78}$ Clinical Trials.gov's website - A service of the U.S. National Institutes of Health. Available at:

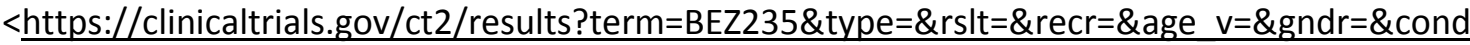


=Cancer\&intr $=\&$ titles $=\&$ outc $=\&$ spons $=\& l e a d=\& i d=\&$ state $1=\&$ cntry $1=\&$ state $2=\&$ cntry $2=\&$ state 3=\&cntry3=\&locn=\&rcv s=\&rcv e=\&lup s=\&lup e=>. Accessed in: February $2^{\text {nd }} 2017$.

${ }^{79}$ Clinical Trials.gov's website - A service of the U.S. National Institutes of Health. Available at: $<$ https://clinicaltrials.gov/ct2/results?term=BEZ235\&Search=Search $>$. Accessed in: September $25^{\text {th }} 2016$.

${ }^{80}$ MedKoo Biosciences's website - Leading supplier of anticancer chemical reagents and kinase inhibitors. Available at: <http://www.medkoo.com/products/5303 >. Accessed in: September $25^{\text {th }} 2016$.

81 Tinib-Tools website. Available at: <http://www.tinib-tools.com/product B017.html>. Accessed in: September $25^{\text {th }} 2016$.

${ }^{82}$ Havlicek, L.; Hanus, J.; Vesely, J.; Leclerc, S.; Meijer, L.; Shaw, G.; Strnad, M. Cytokininderived cyclin-dependent kinase inhibitors: synthesis and cdc2 inhibitory activity of olomoucine and related compounds. Journal of Medicinal Chemistry 1997, 40, 408. [CrossRef] [PubMed]

${ }^{83}$ Kovárová, H.; Hajdúch, M.; Korínková, G.; Halada, P.; Krupicková, S.; Gouldsworthy, A.; Zhelev, N.; Strnad, M. Proteomics approach in classifying the biochemical basis of the anticancer activity of the new olomoucine-derived synthetic cyclin-dependent kinase inhibitor, bohemine. Electrophoresis 2000, 21, 3757. [CrossRef] [PubMed]

${ }^{84}$ Kovarova, H.; Halada, P.; Man, P.; Dzubak, P.; Hajduch, M. Application of proteomics in the search for novel proteins associated with the anti-cancer effect of the synthetic cyclindependent kinases inhibitor, bohemine. Technology Cancer Research Treatment 2002, 1, 247. [CrossRef] [PubMed]

${ }^{85}$ Raynaud, F. I.; Whittaker, S. R.; Fischer, P. M.; McClue, S.; Walton, M. I.; Barrie, S. E.; Garrett, M. D.; Rogers, P.; Clarke, S. J.; Kelland, L. R.; Valenti, M.; Brunton, L.; Eccles, S.; Lane, D. P.; Workman, P. Clinical Cancer Research 2005, 11, 4875. [CrossRef] [PubMed]

${ }^{86}$ Clinical Trials.gov's website - A service of the U.S. National Institutes of Health. Available at: $<$ https://clinicaltrials.gov/ct2/results?term=BOHEMINE\&Search=Search>. Accessed in: September $29^{\text {th }} 2016$.

${ }^{87}$ MedKoo Biosciences's website - Leading supplier of anticancer chemical reagents and kinase inhibitors. Available at: <http://www.medkoo.com/products/6836>. Accessed in: September $25^{\text {th }} 2016$.

88 Tinib-Tools website. Available at: <http://www.tinib-tools.com/product B018.html>. Accessed in: September $25^{\text {th }} 2016$.

${ }^{89}$ Process for the preparation of 7-substituted 3-quinoline and 3-quinol-4-one carbonitriles via nucleophilic substitution Boschelli, Diane Harris; Wang, Yanong Daniel; Johnson, Steve Lawrence; Berger, Dan Maarten Assignee: Wyeth Holdings Corporation, USA Nov 13, 2003, US 20030212276 A1.

${ }^{90}$ Golas, J. M.; Arndt, K.; Etienne, C.; Lucas, J.; Nardin, D.; Gibbons, J.; Frost, P.; Ye, F.; Boschelli, D. H.; Boschelli, F. Cancer Research 2003, 63, 375. [PubMed]

${ }^{91}$ Keller, G.; Schafhausen, P.; Brummendorf, T. H. Bosutinib: a dual SRC/ABL kinase inhibitor for the treatment of chronic myeloid leukemia. Expert Review Hematology 2009, 2, 489. [CrossRef] [PubMed]

${ }^{92}$ Crystal Structure of Human Serine Threonine Kinase- 10 Bound to Bosutinib PDB: $3 Z Z 2$

${ }^{93}$ Clinical Trials.gov's website - A service of the U.S. National Institutes of Health. Available at: $<$ https://clinicaltrials.gov/ct2/results?term=Bosutinib\&Search=Search>. Accessed in: September $25^{\text {th }} 2016$.

${ }^{94}$ MedKoo Biosciences's website - Leading supplier of anticancer chemical reagents and kinase inhibitors. Available at: <http://www.medkoo.com/products/4606>. Accessed in: September $25^{\text {th }} 2016$. 
95 Tinib-Tools website. Available at: <http://www.tinib-tools.com/product B097.html>. Accessed in: September $25^{\text {th }} 2016$.

96 Bannen, L. C.; Chan, D. S.; Chen, J.; Dalrymple, L. E.; Forsyth, T. P.; Huynh, T. P.; Jammalamadaka, V.; Khoury, R. G.; Leahy, J. W.; Mac, M. B.; Mann, G.; Mann, L. W.; Nuss, J. M.; Parks, J. J.; Takeuchi, C. S.; Wang, Y.; Xu, W.; USA, 2005. (WO 2005030140 A2).

97 Durante, C.; Russo, D.; Verrienti, A.; Filetti, S. XL184 (cabozantinib) for medullary thyroid carcinoma. Expert Opinion Investigation Drugs 2011, 20, 407. [CrossRef] [PubMed]

${ }^{98}$ Yakes, F. M.; Chen, J.; Tan, J.; Yamaguchi, K.; Shi, Y.; Yu, P.; Qian, F.; Chu, F.; Bentzien, F.;

Cancilla, B.; Orf, J.; You, A.; Laird, A. D.; Engst, S.; Lee, L.; Lesch, J.; Chou Y. C.; Joly, A. H.

Cabozantinib (XL184), a novel MET and VEGFR2 inhibitor, simultaneously suppresses

metastasis, angiogenesis, and tumor growth. Molecular Cancer Therapeutics 2011, 10, 2298.

[CrossRef] [PubMed]

${ }^{99}$ Clinical Trials.gov's website - A service of the U.S. National Institutes of Health. Available at: $<$ https://clinicaltrials.gov/ct2/results?term=Cabozantinib\&type=\&rslt=\&recr=\&age $v=\& g n d r=$ \&cond=Cancer\&intr $=\&$ titles $=\&$ outc $=\&$ spons $=\&$ lead $=\& i d=\&$ state $1=\&$ cntry $1=\&$ state $2=\&$ cntry $2=$ \&state $=$ \&cntry3=\&locn=\&phase=1\&phase=2\&phase=3\&rcv s=\&rcv e=\&lup s=\&lup e=>.

Accessed in: February $2^{\text {nd }} 2017$.

${ }^{100}$ Clinical Trials.gov's website - A service of the U.S. National Institutes of Health. Available at: $<$ https://clinicaltrials.gov/ct2/results?term=Cabozantinib\&Search=Search>. Accessed in: September $25^{\text {th }} 2016$.

${ }^{101}$ MedKoo Biosciences's website - Leading supplier of anticancer chemical reagents and kinase inhibitors. Available at: <http://www.medkoo.com/products/4613 $>$. Accessed in: September $25^{\text {th }} 2016$.

102 Tinib-Tools website. Available at: < http://ww.tinib-tools.com/product C090.html $>$. Accessed in: September $25^{\text {th }} 2016$.

${ }^{103}$. Fowler, K. W.; Huang, D.; Kesicki, E. A.; Ooi, H. C.; Oliver, A. R.; Ruan, F.; Treiberg, J.; USA, 2005. (WO 2005113556 A1).

${ }^{104}$ Herman, S. E.; Gordon, A. L.; Wagner, A. J.; Heerema, N. A.; Zhao, W.; Flynn, J. M.; Jones, J.; Andritsos, L.; Puri, K. D.; Lannutti, B. J.; Giese, N. A.; Zhang, X.; Wei, L.; Byrd, J. C.; Johnson, A. J. Blood, Phosphatidylinositol 3-kinase- $\delta$ inhibitor CAL-101 shows promising preclinical activity in chronic lymphocytic leukemia by antagonizing intrinsic and extrinsic cellular survival signals. Blood 2010, 116, 2078. [CrossRef] [PubMed]

${ }^{105}$ Clinical Trials.gov's website - A service of the U.S. National Institutes of Health. Available at: $<$ https://clinicaltrials.gov/ct2/results?term=Idelalisib\&Search=Search>. Accessed in: September $25^{\text {th }} 2016$.

${ }^{106}$ MedKoo Biosciences's website - Leading supplier of anticancer chemical reagents and kinase inhibitors. Available at: <http://www.medkoo.com/products/4672>. Accessed in: September $25^{\text {th }} 2016$.

107 Tinib-Tools website. Available at: <http://www.tinib-tools.com/product C020.html $>$. Accessed in: September $25^{\text {th }} 2016$.

108 Krystof, V.; Cankar, P.; Frysová, I.; Slouka, J.; Kontopidis, G.; Dzubák, P.; Hajdúch, M.; Srovnal, J.; de Azevedo W. F. Jr.; Orság, M.; Paprskárová, M.; Rolcík, J.; Látr, A.; Fischer, P. M.; Strnad, M. 4-Arylazo-3,5-diamino-1H-pyrazole CDK Inhibitors: SAR Study, Crystal Structure in Complex with CDK2, Selectivity, and Cellular Effects. Journal of Medicinal Chemistry 2006, 49, 6500. [CrossRef] [PubMed]

${ }^{109}$ Kryštof, V.; Rárová, L.; Liebl, J.; Zahler, S.; Jorda, R.; Voller, J.; Cankař, P. The selective P-TEFb inhibitor CAN508 targets angiogenesis. European Journal of Medicinal Chemistry 2011, 46, 4289. [CrossRef] [PubMed] 
${ }^{110}$ Baumli, S.; Hole, A. J.; Noble, M. E.; Endicott, J. A. The CDK9 C-helix exhibits conformational plasticity that may explain the selectivity of CAN508. ACS Chemical Biology 2012. [CrossRef] [PubMed]

${ }^{111}$ PDB Structure of its co-crystal with CDK2: 2CLX

${ }^{112}$ PDB Structure of its co-crystal with CDK9/cyclin T: 3TN8

${ }^{113}$ Clinical Trials.gov's website - A service of the U.S. National Institutes of Health. Available at: $<$ https://clinicaltrials.gov/ct2/results?term=CAN508>. Accessed in: September $29^{\text {th }} 2016$.

${ }^{114}$ Santa Cruz Biotechnoly's website. Available at: <http://www.scbt.com/datasheet-203326cdk9-inhibitor-ii.html>. Accessed in: September $25^{\text {th }} 2016$.

115 Tinib-Tools website. Available at: <http://www.tinib-tools.com/product C021.html>. Accessed in: September $25^{\text {th }} 2016$.

${ }^{116}$ Smaill, J. B.; Rewcastle, G. W.; Loo, J. A.; Greis, K. D.; Chan, O. H.; Reyner, E. L.; Lipka, E.; Showalter, H. D.; Vincent, P. W.; Elliott, W. L.; Denny. W. A. Tyrosine Kinase Inhibitors. 17. Irreversible Inhibitors of the Epidermal Growth Factor Receptor: 4-(Phenylamino)quinazolineand 4-(Phenylamino)pyrido[3,2-d]pyrimidine-6-acrylamides Bearing Additional Solubilizing Functions. Journal of Medicinal Chemistry 2000, 43,1380. [CrossRef] [PubMed]

${ }^{117}$ Galmarini, C. M. IDrugs, 2004, 7, 58. [PubMed]

${ }^{118}$ Clinical Trials.gov's website - A service of the U.S. National Institutes of Health. Available at: $<$ https://clinicaltrials.gov/ct2/results?term=Canertinib\&type=\&rslt=\&recr=\&age $v=\& g n d r=\& c 0$ nd=Cancer\&intr=\&titles=\&outc=\&spons=\&lead=\&id=\&state1=\&cntry1=\&state2=\&cntry2=\&sta te3=\&cntry3=\&locn=\&rcv s=\&rcv e=\&lup s=\&lup e=>. Accessed in: February $2^{\text {nd }} 2017$.

${ }^{119}$ Clinical Trials.gov's website - A service of the U.S. National Institutes of Health. Available at: $<$ https://clinicaltrials.gov/ct2/results?term=Canertinib\&Search=Search>. Accessed in: September $25^{\text {th }} 2016$.

${ }^{120}$ MedKoo Biosciences's website - Leading supplier of anticancer chemical reagents and kinase inhibitors. Available at: <http://www.medkoo.com/products/5334>. Accessed in: September $25^{\text {th }} 2016$.

121 Tinib-Tools website. Available at: <http://www.tinib-tools.com/product C098.html $>$. Accessed in: September $25^{\text {th }} 2016$.

${ }^{122}$ Wedge, S. R.; Kendrew, J.; Hennequin, L. F.; Valentine, P. J.; Barry, S. T.; Brave, S. R.; Smith, N. R.; James N. H.; Dukes, M.; Curwen, J. O.; Chester, R.; Jackson, J. A.; Boffey, S. J.; Kilburn, L. L.; Barnett, S.; Richmond, G. H.; Wadsworth, P. F.; Walker, M.; Bigley, A. L.; Taylor, S. T.; Cooper, L.; Beck, S.; Jürgensmeier, J. M.; Ogilvie, D. J. Cancer Research 2005, 65, 4389. [CrossRef] [PubMed]

${ }^{123}$ Clinical Trials.gov's website - A service of the U.S. National Institutes of Health. Available at: $<$ https://clinicaltrials.gov/ct2/results?term=Cediranib\&Search=Search>. Accessed in: September $25^{\text {th }} 2016$.

${ }^{124}$ MedKoo Biosciences's website - Leading supplier of anticancer chemical reagents and kinase inhibitors. Available at: <http://www.medkoo.com/products/5352>. Accessed in: September $25^{\text {th }} 2016$.

125 Tinib-Tools website. Available at: <http://www.tinib-tools.com/product C099.html $>$. Accessed in: September $25^{\text {th }} 2016$.

${ }^{126}$ Bennett, C. N.; Ross, S. E.; Longo, K. A.; Bajnok, L.; Hemati, N.; Johnson, K. W.; Harrison, S. D.; MacDougald, O. A. Regulation of Wnt Signaling during Adipogenesis. The Journal of Biological Chemistry 2002, 277, 30998. [CrossRef] [PubMed]

${ }^{127}$ Ring, D. B.; Johnson, K. W.; Henriksen, E. J.; Nuss, J. M.; Goff, D.; Kinnick, T. R.; Ma, S. T.; Reeder, J. W.; Samuels, I.; Slabiak, T.; Wagman, A. S.; Hammond, M. E.; Harrison, S. D. Selective glycogen synthase kinase 3 inhibitors potentiate insulin activation of glucose transport and utilization in vitro and in vivo. Diabetes 2003, 52, 588. [CrossRef] [PubMed] 
128 Marchand, B.; Arsenault, D.; Raymond-Fleury, A.; Boisvert, F.; Boucher, M. Glycogen Synthase Kinase-3 (GSK3) Inhibition Induces Prosurvival Autophagic Signals in Human Pancreatic Cancer Cells. The Journal of Biological Chemistry 2015, 290, 5592. [CrossRef] [PubMed]

${ }^{129}$ Clinical Trials.gov's website - A service of the U.S. National Institutes of Health. Available at: $<$ https://clinicaltrials.gov/ct2/results?term=CHIR-99021\&Search=Search>. Accessed in: September $29^{\text {th }} 2016$.

${ }^{130}$ MedKoo Biosciences's website - Leading supplier of anticancer chemical reagents and kinase inhibitors. Available at: <http://www.medkoo.com/products/5372>. Accessed in: September $25^{\text {th }} 2016$.

131 Tinib-Tools website. Available at: <http://www.tinib-tools.com/product C038.html $>$. Accessed in: September $25^{\text {th }} 2016$.

132 Renhowe, P.; Pecchi, S.; Machajewski, T.; Shafer, C.; Taylor, C.; McCrea, B.; McBride, C.; Jazan, E.; Wernette-Hammond, M.; Harris, A.; USA, 2002. (WO 2002022598 A1).

${ }^{133}$ Trudel, S.; Li, Z. H.; Wei, E.; Wiesmann, M.; Chang, H.; Chen, C.; Reece, D.; Heise, C.; Stewart, A. K. CHIR-258, a novel, multitargeted tyrosine kinase inhibitor for the potential treatment of $\mathrm{t}(4 ; 14)$ multiple myeloma. Blood 2005, 105, 2941. [CrossRef] [PubMed]

${ }^{134}$ Renhowe, P. A.; Pecchi, S.; Shafer, C. M.; Machajewski, T. D.; Jazan, E. M.; Taylor, C.; Antonios-McCrea, W.; McBride, C. M.; Frazier, K.; Wiesmann, M.; Lapointe, G. R.; Feucht, P. H.; Warne, R. L.; Heise, C. C.; Menezes, D.; Aardalen, K.; Ye, H.; He, M.; Le, V.; Vora, J.; Jansen, J. M.; Wernette-Hammond, M. E.; Harris, A. L. Design, structure-activity relationships and in vivo characterization of 4-amino-3-benzimidazol-2-ylhydroquinolin-2-ones: a novel class of receptor tyrosine kinase inhibitors. Journal Medicinal Chemistry 2009, 52, 278. [CrossRef] [PubMed]

${ }^{135}$ Clinical Trials.gov's website - A service of the U.S. National Institutes of Health. Available at: $<$ https://clinicaltrials.gov/ct2/results?term=CHIR-258\&Search=Search>. Accessed in: September $25^{\text {th }} 2016$.

${ }^{136}$ MedKoo Biosciences's website - Leading supplier of anticancer chemical reagents and kinase inhibitors. Available at: <http://www.medkoo.com/products/4942>. Accessed in: September $25^{\text {th }} 2016$.

137 Tinib-Tools website. Available at: <http://www.tinib-tools.com/product C039.html $>$. Accessed in: September $25^{\text {th }} 2016$.

${ }^{138}$ Cui, J. J.; Funk, L. A.; Jia, L.; Kung, P.; Meng, J. J.; Nambu, M. D.; Pairish, M. A.; Shen, H.; TranDube, M. B.; USA, 2006, (WO 2006021881 A2).

${ }^{139}$ Rodig, S. J.; Shapiro, G. I. Crizotinib, a small-molecule dual inhibitor of the c-Met and ALK receptor tyrosine kinases. Current Opinion Investigation Drugs 2010, 11, 1477. [PubMed]

${ }^{140}$ Cui, J. J.; Tran-Dubé, M.; Shen, H.; Nambu, M.; Kung, P. P.; Pairish, M.; Jia, L.; Meng, J.; Funk, L.; Botrous, I.; McTigue, M.; Grodsky, N.; Ryan, K.; Padrique, E.; Alton, G.; Timofeevski, S.; Yamazaki, S.; Li, Q.; Zou, H.; Christensen, J.; Mroczkowski, B.; Bender, S.; Kania, R. S. Edwards, M. P. Structure based drug design of crizotinib (PF-02341066), a potent and selective dual inhibitor of mesenchymal-epithelial transition factor (c-MET) kinase and anaplastic lymphoma kinase (ALK). Journal of Medicinal Chemistry 2011, 54, 6342. [CrossRef] [PubMed]

${ }^{141}$ Crystal structure of the PF-02341066/c-MET complex PDB: $2 \mathrm{wgj}$

${ }^{142}$ Crystal structure of the PF-02341066/ALK complex PDB: 2xp2

${ }^{143}$ Clinical Trials.gov's website - A service of the U.S. National Institutes of Health. Available at: $<$ https://clinicaltrials.gov/ct2/results?term=Crizotinib\&Search=Search>. Accessed in: September $25^{\text {th }} 2016$. 
${ }^{144}$ MedKoo Biosciences's website - Leading supplier of anticancer chemical reagents and kinase inhibitors. Available at: <http://www.medkoo.com/products/4537>. Accessed in: September $25^{\text {th }} 2016$.

145 Tinib-Tools website. Available at: <http://www.tinib-tools.com/product C023.html >. Accessed in: September $25^{\text {th }} 2016$.

${ }^{146}$ Brooks, E. E.; Gray, N. S.; Joly, A.; Kerwar, S. S.; Lum, R.; Mackman, R. L.; Norman, T. C.; Rosete, J.; Rowe, M.; Schow, S. R.; Schultz, P. G.; Wang, X.; Wick, M. M.; Shiffman, D. Journal of Biological Chemistry 1997, 272, 29207. [CrossRef] [PubMed]

${ }^{147}$ Faber, A. C.; Chiles, T. C. Inhibition of cyclin-dependent kinase-2 induces apoptosis in human diffuse large B-cell lymphomas. Cell cycle-dependent phosphorylation of human CDC5 regulates RNA processing. Cell Cycle 2007, 6, 2982. [CrossRef] [PubMed]

${ }^{148}$ Gräub, R.; Lancero, H.; Pedersen, A.; Chu, M.; Padmanabhan, K.; Xu, X. Q.; Spitz, P.; Chalkley, R.; Burlingame, A. L.; Stokoe, D.; Bernstein, H. S. Cell Cycle 2008, 7, 1795. [CrossRef] [PubMed]

${ }^{149}$ Clinical Trials.gov's website - A service of the U.S. National Institutes of Health. Available at: $<$ https://clinicaltrials.gov/ct2/results?term=CVT313\&Search=Search>. Accessed in: September $29^{\text {th }} 2016$.

${ }^{150}$ MedKoo Biosciences's website - Leading supplier of anticancer chemical reagents and kinase inhibitors. Available at: <http://www.medkoo.com/products/9227>. Accessed in: September $25^{\text {th }} 2016$.

${ }^{151}$ Tinib-Tools website. Available at: $<$ http://www.tinib-tools.com/product C024.html $>$.

152 Wang, S.; Midgley, C. A.; Scaërou, F.; Grabarek, J. B.; Griffiths, G.; Jackson, W.; Kontopidis, G.; McClue, S. J.; McInnes, C.; Meades, C.; Mezna, M.; Plater, A.; Stuart, I.; Thomas, M. P., Wood, G.; Clarke, R. G.; Blake, D. G.; Zheleva, D. I.; Lane, D. P.; Jackson, R. C.; Glover, D. M.; Fischer, P. M. Discovery of N-phenyl-4-(thiazol-5-yl)pyrimidin-2-amine aurora kinase inhibitors. Journal of Medicinal Chemistry 2010, 53, 4367. [CrossRef] [PubMed]

${ }^{153}$ Clinical Trials.gov's website - A service of the U.S. National Institutes of Health. Available at: $<$ https://clinicaltrials.gov/ct2/results?term=CYC116\&Search=Search>. Accessed in: September $25^{\text {th }} 2016$.

${ }^{154}$ MedKoo Biosciences's website - Leading supplier of anticancer chemical reagents and kinase inhibitors. Available at: <http://www.medkoo.com/products/5397>. Accessed in: September $25^{\text {th }} 2016$.

155 Tinib-Tools website. Available at: <http://www.tinib-tools.com/product C025.html>. Accessed in: September $25^{\text {th }} 2016$.

${ }^{156}$ Burns, C J.; Donohue, A. C.; Feutrill, J. T.; Ngygen, T. L. T.; Wilks, A. F.; Zeng, J.; Australia. PCT/WO2008/00339 2008. (WO 2008109943 A1).

${ }^{157}$ Pardanani, A.; Lasho, T.; Smith, G.; Burns, C. J.; Fantino, E.; Tefferi, A. CYT387, a selective JAK1/JAK2 inhibitor: in vitro assessment of kinase selectivity and preclinical studies using cell lines and primary cells from polycythemia vera patients. Leukemia, 2009, 23, 1441. [CrossRef] [PubMed]

${ }^{158}$ Burns, C. J.; Bourke, D. G.; Andrau, L.; Bu, X.; Charman, S. A.; Donohue, A. C.; Fantino, E.; Farrugia, M.; Feutrill, J. T.; Joffe, M.; Kling, M. R.; Kurek, M.; Nero, T. L., Nguyen, T.; Palmer, J. T.; Phillips, I.; Shackleford, D. M.; Sikanyika, H.; Styles, M.; Su, S.; Treutlein, H.; Zeng, J.; Wilks, A. F. Phenylaminopyrimidines as inhibitors of Janus kinases (JAKs). Bioorganic \& Medicinal Chemistry Letters 2009, 19, 5887. [CrossRef] [PubMed]

${ }^{159}$ Tyner, J. W.; Bumm, T. G.; Deininger, J.; Wood, L.; Aichberger, K. J.; Loriaux, M. M.; Druker, B. J.; Burns, C. J.; Fantino, E.; Deininger, M. W. CYT387, a novel JAK2 inhibitor, induces hematologic responses and normalizes inflammatory cytokines in murine myeloproliferative neoplasms. Blood 2010, 115, 5232. [CrossRef] [PubMed] 
${ }^{160}$ Clinical Trials.gov's website - A service of the U.S. National Institutes of Health. Available at: $<$ https://clinicaltrials.gov/ct2/results?term=CYT387\&Search=Search $>$. Accessed in: September $25^{\text {th }} 2016$.

${ }^{161}$ MedKoo Biosciences's website - Leading supplier of anticancer chemical reagents and kinase inhibitors. Available at: <http://www.medkoo.com/products/5027>. Accessed in: September $25^{\text {th }} 2016$.

162 Tinib-Tools website. Available at: <http://www.tinib-tools.com/product C101.html>. Accessed in: September $25^{\text {th }} 2016$.

${ }^{163}$ Adams, J. L.; Dickerson, S. H.; Johnson, N. W.; Kuntz, K.; Petrov, K.; Ralph, J. M.; Rheault, T. R.; Schaaf, G.; Stellwagen, J.; Tian, X.; Uehling, D. E.; Waterson, A. G.; Wilson, B.; USA, 2009, (WO 2009137391 A2).

${ }^{164}$ Greger, J. G.; Eastman, S. D.; Zhang, V.; Bleam, M. R.; Hughes, A. M.; Smitheman, K. N.; Dickerson, S. H.; Laquerre, S. G.; Liu, L.; Gilmer, T. M. Combinations of BRAF, MEK, and $\mathrm{PI} 3 \mathrm{~K} / \mathrm{mTOR}$ inhibitors overcome acquired resistance to the BRAF inhibitor GSK2118436 dabrafenib, mediated by NRAS or MEK mutations. Molecular Cancer Therapeutics 2012, 11, 909. [CrossRef] [PubMed]

${ }^{165}$ King, A. J.; Arnone, M. R.; Bleam, M. R.; Moss, K. G.; Yang, J.; Fedorowicz, K. E.; Smitheman, K. N.;, Erhardt, J. A.; Hughes-Earle, A.; Kane-Carson, L. S.; Sinnamon, R. H.; Qi, H.; Rheault, T. R.; Uehling, D. E.; Laquerre, S. G.; Dabrafenib; preclinical characterization, increased efficacy when combined with trametinib, while BRAF/MEK tool combination reduced skin lesions. PLoS One 2013, 8, e67583 [CrossRef] [PubMed]

166 Banzi, M.; De Blasio, S.; Lallas, A.; Longo, C.; Moscarella, E.; Alfano, R.; Argenziano, G. Dabrafenib: a new opportunity for the treatment of BRAF V600-positive melanoma. OncoTargets and Therapy 2016, 9, 2725. [CrossRef] [PubMed]

${ }^{167}$ Clinical Trials.gov's website - A service of the U.S. National Institutes of Health. Available at: $<$ https://clinicaltrials.gov/ct2/results?term=Dabrafenib\&Search=Search>. Accessed in: September $25^{\text {th }} 2016$.

168 MedKoo Biosciences's website - Leading supplier of anticancer chemical reagents and kinase inhibitors. Available at: <http://www.medkoo.com/products/4470>. Accessed in: September $25^{\text {th }} 2016$.

169 Tinib-Tools website. Available at: <http://www.tinib-tools.com/product D173.html>. Accessed in: September $25^{\text {th }} 2016$.

${ }^{170}$ Fancelli, D.; Moll, J.; Varasi, M.; Bravo, R.; Artico, R.; Berta, D.; Bindi, S.; Cameron, A.; Candiani, I.; Cappella, P.; Carpinelli, P.; Croci, W.; Forte, B.; Giorgini, M. L.; Klapwijk, J.; Marsiglio, A.; Pesenti, E.; Rocchetti, M.; Roletto, F.; Severino, D.; Soncini, C.; Storici, P.; Tonani, R.; Zugnoni, P.; Vianello P. 1,4,5,6-Tetrahydropyrrolo[3,4-c]pyrazoles: Identification of a Potent Aurora Kinase Inhibitor with a Favorable Antitumor Kinase Inhibition Profile Aurora kinase inhibitor with a favorable antitumor kinase inhibition profile. Journal of Medicinal Chemistry 2006, 49, 7247. [CrossRef] [PubMed]

${ }^{171}$ Modugno, M.; Casale, E.; Soncini, C.; Rosettani, P.; Colombo, R.; Lupi, R.; Rusconi, L.; Fancelli, D.; Carpinelli, P.; Cameron, A. D.; Isacchi, A.; Moll, J. Crystal structure of the T315I Abl mutant in complex with the aurora kinases inhibitor PHA-739358. Cancer Research 2007, 67, 7987. [CrossRef] [PubMed]

172 Carpinelli, P.; Ceruti, R.; Giorgini, M. L.; Cappella, P.; Gianellini, L.; Croci, V.; Degrassi, A.; Texido, G.; Rocchetti, M.; Vianello, P.; Rusconi, L.; Storici, P.; Zugnoni, P.; Arrigoni, C.; Soncini, C.; Alli, C.; Patton, V.; Marsiglio, A.; Ballinari, D.; Pesenti, E.; Fancelli, D.; Moll, PHA-739358, a potent inhibitor of Aurora kinases with a selective target inhibition profile relevant to cancer. Molecular Cancer Therapeutics 2007, 6, 3158. [CrossRef] [PubMed] 
${ }^{173}$ Clinical Trials.gov's website - A service of the U.S. National Institutes of Health. Available at: $<$ https://clinicaltrials.gov/ct2/results?term=Danusertib+\&type=\&rslt=\&recr=\&age $v=\& g n d r=\&$ cond=Cancer\&intr $=\&$ titles $=$ \&outc $=\&$ spons $=\&$ lead $=\&$ id $=\&$ state $1=\&$ cntry $1=\&$ state $2=\&$ cntry $2=\& \mathrm{~s}$ tate3=\&cntry3=\&locn=\&rcv s=\&rcv e=\&lup s=\&lup e=>. Accessed in: February $2^{\text {nd }} 2017$.

${ }^{174}$ Clinical Trials.gov's website - A service of the U.S. National Institutes of Health. Available at: $<$ https://clinicaltrials.gov/ct2/results?term=Danusertib\&Search=Search>. Accessed in: September $25^{\text {th }} 2016$.

${ }^{175}$ MedKoo Biosciences's website - Leading supplier of anticancer chemical reagents and kinase inhibitors. Available at: <http://www.medkoo.com/products/5403>. Accessed in: September $25^{\text {th }} 2016$.

176 Tinib-Tools website. Available at: <http://www.tinib-tools.com/product D026.html $>$. Accessed in: September $25^{\text {th }} 2016$.

${ }^{177}$ Das, J.; Padmanabha, R.; Chen, P.; Norris, D. J.; Doweyko, Arthur M. P.; Barrish, J. C.; Wityak, J. PCT/US2000/009753 2000. (WO 2000062778 A1).

${ }^{178}$ Clinical Trials.gov's website - A service of the U.S. National Institutes of Health. Available at: $<$ https://clinicaltrials.gov/ct2/results?term=Dasatinib\&type=\&rslt=\&recr=\&age $v=\& g n d r=\& c 0$ nd=Cancer\&intr $=\&$ titles $=$ \&outc $=\&$ spons $=\&$ lead $=\& i d=\&$ state $1=\&$ cntry $1=\&$ state $2=\&$ cntry $2=\&$ sta te3=\&cntry3=\&locn=\&phase=3\&rcv $s=\& r c v$ e=\&lup $s=\& l u p ~ e=>$. Accessed in: February $2^{\text {nd }}$ 2017.

${ }^{179}$ Lombardo, L. J.; Lee, F. Y.; Chen, P.; Norris, D.; Barrish, J. C.; Behnia, K.; Castaneda, S.; Cornelius, L. A.; Das, J.; Doweyko, A. M.; Fairchild, C.; Hunt, J. T.; Inigo, I.; Johnston, K.; Kamath, A.; Kan, D.; Klei, H.; Marathe, P.; Pang, S.; Peterson, R.; Pitt, S.; Schieven, G. L.; Schmidt, R. J.; Tokarski, J.; Wen, M. L.; Wityak, J.; Borzilleri, R M. Discovery of N-(2-chloro-6-methyl- phenyl)2-(6-(4-(2-hydroxyethyl)- piperazin-1-yl)-2-methylpyrimidin-4- ylamino)thiazole-5-carboxamide (BMS-354825), a dual Src/Abl kinase inhibitor with potent antitumor activity in preclinical assays. Journal of Medicinal Chemistry 2004, 47, 6658. [CrossRef] [PubMed]

${ }^{180}$ Breccia, M.; Alimena, G. Activity and safety of dasatinib as second-line treatment or in newly diagnosed chronic phase chronic myeloid leukemia patients. BioDrugs 2011, 25, 147. [CrossRef] [PubMed]

${ }^{181}$ Crystal Structure of Dasatinib Bound to ABL Kinase PDB: 2GQG

${ }^{182}$ Crystal Structure of Dasatinib Bound to C-KIT PDB: 3G5D

${ }^{183}$ Clinical Trials.gov's website - A service of the U.S. National Institutes of Health. Available at: $<$ https://clinicaltrials.gov/ct2/results?term=Danusertib\&Search=Search>. Accessed in: September $25^{\text {th }} 2016$.

${ }^{184}$ MedKoo Biosciences's website - Leading supplier of anticancer chemical reagents and kinase inhibitors. Available at: <http://www.medkoo.com/products/4548>. Accessed in: September $25^{\text {th }} 2016$.

185 Tinib-Tools website. Available at: <http://www.tinib-tools.com/product D027.html >. Accessed in: September $25^{\text {th }} 2016$.

${ }^{186}$ Paruch, K.; Dwyer, M. P.; Alvarez, C.; Brown, C.; Chan, T. Y.; Doll, R.; Keertikar,K.; Knutson, C.; McKittrick, B.; Rivera, R.; Rossman, R.; Tucker, G.; Fischmann, T.; Hruza, A.; Madison, V.; Nomeir, A. A.; Wang, Y.; Kirschmeier, P.; Lees, E. M.; Parry, D.; Sgambellone, N.; Seghezzi, W.; Schultz, L.; Shanahan, F.; Wiswell, D.; Xu, X.; Zhou, Q.; James, R. A.; Paradkar, V. M.; Park, H.; Rokosz, L. R.; Stauffer, T. M Guzi, T. J. Discovery of Dinaciclib (SCH 727965): A Potent and Selective Inhibitor of Cyclin-Dependent Kinases American Chemistry Society Medicinal Chemistry Letters 2010, 1, 204. [CrossRef]

187 Parry, D.; Guzi, T.; Shanahan, F.; Davis, N.; Prabhavalkar, D.; Wiswell, D.; Seghezzi, W.; Paruch, K.; Dwyer, M. P.; Doll, R.; Nomeir, A.; Windsor, W.; Fischmann, T.; Wang, Y.; Oft, M.; 
Chen, T.; Kirschmeier, P.; Lees, E. M. Dinaciclib (SCH 727965), a novel and potent cyclindependent kinase inhibitor. Molecular Cancer Therapeutics 2010, 9, 2344. [CrossRef] [PubMed] ${ }^{188}$ Guzi, T. J.; Paruch, K.; Dwyer, M. P.; Labroli, M.; Shanahan, F.; Davis, N.; Taricani, L.; Wiswell, D.; Seghezzi, W.; Penaflor, E.; Bhagwat, B.; Wang, W.; Gu, D.; Hsieh, Y.; Lee, S.; Liu, M.; Parry, D. Targeting the replication checkpoint using $\mathrm{SCH}$ 900776, a potent and functionally selective CHK1 inhibitor identified via high content screening. Molecular Cancer Therapeutics 2011, 10, 591. [CrossRef] [PubMed]

${ }^{189}$ Clinical Trials.gov's website - A service of the U.S. National Institutes of Health. Available at: $<$ https://clinicaltrials.gov/ct2/results?term=Dinaciclib\&type $=\& \mathrm{rs} / \mathrm{t}=\& \mathrm{recr}=\& a g e \mathrm{v}=\& g n d r=\& c 0$ nd=Cancer\&intr=\&titles=\&outc=\&spons=\&lead=\&id=\&state1=\&cntry1=\&state $2=\&$ cntry2=\&sta te3=\&cntry3=\&locn=\&phase=0\&phase=1\&phase=2\&phase=3\&rcv s=\&rcv e=\&lup s=\&lup e= $>$. Accessed in: February $2^{\text {nd }} 2017$.

${ }^{190}$ Clinical Trials.gov's website - A service of the U.S. National Institutes of Health. Available at: $<$ https://clinicaltrials.gov/ct2/results?term=Dinaciclib\&Search=Search>. Accessed in: September $25^{\text {th }} 2016$.

${ }^{191}$ MedKoo Biosciences's website - Leading supplier of anticancer chemical reagents and kinase inhibitors. Available at: <http://www.medkoo.com/products/4634>. Accessed in: September $25^{\text {th }} 2016$.

192 Tinib-Tools website. Available at: <http://www.tinib-tools.com/product D071.html>. Accessed in: September $25^{\text {th }} 2016$.

${ }^{193}$ Teicher, B. A.; Alvarez, E.; Menon, K.; Esterman, M. A.; Considine, E.; Shih, C.; Faul M. M. Antiangiogenic effects of a protein kinase $\beta$-selective small molecule. Cancer Chemotherapy and Pharmacology 2002, 49, 69. [CrossRef]

194 Tinib-Tools website. Available at: <http://www.tinib-tools.com/products E.html\#E136>. Accessed in: September $5^{\text {th }} 2016$.

195 Chen, Y. B.; LaCasce, A. S. Enzastaurin. Expert Opinion on Investigational Drugs 2008, 17, 939. [CrossRef] [PubMed]

${ }^{196}$ Clinical Trials.gov's website - A service of the U.S. National Institutes of Health. Available at: $<$ https://clinicaltrials.gov/ct2/results?term=Enzastaurin\&type=\&rslt=\&recr=\&age $v=\& g n d r=\& c$ ond=Cancer\&intr $=\&$ titles $=\&$ outc $=\&$ spons $=\&$ lead $=\& \mathrm{id}=\&$ state $1=\& \mathrm{cntry} 1=\&$ state $2=\& \mathrm{cntry} 2=\& \mathrm{st}$ ate $=\&$ cntry3=\&locn=\&phase $=0$ \&phase $=1$ \&phase $=2$ \&phase=3\&rcv $s=\&$ rcv e=\&lup $s=\& l u p ~ e$ $\Rightarrow$. Accessed in: February $2^{\text {nd }} 2017$.

${ }^{197}$ Clinical Trials.gov's website - A service of the U.S. National Institutes of Health. Available at: $<$ https://clinicaltrials.gov/ct2/results?term=ENZASTAURIN\&recr=\&type=\&rslt=\&age v=\&gndr= \&cond=\&intr=\&titles=\&outc=\&spons=\&lead=\&id=\&state1=\&cntry1=\&state2=\&cntry2=\&state3 $=$ \&cntry3=\&locn=\&phase=2\&rcv s=\&rcv e=\&lup s=\&lup e $>$. Accessed in: September $5^{\text {th }}$ 2016.

198 ChemBlink's website - Material Safety Data Sheet. Available at: $<$ http://www.chemblink.com/MSDS/MSDSFiles/170364-57-5 Ark\%20Pharm.pdf $>$. Accessed in: September $5^{\text {th }} 2016$.

${ }^{199}$ Moyer, J. D.; Barbacci, E. G.; Iwata, K. K.; Arnold, L.; Boman, B.; Cunningham, A.; DiOrio, C.; Doty, J.; Morin, M. J.; Moyer, M. P.; Neveu, M.; Pollack, V. A.; Pustilnik, L. R.; Reynolds, M. M.; Sloan, D.; Theleman, A.; Miller, P. Induction of apoptosis and cell cycle arrest by CP-358,774, an inhibitor of epidermal growth factor receptor tyrosine kinase. Cancer Research 1997, 57, 4838. [PubMed]

${ }^{200}$ Tinib-Tools website. Available at: <http://www.tinib-tools.com/products E.html\#E029>. Accessed in: September $5^{\text {th }} 2016$. 
201 Pollack, V. A.; Savage, D. M.; Baker, D. A.; Tsaparikos, K. E.; Sloan, D. E.; Moyer, J. D.; Barbacci, E. G.; Pustilnik, L. R.; Smolarek, T. A.; Davis, J. A.; Vaidya, M. P.; Arnold, L. D.; Doty, J. L.; Iwata, K. K.; Morin, M. J. Inhibition of epidermal growth factor receptor-associated tyrosine phosphorylation in human carcinomas with CP-358,774: dynamics of receptor inhibition in situ and antitumor effects in athymic mice. The Journal of Pharmacology and Experimental Therapeutics 1999, 291, 739. [PubMed]

202 Varkondi, E.; Pinter, F.; Robert, K.; Schwab, R.; Breza, N.; Orfi, L.; Keri, G.; Petak, I. Biochemical assay-based selectivity profiling of clinically relevant kinase inhibitors on mutant forms of EGF receptor. Journal of Receptor and Signal Transduction Research 2008, 28, 295. [CrossRef] [PubMed]

${ }^{203}$ Clinical Trials.gov's website - A service of the U.S. National Institutes of Health. Available at: $<$ https://clinicaltrials.gov/ct2/results?term=erlotinib\&recr=\&type=\&rslt=\&age v=\&gndr=\&con $\mathrm{d}=$ \&intr=\&titles=\&outc=\&spons=\&lead=\&id=\&state1=\&cntry1=\&state2=\&cntry2=\&state3=\&cn try3=\&locn=\&phase=3\&rcv s=\&rcv e=\&lup s=\&lup e $>$. Accessed in: September $5^{\text {th }} 2016$.

204 ChemBlink's website - Material Safety Data Sheet. Available at: $<$ http://www.chemblink.com/MSDS/MSDSFiles/183319-69-9 Ark\%20Pharm.pdf $>$. Accessed in: September $5^{\text {th }} 2016$.

${ }^{205}$ Gumireddy, K.; Reddy, M. V. R.; Cosenza, S. C.; Nathan, R. B.; Baker, S. J.; Papathi, N.; Jiang, J.; Holland, J.; Reddy, E. P. ON01910, a non-ATP-competitive small molecule inhibitor of Plk1, is a potent anticancer agent. Cancer Cell 2005, 7, 275. [CrossRef]

${ }^{206}$ Reddy, M. V.; Venkatapuram, P.; Mallireddigari, M. R.; Pallela, V. R.; Cosenza, S. C.; Robell, K. A.; Akula, B.; Hoffman, B. S.; Reddy, E. P. Discovery of a clinical stage multi-kinase inhibitor sodium (E)-2-\{2-methoxy-5-[(2',4',6' trimethoxystyrylsulfonyl)methyl]phenylamino\} acetate (ON 01910.Na): synthesis, structure-activity relationship, and biological activity. Journal of Medicinal Chemistry 2011, 54, 6254. [CrossRef] [PubMed]

207 Tinib-Tools website. Available at: <http://www.tinib-tools.com/products E.html\#E030>. Accessed in: September $6^{\text {th }} 2016$.

${ }^{208}$ Clinical Trials.gov's website - A service of the U.S. National Institutes of Health. Available at: $<$ https://clinicaltrials.gov/ct2/results?term=Rigosertib\&type=\&rslt=\&recr=\&age $v=\& g n d r=\& c 0$ nd=Cancer\&intr $=\&$ titles $=\&$ outc $=\&$ spons $=\&$ spons ex $=Y \&$ lead $=\& \mathrm{id}=\&$ state $1=\&$ cntry $1=\&$ state $2=$ \&cntry $2=\&$ state $3=\&$ cntry $3=\&$ locn $=$ \&phase $=0$ \&phase $=1 \&$ phase $=2 \&$ phase $=3 \&$ rcv $s=\& r c v$ e $=\& 1$ up $\mathrm{s}=$ \&lup $\mathrm{e}=>$. Accessed in: February $2^{\text {nd }} 2017$.

${ }^{209}$ Clinical Trials.gov's website - A service of the U.S. National Institutes of Health. Available at:https://clinicaltrials.gov/ct2/results?term=estybon\&recr=\&type=\&rslt=\&age $\mathrm{v}=$ \&gndr=\&co nd=\&intr=\&titles=\&outc=\&spons=\&lead=\&id=\&state1=\&cntry1=\&state2=\&cntry2=\&state $3=\& \mathrm{c}$ ntry3=\&locn=\&phase=1\&rcv s=\&rcv e=\&lup s=\&lup e= Accessed in: September $6^{\text {th }} 2016$.

210 Apexbio website - Material Safety Data Sheet. Available at: $<$ http://www.apexbt.com/downloader/document/A1404/MSDS.pdf $>$. Accessed in: September $6^{\text {th }} 2016$.

${ }^{211}$ Grgic, T.; Mis, L.; Hammond, J. M. Everolimus: a new mammalian target of rapamycin inhibitor for the treatment of advanced renal cell carcinoma. The Annals of Pharmacotherapy 2011, 45, 78. [CrossRef] [PubMed]

212 Tinib-Tools website. Available at: <http://www.tinib-tools.com/products E.html\#E030>. Accessed in: September $7^{\text {th }} 2016$.

${ }^{213}$ Clinical Trials.gov's website - A service of the U.S. National Institutes of Health. Available at: $<$ https://clinicaltrials.gov/ct2/results?term=Everolimus\&type=\&rslt=\&recr=\&age $v=\& g n d r=\& c$ ond=Cancer\&intr $=\&$ titles $=\&$ outc $=\&$ spons $=\& l e a d=\& i d=\&$ state $1=\&$ cntry $1=\&$ state $2=\&$ cntry $2=\&$ st ate $3=\&$ cntry $3=\& l o c n=\&$ phase $=1$ \&phase $=2 \&$ phase $=3 \&$ rcv $s=\& r c v$ e $=$ \&lup $s=\& l u p ~ e=>$. Accessed in: February $2^{\text {nd }} 2017$. 
${ }^{214}$ Clinical Trials.gov's website - A service of the U.S. National Institutes of Health. Available at: $<$ https://clinicaltrials.gov/ct2/results?term=everolimus\&recr=\&type=\&rslt=\&age v=\&gndr=\&c ond=\&intr=\&titles=\&outc $=\&$ spons $=\&$ lead $=\& i d=\&$ state $1=\&$ cntry $1=\&$ state $2=\&$ cntry $2=\&$ state $3=$ \&cntry3=\&locn=\&phase=3\&rcv s=\&rcv e=\&lup s=\&lup e $>$. Accessed in: September $7^{\text {th }} 2016$. 215 ChemBlink's website - Material Safety Data Sheet. Available at: $<$ http://www.chemblink.com/MSDS/MSDSFiles/159351-69-6 Sigma-Aldrich.pdf>. Accessed in: September $7^{\text {th }} 2016$.

${ }^{216}$ Uehata, M.; Ishizaki, T.; Satoh, H.; Ono, T.; Kawahara, T.; Morishita, T.; Tamakawa, H.; Yamagami, K.; Inui, J.; Maekawa, M. M.; Narumiya, S. Calcium sensitization of smooth muscle mediated by a Rho-associated protein kinase in hypertension. Nature 1997, 389, 990. [CrossRef] [PubMed]

${ }^{217}$ Tinib-Tools website. Available at: <http://www.tinib-tools.com/products F.html\#F137>. Accessed in: September $7^{\text {th }} 2016$.

${ }^{218}$ Asano, T.; Ikegaki, I.; Satoh, S.; Suzuki, Y.; Shibuya, M.; Takayasu, M.; Hidaka, H. Mechanism of action of a novel antivasospasm drug, HA1077. The Journal of Pharmacology and Experimental Therapeutics 1987, 241, 1033. [PubMed]

${ }^{219}$ Yamaguchi, H.; Kasa, M.; Amano, M.; Kaibuchi, K.; Hakoshima, T. Molecular mechanism for the regulation of rho-kinase by dimerization and its inhibition by fasudil. Structure 2006, 14, 589. [CrossRef] [PubMed]

${ }^{220}$ Clinical Trials.gov's website - A service of the U.S. National Institutes of Health. Available at: $<$ https://clinicaltrials.gov/ct2/results?term=fasudil\&recr=\&type=\&rslt=\&age $v=\& g n d r=\&$ cond= \&intr $=\&$ titles=\&outc=\&spons=\&lead=\&id=\&state $1=\&$ cntry $1=\&$ state $2=\&$ cntry2=\&state $3=\&$ cntr y3=\&locn=\&phase=3\&rcv s=\&rcv e=\&lup s=\&lup e>. Accessed in: September $7^{\text {th }} 2016$.

221 ChemBlink's website - Material Safety Data Sheet. Available at: $<$ http://www.chemblink.com/MSDS/MSDSFiles/105628-07-7 Ark\%20Pharm.pdf>. Accessed in: September $7^{\text {th }} 2016$.

${ }^{222}$ Kino, T.; Hatanaka, H.; Hashimoto, M.; Nishiyama, M.; Goto, T.; Okuhara, M.; Kohsaka, M.; Aoki, H.; Imanaka, H. FK-506, a novel immunosuppressant isolated from a Streptomyces. I. Fermentation, isolation, and physico-chemical and biological characteristics. The Journal of Antibiotics 1987, 40, 1249. [PubMed]

223 Tinib-Tools website. Available at: <http://www.tinib-tools.com/products F.html\#F138>. Accessed in: September $7^{\text {th }} 2016$.

224 Dumont, F. J. FK506, an immunosuppressant targeting calcineurin function. Current Medicinal Chemistry 2000, 7, 731. [CrossRef] [PubMed]

${ }^{225}$ Clinical Trials.gov's website - A service of the U.S. National Institutes of Health. Available at: $<$ https://clinicaltrials.gov/ct2/results?term=FK+\%E2\%80\%93+506\&type=\&rslt=\&recr=\&age v= \&gndr=\&cond=cancer\&intr=\&titles=\&outc=\&spons=\&lead=\&id=\&state1=\&cntry1=\&state $2=\& c$ ntry $2=\&$ state $3=\&$ cntry $3=\& l o c n=\&$ phase $=1$ \&phase $=2 \&$ phase $=3 \&$ rcv $s=\& r c v$ e=\&lup $s=\&$ lup e $=>$. Accessed in: February $2^{\text {nd }} 2017$.

${ }^{226}$ Clinical Trials.gov's website - A service of the U.S. National Institutes of Health. Available at: $<$ https://clinicaltrials.gov/ct2/results?term=FK506\&recr=\&type=\&rslt=\&age v=\&gndr=\&cond= \&intr $=\&$ titles $=$ \&outc $=\&$ spons $=\&$ lead $=\& i d=\&$ state $1=\&$ cntry $1=\&$ state $2=\&$ cntry $2=\&$ state $3=\&$ cntr $y 3=\& l o c n=\& p h a s e=3 \&$ rcv $s=\& r c v$ e=\&lup $s=\& l u p ~ e>$. Accessed in: September $7^{\text {th }} 2016$.

227 ChemBlink's website - Material Safety Data Sheet. Available at: $<$ http://www.chemblink.com/MSDS/MSDSFiles/104987-11-3 Spectrum.pdf $>$. Accessed in: September $7^{\text {th }} 2016$.

${ }^{228}$ Kattige, S. L.; Naik, R. G.; Lakadawalla, A. D.; Dohadwalla, A. N.; Rupp, R. H.; Souza, N. J.; Germany. 1986. (DE 3612337 A1) 
229 Tinib-Tools website. Available at: <http://www.tinib-tools.com/products F.html\#F031> Accessed in: September $7^{\text {th }} 2016$.

${ }^{230}$ Kaur, G.; Stetler-Stevenson, M.; Sebers, S.; Worland, P.; Sedlacek, H.; Myers, C.; Czech, J.; Naik, R.; Sausville, E. Growth inhibition with reversible cell cycle arrest of carcinoma cells by flavone L86-8275. Journal of the National Cancer Institute 1992, 84, 1736. [CrossRef] [PubMed]

${ }^{231}$ Blagosklonny, M. V. Flavopiridol, an inhibitor of transcription: implications, problems and solutions. Cell Cycle 2004, 3, 1537. [CrossRef] [PubMed]

${ }^{232}$ Clinical Trials.gov's website - A service of the U.S. National Institutes of Health. Available at: $<$ https://clinicaltrials.gov/ct2/results?term=Flavopiridol\&type=\&rslt=\&recr=\&age $v=\& g n d r=\& c$ ond=Cancer\&intr=\&titles $=\&$ outc $=\&$ spons $=\&$ lead $=\& i d=\&$ state $1=\&$ cntry $1=\&$ state $2=\&$ cntry $2=\&$ st ate3=\&cntry3=\&locn=\&phase $=0$ \&phase $=1$ \&phase $=2 \&$ phase $=3 \&$ rcv $s=\& r c v$ e=\&lup $s=\& l u p ~ e$ $>$. Accessed in: February $2^{\text {nd }} 2017$.

${ }^{233}$ Clinical Trials.gov's website - A service of the U.S. National Institutes of Health. Available at: $<$ https://clinicaltrials.gov/ct2/results?term=flavopiridol\&recr=\&type=\&rslt=\&age $v=\& g n d r=\& c$ ond=\&intr=\&titles=\&outc=\&spons=\&lead=\&id=\&state1=\&cntry1=\&state2=\&cntry2=\&state3= \&cntry3=\&locn=\&phase=1\&rcv s=\&rcv e=\&lup s=\&lup e $>$. Accessed in: September $7^{\text {th }} 2016$. 234 Sigma-Aldrich website - Material Safety Data Sheet. Available at: $<$ http://www.sigmaaldrich.com/MSDS/MSDS/DisplayMSDSPage.do?country=BR\&language=pt \&productNumber=F3055\&brand=SIGMA\&PageToGoToURL=http\%3A\%2F\%2Fwww.sigmaaldric h.com\%2Fcatalog\%2Fsearch\%3Fterm\%3Dflavopiridol\%26interface\%3DAll\%26N\%3D0\%26mode \%3Dmatch\%2520partialmax\%26lang\%3Dpt\%26region\%3DBR\%26focus\%3Dproduct>. Accessed in: September $7^{\text {th }} 2016$.

235 Bannen, L. C.; Chan, D. S-M.; Chen, J.; Dalrymple, L. E.; Forsyth, T. P.; Huynh, T. P.; Jammalamadaka, V.; Khoury, R. G.; Leahy, J. W.; Mac, M. B.; Mann, G.; Mann, L. W.; Nuss, J. M.; Parks, J. J.; Takeuchi, C. S.; Wang, Y.; Xu, W.; USA 2003. (WO 2005030140 A2)

${ }^{236}$ Tinib-Tools website. Available at: <http://www.tinib-tools.com/products F.html\#F166>. Accessed in: September $7^{\text {th }} 2016$.

237 Dufies, M.; Jacquel, A.; Robert, G.; Cluzeau, T.; Puissant, A.; Fenouille, N.; Legros, L.; Raynaud, S.; Cassuto, J. P.; Luciano, F.; Auberger, P. Mechanism of action of the multikinase inhibitor Foretinib. Cell Cycle 2011, 10, 4138. [CrossRef] [PubMed]

${ }^{238}$ Clinical Trials.gov's website - A service of the U.S. National Institutes of Health. Available at: $<$ https://clinicaltrials.gov/ct2/results?term=Foretinib\&type=\&rslt=\&recr=\&age $v=\& g n d r=\& c o n$ $\mathrm{d}=$ Cancer\&intr=\&titles=\&outc=\&spons=\&lead=\&id=\&state1=\&cntry1=\&state2=\&cntry2=\&stat e3=\&cntry3=\&locn=\&phase=0\&phase=1\&phase=2\&phase=3\&rcv s=\&rcv e=\&lup $s=\&$ lup e $=>$ . Accessed in: February $2^{\text {nd }} 2017$.

${ }^{239}$ Clinical Trials.gov's website - A service of the U.S. National Institutes of Health. Available at: $<$ https://clinicaltrials.gov/ct2/results?term=foretinib\&recr=\&type=\&rslt=\&age $v=\& g n d r=\& c o n$ $\mathrm{d}=\&$ intr $=\&$ titles=\&outc=\&spons=\&lead=\&id=\&state1=\&cntry1=\&state2=\&cntry2=\&state $3=\& \mathrm{cn}$ try3=\&locn=\&phase=1\&rcv s=\&rcv e=\&lup s=\&lup e $>$. Accessed in: September $7^{\text {th }} 2016$.

240 ChemBlink's website - Material Safety Data Sheet. Available at: $<$ http://www.chemblink.com/MSDS/MSDSFiles/849217-64-7 Ark\%20Pharm.pdf>. Accessed in: September $7^{\text {th }} 2016$.

${ }^{241}$ Lemmon, M. A.; Schlessinger, J. Regulation of signal transduction and signal diversity by receptor oligomerization. Trends in Biochemical Sciences 1994, 19, 459. [PubMed]

242 Tinib-Tools website. Available at: <http://www.tinib-tools.com/products G.html\#G034>. Accessed in: September $7^{\text {th }} 2016$.

243 Baselga, J.; Averbuch, S. D. ZD1839 ('Iressa') as an anticancer agent. Drugs 2000, 60, 33. [CrossRef] [PubMed] 
${ }^{244}$ Clinical Trials.gov's website - A service of the U.S. National Institutes of Health. Available at: $<$ https://clinicaltrials.gov/ct2/results?term=Gefitinib\&type=\&rslt=\&recr=\&age $v=\& g n d r=\& c o n$ $\mathrm{d}=$ =ancer\&intr $=\&$ titles $=$ \&outc $=$ \&spons $=$ \&lead $=\& \mathrm{id}=\&$ state $1=\&$ cntry1=\&state $2=\&$ cntry $2=\&$ stat e3=\&cntry3=\&locn=\&phase=2\&phase=3\&rcv s=\&rcv e=\&lup s=\&lup e=>. Accessed in: February $2^{\text {nd }} 2017$.

${ }^{245}$ Clinical Trials.gov's website - A service of the U.S. National Institutes of Health. Available at: $<$ https://clinicaltrials.gov/ct2/results?term=gefitinib\&recr=\&type=\&rslt=\&age $v=\& g n d r=\& c o n$ $\mathrm{d}=$ \&intr=\&titles=\&outc=\&spons=\&lead=\&id=\&state1=\&cntry1=\&state2=\&cntry2=\&state3=\&cn try3=\&locn=\&phase=3\&rcv s=\&rcv e=\&lup s=\&lup e $>$. Accessed in: September $7^{\text {th }} 2016$.

${ }^{246}$ ChemBlink's website - Material Safety Data Sheet. Available at: <http://www.chemblink.com/MSDS/MSDSFiles/849217-64-7 Ark\%20Pharm.pdf>. Accessed in: September $7^{\text {th }} 2016$.

${ }^{247}$ Akiyama, T.; Ishida, J.; Nakagawa, S.; Ogawara, H.; Watanabe, S.; Itoh, N.; Shibuya, M.; Fukami, Y. Genistein, a specific inhibitor of tyrosine-specific protein kinases. The Journal of Biological Chemistry, 1987, 262, 5592. [PubMed]

248 Tinib-Tools website. Available at: <http://www.tinib-tools.com/products G.html\#G036>. Accessed in: September $7^{\text {th }} 2016$.

${ }^{249}$ Banerjee, S.; Li, Y.; Wang, Z.; Sarkar, F. H. Multi-targeted therapy of cancer by genistein. Cancer Letters, 2008, 269, 226. [CrossRef] [PubMed]

${ }^{250}$ Clinical Trials.gov's website - A service of the U.S. National Institutes of Health. Available at: $<$ https://clinicaltrials.gov/ct2/results?term=Genistein\&type=\&rslt=\&recr=\&age $v=\& g n d r=\& c 0$ nd=Cancer\&intr $=\&$ titles $=\&$ outc $=\&$ spons $=\& l e a d=\& i d=\&$ state $1=\&$ cntry $1=\&$ state $2=\&$ cntry $2=\&$ sta te3=\&cntry3=\&locn=\&phase=1\&phase=2\&phase=3\&rcv s=\&rcv e=\&lup s=\&lup e=>.

Accessed in: February $2^{\text {nd }} 2017$.

${ }^{251}$ Clinical Trials.gov's website - A service of the U.S. National Institutes of Health. Available at: $<$ https://clinicaltrials.gov/ct2/results?term=genistein\&recr=\&type=\&rslt=\&age $\mathrm{v}=\& g n d r=\& c o n$ $\mathrm{d}=$ \&intr=\&titles=\&outc=\&spons=\&lead=\&id=\&state1=\&cntry1=\&state2=\&cntry2=\&state3=\&cn try3=\&locn=\&phase=3\&rcv s=\&rcv e=\&lup s=\&lup e>. Accessed in: September $7^{\text {th }} 2016$.

${ }^{252}$ ChemBlink's website - Material Safety Data Sheet. Available at: $<$ http://www.chemblink.com/MSDS/MSDSFiles/446-72-0 Science\%20Lab.pdf $>$. Accessed in: September $7^{\text {th }} 2016$.

${ }^{253}$ Hartenstein, J.; Aranda, J.; Barth, H.; Betche, H.; Kleinschroth, J.; Reck, R.; Rudolph, C.; Trostmann, U.; Schachtele, C. The design of protein kinase $C$ inhibitors. In perspectives in medicinal chemistry. Testa, B., Kyburz, E., Fuhrer, W., Giger, R., eds., Verlag Helvetica Chimica Acta, 1993, 99.

254 Tinib-Tools website. Available at: <http://www.tinib-tools.com/products G.html\#G140>. Accessed in: September $7^{\text {th }} 2016$.

255 Martiny-Baron, G.; Kazanietz, M. G.; Mischak, H.; Blumberg, P. M.; Kochs, G.; Hug, H.; Marmé, D.; Schächtele, C. Selective inhibition of protein kinase $C$ isozymes by the indolocarbazole Gö 6976. The Journal of Biological Chemistry 1993, 268, 9194. [PubMed]

${ }^{256}$ Aaltonen, V.; Peltonen , J. PKCalpha/beta I inhibitor Go6976 induces dephosphorylation of constitutively hyperphosphorylated Rb and G1 arrest in T24 cells. Anticancer Research 2010, 10, 3995. [CrossRef] [PubMed]

${ }^{257}$ Clinical Trials.gov's website - A service of the U.S. National Institutes of Health. Available at: $<$ https://clinicaltrials.gov/ct2/results?term=G\%C3\%96+6976\&Search=Search>. Accessed in: September $7^{\text {th }} 2016$. 
258 ChemBlink's website - Material Safety Data Sheet. Available at: $<$ http://www.chemblink.com/MSDS/MSDSFiles/136194-77-9 Clear\%20Synth.pdf >. Accessed in: September $7^{\text {th }} 2016$.

${ }^{259}$ Conway, J. G.; McDonald, B.; Parham, J.; Keith, B.; Rusnak, D. W.; Shaw, E.; Jansen, M.; Lin, P.; Payne, A.; Crosby, R. M.; Johnson, J. H.; Frick, L.; Lin, M. H.; Depee, S.; Tadepalli, S.; Votta, B.; James, I.; Fuller, K.; Chambers, T. J.; Kull, F. C.; Chamberlain, S. D.; Hutchins, J. T. Inhibition of colony-stimulating-factor-1 signaling in vivo with the orally bioavailable cFMS kinase inhibitor GW2580. Proceedings of the National Academy of Sciences of the United States of America 2005, 102, 16078. [CrossRef] [PubMed]

260 Tinib-Tools website. Available at: <http://www.tinib-tools.com/products G.html\#G141>. Accessed in: September $7^{\text {th }} 2016$.

${ }^{261}$ Conway, J. G.; Pink, H.; Bergquist, M. L.; Han, B.; Depee, S.; Tadepalli, S.; Lin, P.; Crumrine, R. C.; Binz, J.; Clark, R. L.; Selph, J. L.; Stimpson, S. A.; Hutchins, J. T.; Chamberlain, S. D.; Brodie, T. A. Effects of the cFMS kinase inhibitor 5-(3-methoxy-4-((4methoxybenzyl)oxy)benzyl)pyrimidine-2,4-diamine (GW2580) in normal and arthritic rats. The Journal of Pharmacology and Experimental Therapeutics 2008, 326, 41. [CrossRef] [PubMed]

${ }^{262}$ Clinical Trials.gov's website - A service of the U.S. National Institutes of Health. Available at: $<$ https://clinicaltrials.gov/ct2/results?term=GW2580\&Search=Search>. Accessed in: September $7^{\text {th }} 2016$.

263 Sigma-Aldrich website - Material Safety Data Sheet. Available at: $<$ http://www.sigmaaldrich.com/MSDS/MSDS/DisplayMSDSPage.do?country=BR\&language=pt \&productNumber=SML1047\&brand=SIGMA\&PageToGoToURL=http\%3A\%2F\%2Fwww.sigmaal drich.com\%2Fcatalog\%2Fsearch\%3Fterm\%3DGW2580\%26interface\%3DProduct\%2520Name\% 26N\%3D0\%2B\%26mode\%3Dmode\%2520matchpartialmax\%26lang\%3Dpt\%26region\%3DBR\%2 6focus\%3DproductN\%3D0\%2520220003048\%2520219853286\%2520219853075>. Accessed in: September $7^{\text {th }} 2016$.

${ }^{264}$ Chijiwa, T.; Mishima, A.; Hagiwara, M.; Sano, M.; Hayashi, K.; Inoue, T.; Naito, K.; Toshioka, T.; Hidaka, H. Inhibition of forskolin-induced neurite outgrowth and protein phosphorylation by a newly synthesized selective inhibitor of cyclic AMP-dependent protein kinase, N-[2-(pbromocinnamylamino)ethyl]-5-isoquinolinesulfonamide (H-89), of PC12D pheochromocytoma cells. The Journal of Biological Chemistry 1990, 265, 5267. [PubMed]

${ }^{265}$ Tinib-Tools website. Available at: <http://www.tinib-tools.com/products H.html\#H142>. Accessed in: September $8^{\text {th }} 2016$.

${ }^{266}$ Davies, S. P.; Reddy, H.; Caivano, M.; Cohen, P. Specificity and mechanism of action of some commonly used protein kinase inhibitors. The Biochemical journal 2000, 351, 95. [CrossRef] [PubMed]

${ }^{267}$ Clinical Trials.gov's website - A service of the U.S. National Institutes of Health. Available at: $<$ https://clinicaltrials.gov/ct2/show/NCT00002050?term=H-89\&rank=2>. Accessed in: September $8^{\text {th }} 2016$.

${ }^{268}$ ChemBlink's website - Material Safety Data Sheet. Available at: <http://www.chemblink.com/MSDS/MSDSFiles/127243-85-0 Reagent\%20World.pdf>.

Accessed in: September $8^{\text {th }} 2016$.

${ }^{269}$ Walter, R.; Heckel, A.; Roth, G. J.; Kley, J.; Schnapp, G.; Lenter, M.; van Meel, J. C. A.; Spevak, W.; Weyer-Czernilofsky, U. Sulfonylamino substituted 3-(aminomethylide)-2-indolinones as cell proliferation inhibitors. Patent Cooperation Treaty, International Publication Number WO 02/36564, 2002.

270 Tinib-Tools website. Available at: <http://www.tinib-tools.com/products H.html\#H037>. Accessed in: September $8^{\text {th }} 2016$. 
${ }^{271}$ Sessa, F.; Mapelli, M.; Ciferri, C.; Tarricone, C.; Areces, L. B.; Schneider, T. R.; Stukenberg, P. T.; Musacchio, A. Mechanism of Aurora B activation by INCENP and inhibition by hesperadin. Molecular Cell 2005, 18, 379. [CrossRef] [PubMed]

${ }^{272}$ Clinical Trials.gov's website - A service of the U.S. National Institutes of Health. Available at: $<$ https://clinicaltrials.gov/ct2/results?term=\&recr=\&type=\&rslt=\&age $v=\& g n d r=\&$ cond=\&intr= \&titles $=\&$ outc $=\&$ spons $=\& l e a d=\& i d=\&$ state $1=\&$ cntry1=\&state $2=\&$ cntry2 $=\&$ state $3=\&$ cntry3=\&lo cn=\&phase=3\&rcv s=\&rcv e=\&lup s=\&lup e>. Accessed in: September $8^{\text {th }} 2016$.

273 ChemBlink's website - Material Safety Data Sheet. Available at: $<$ http://www.chemblink.com/MSDS/MSDSFiles/422513-13-1 Clear\%20Synth.pdf $>$. Accessed in: September $8^{\text {th }} 2016$.

274 Zimmermann, J.; Buchdunger, E.; Mett, H.; Meyer, T.; Lydon, N. B.; Traxler, P. (Phenylamino)pyrimidine (PAP) derivatives: a new class of potent and highly selective PDGFreceptor autophosphorylation inhibitors. Bioorganic \& Medicinal Chemistry Letters 1996, 6, 1221. [CrossRef]

275 Tinib-Tools website. Available at: <http://www.tinib-tools.com/products I.html\#I040>. Accessed in: September $8^{\text {th }} 2016$.

${ }^{276}$ Capdeville, R.; Buchdunger, E.; Zimmermann, J.; Matter, A. Glivec (STI571, imatinib), a rationally developed, targeted anticancer drug. Nature Reviews. Drug discovery 2002, 1, 493. [CrossRef] [PubMed]

${ }^{277}$ Clinical Trials.gov's website - A service of the U.S. National Institutes of Health. Available at: $<$ https://clinicaltrials.gov/ct2/results?term=imatinib\&recr=\&type=\&rslt=\&age $v=\& g n d r=\& c o n$ $\mathrm{d}=$ \&intr $=$ \&titles=\&outc=\&spons=\&lead=\&id=\&state1=\&cntry1=\&state2=\&cntry2=\&state3=\&cn try3=\&locn=\&phase=3\&rcv s=\&rcv e=\&lup s=\&lup e >. Accessed in: September $8^{\text {th }} 2016$.

278 ChemBlink's website - Material Safety Data Sheet. Available at: $<$ http://www.chemblink.com/MSDS/MSDSFiles/220127-57-1 Ark\%20Pharm.pdf>. Accessed in: September $8^{\text {th }} 2016$.

${ }^{279}$ Zheng, Q. T.; Lu, D. J.; Yang, S. L. Pharmacological studies of indirubin. I. Antitumor effect. Communications of Chinese Herbal Medicine 1979, 10, 35.

280 Tinib-Tools website. Available at: <http://www.tinib-tools.com/products I.html\#I040>. Accessed in: September $8^{\text {th }} 2016$.

${ }^{281}$ Hoessel, R.; Leclerc, S.; Endicott, J. A.; Nobel, M. E.; Lawrie, A.; Tunnah, P.; Leost, M.; Damiens, E.; Marie, D.; Marko, D.; Niederberger, E.; Tang, W.; Eisenbrand, G.; Meijer, L. Indirubin, the active constituent of a Chinese antileukaemia medicine, inhibits cyclindependent kinases. Nature Cell Biology 1999, 1, 60. [CrossRef] [PubMed]

${ }^{282}$ Clinical Trials.gov's website - A service of the U.S. National Institutes of Health. Available at: $<$ https://clinicaltrials.gov/ct2/show/NCT02200978?term=Indirubin\&cond=Cancer\&phase $=012$ 3 \&rank=1>. Accessed in: September $8^{\text {th }} 2016$.

${ }^{283}$ ChemBlink's website - Material Safety Data Sheet. Available at: $<$ http://www.chemblink.com/MSDS/MSDSFiles/479-41-4 TCl.pdf>. Accessed in: September $8^{\text {th }}$ 2016.

284 Tinib-Tools website. Available at: <http://www.tinib-tools.com/products I.html\#I042>. Accessed in: September $8^{\text {th }} 2016$.

${ }^{285}$ Kameswaran, T. R.; Ramanibai, R. Indirubin-3-monooxime induced cell cycle arrest and apoptosis in Hep-2 human laryngeal carcinoma cells. Biomedicine and Pharmacotherapy 2009, 63, 146. [CrossRef] [PubMed]

${ }^{286}$ Kameswaran, T.R.; Ramanibai, R. Indirubin-3-monooxime induced cell cycle arrest and apoptosis in Hep-2 human laryngeal carcinoma cells. Biomed Pharmacotherapy 2009, 63, 146. [CrossRef] [PubMed] 
${ }^{287}$ Clinical Trials.gov's website - A service of the U.S. National Institutes of Health. Available at: $<$ https://clinicaltrials.gov/ct2/results?term=INDIRUBIN-3\%E2\%80\%99-

MONOOXIME\&Search=Search>. Accessed in: September $8^{\text {th }} 2016$.

288 ChemBlink's website - Material Safety Data Sheet. Available at: $<$ http://www.chemblink.com/MSDS/MSDSFiles/160807-49-8 Cayman.pdf>. Accessed in: September $8^{\text {th }} 2016$.

289 Tinib-Tools website. Available at: <http://www.tinib-tools.com/products I.htm|\#|043>. Accessed in: September $8^{\text {th }} 2016$.

${ }^{290}$ Kosmopoulou, M. N.; Leonidas, D. D.; Chrysina, E. D.; Bischler, N.; Eisenbrand, G.; Sakarellos, C. E.; Pauptit, R.; Oikonomakos, N. G. Binding of the potential antitumour agent indirubin-5sulphonate at the inhibitor site of rabbit muscle glycogen phosphorylase b. Comparison with ligand binding to pCDK2-cyclin A complex. European Journal of Biochemistry 2004, 271, 2280. [CrossRef] [PubMed]

${ }^{291}$ Clinical Trials.gov's website - A service of the U.S. National Institutes of Health. Available at: $<$ https://clinicaltrials.gov/ct2/results?term=INDIRUBIN-5-SULFONIC+ACID\&Search=Search>.

Accessed in: September $8^{\text {th }} 2016$.

292 Santa Cruz Biotechnology website - Material Safety Data Sheet. Available at: $<$ http://datasheets.scbt.com/sds/bghs/br/sc-221755.pdf $>$. Accessed in: September $8^{\text {th }} 2016$.

${ }^{293}$ Hilberg, F.; Roth, G. J.; Krssak, M.; Kautschitsch, S.; Sommergruber, W.; Tontsch-Grunt, U.; Garin-Chesa, P.; Bader, G.; Zoephel, A.; Quant, J.; Heckel, A.; Rettig, W. J. BIBF 1120: triple angiokinase inhibitor with sustained receptor blockade and good antitumor efficacy. Cancer Research 2008, 68, 4774. [CrossRef]

294 Tinib-Tools website. Available at: <http://www.tinib-tools.com/products I.htm|\#l144>. Accessed in: September $8^{\text {th }} 2016$.

${ }^{295}$ Antoniu, S. A.; Kolb, M. R. Intedanib, a triple kinase inhibitor of VEGFR, FGFR and PDGFR for the treatment of cancer and idiopathic pulmonary fibrosis. IDrugs: the Investigational Drugs Journal 2010, 13, 332. [PubMed]

${ }^{296}$ Clinical Trials.gov's website - A service of the U.S. National Institutes of Health. Available at: $<$ https://clinicaltrials.gov/ct2/results?term=Intedanib\&recr=\&type=\&rslt=\&age $v=\& g n d r=\& c 0$ nd=\&intr $=$ \&titles $=$ \&outc $=$ \&spons $=\&$ lead $=\& i d=\&$ state $1=\&$ cntry $1=\&$ state $2=\&$ cntry $2=\&$ state $3=\& \mathrm{c}$ ntry3=\&locn=\&phase=2\&rcv s=\&rcv e=\&lup s=\&lup e >. Accessed in: September $8^{\text {th }} 2016$.

297 ChemBlink's website - Material Safety Data Sheet. Available at: $<$ http://www.chemblink.com/MSDS/MSDSFiles/656247-17-5 Clear\%20Synth.pdf>. Accessed in: September $8^{\text {th }} 2016$.

298 Emanuel, S.; Rugg, C. A.; Gruninger, R. H.; Lin, R.; Fuentes-Pesquera, A.; Connolly, P. J.; Wetter, S. K.; Hollister, B.; Kruger, W. W.; Napier, C.; Jolliffe, L.; Middleton, S. A. The in vitro and in vivo effects of JNJ-7706621: a dual inhibitor of cyclin-dependent kinases and aurora kinases. Cancer Research 2005, 65, 9038. [CrossRef] [PubMed]

299 Tinib-Tools website. Available at: <http://www.tinib-tools.com/products J.html\#J045>. Accessed in: September $8^{\text {th }} 2016$.

${ }^{300}$ Pflug, A.; de Oliveira, T. M.; Bossemeyer, D.; Engh, R. A. Mutants of protein kinase A that mimic the ATP-binding site of Aurora kinase. The Biochemical Journal 2011, 440, 85. [CrossRef] [PubMed]

${ }^{301}$ Clinical Trials.gov's website - A service of the U.S. National Institutes of Health. Available at: $<$ https://clinicaltrials.gov/ct2/results?term=JNJ-7706621\&Search=Search>. Accessed in: September $8^{\text {th }} 2016$.

${ }_{302}$ ChemBlink's website - Material Safety Data Sheet. Available at: $<$ http://www.chemblink.com/MSDS/MSDSFiles/443797-96-4 Ark\%20Pharm.pdf>. Accessed in: September $8^{\text {th }} 2016$. 
${ }^{303}$ Kase, H.; Iwahashi, K.; Matsuda, Y. K-252a, a potent inhibitor of protein kinase C from microbial origin. The Journal of Antibiotics 1986, 39, 1059. [CrossRef] [PubMed]

304 Tinib-Tools website. Available at: <http://www.tinib-tools.com/products K.html\#K145>. Accessed in: September $8^{\text {th }} 2016$.

${ }^{305}$ Elliott, L. H.; Wilkinson, S. E.; Sedgwick, A. D.; Hill, C. H.; Lawton, G.; Davis, P. D.; Nixon, J. S. $\mathrm{K} 252 \mathrm{a}$ is a potent and selective inhibitor of phosphorylase kinase. Biochemical and Biophysical Research Communications 1990, 171, 148. [PubMed]

${ }^{306}$ Morotti, A.; Mila, S.; Accornero, P.; Tagliabue, E.; Ponzetto, C. K252a inhibits the oncogenic properties of Met, the HGF receptor. Oncogene 2002, 21, 4885. [CrossRef] [PubMed]

${ }^{307}$ Clinical Trials.gov's website - A service of the U.S. National Institutes of Health. Available at: $<$ https://clinicaltrials.gov/ct2/results?term=K252a\&type=\&rslt=\&recr=\&age $v=$ \&gndr $=\&$ cond $=$ cancer\&intr $=\&$ titles $=$ \&outc $=\&$ spons $=\&$ lead $=\& i d=\&$ state $1=\&$ cntry $1=\&$ state $2=\&$ cntry $2=\&$ state $3=$ \&cntry3=\&locn=\&rcv s=\&rcv e=\&lup $s=\&$ lup e $=>$. Accessed in: February $4^{\text {th }} 2017$.

308 ChemBlink's website - Material Safety Data Sheet. Available at: $<$ http://www.chemblink.com/MSDS/MSDSFiles/99533-80-9 Cayman.pdf $>$. Accessed in: September $8^{\text {th }} 2016$.

${ }^{309}$ García-Martínez, J. M.; Moran, J.; Clarke, R. G.; Gray, A.; Cosulich, S. C.; Chresta, C. M.; Alessi, D. R. Ku-0063794 is a specific inhibitor of the mammalian target of rapamycin (mTOR). The Biochemical Journal 2009, 421, 29. [CrossRef] [PubMed]

310 Tinib-Tools website. Available at: <http://www.tinib-tools.com/products K.html\#K046>. Accessed in: September $8^{\text {th }} 2016$.

${ }^{311}$ Clinical Trials.gov's website - A service of the U.S. National Institutes of Health. Available at: $<$ https://clinicaltrials.gov/ct2/results?term=KU0063794\&Search=Search>. Accessed in: September $8^{\text {th }} 2016$.

312 ChemBlink's website - Material Safety Data Sheet. Available at: $<$ http://www.chemblink.com/MSDS/MSDSFiles/938440-64-3 Clear\%20Synth.pdf $>$. Accessed in: September $8^{\text {th }} 2016$.

${ }^{313}$ Carter, M. C.; Cockerill, G. S.; Guntrip, S. B.; Lackey, K. E.; Smith, K. J. Bicyclic heteroaromatic compounds (quinazolinamines and analogs) useful as protein tyrosine kinase inhibitors. PCT Int. Appl. WO9935146, Glaxo Wellcome, 1999.

314 Tinib-Tools website. Available at: <http://www.tinib-tools.com/products L.html\#L047>. Accessed in: September $8^{\text {th }} 2016$.

${ }^{315}$ Xia, W.; Mullin, R. J.; Keith, B. R.; Liu, L. H.; Ma, H.; Rusnak, D. W.; Owens, G.; Alligood, K. J.; Spector, N. L. Anti-tumor activity of GW572016: a dual tyrosine kinase inhibitor blocks EGF activation of EGFR/erbB2 and downstream Erk1/2 and AKT pathways. Oncogene 2002, 21, 6255. [CrossRef] [PubMed]

${ }^{316}$ Clinical Trials.gov's website - A service of the U.S. National Institutes of Health. Available at: $<$ https://clinicaltrials.gov/ct2/results?term=LAPATINIB\&recr=\&type=\&rslt=\&age v=\&gndr=\&co

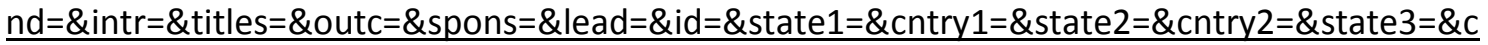
ntry3=\&locn=\&phase=3\&rcv s=\&rcv e=\&lup s=\&lup e $>$. Accessed in: September ${ }^{\text {th }} 2016$.

317 ChemBlink's website - Material Safety Data Sheet. Available at: $<$ http://www.chemblink.com/MSDS/MSDSFiles/388082-78-8 Ark\%20Pharm.pdf >. Accessed in: September $8^{\text {th }} 2016$.

${ }^{318}$ George, D. J.; Dionne, C. A.; Jani, J.; Angeles, T.; Murakata, C.; Lamb, J.; Isaacs, J. T. Sustained in vivo regression of Dunning $\mathrm{H}$ rat prostate cancers treated with combinations of androgen ablation and Trk tyrosine kinase inhibitors, CEP-751 (KT-6587) or CEP-701 (KT-5555). Cancer Research 1999, 59, 2395. [PubMed] 
319 Tinib-Tools website. Available at: <http://www.tinib-tools.com/products L.html\#L100>. Accessed in: September $8^{\text {th }} 2016$.

${ }^{320}$ Shabbir, M.; Stuart, R. Lestaurtinib, a multitargeted tyrosine kinase inhibitor: from bench to bedside. Expert Opinion On Investigational Drugs 2010, 19, 427. [CrossRef] [PubMed]

${ }^{321}$ Clinical Trials.gov's website - A service of the U.S. National Institutes of Health. Available at: $<$ https://clinicaltrials.gov/ct2/results?term=LESTAURTINIB\&recr=\&type=\&rslt=\&age v=\&gndr= \&cond $=$ \&intr $=\&$ titles $=$ \&outc $=$ \&spons $=$ \&lead $=\& i d=\&$ state $1=\&$ cntry $1=\&$ state $2=\&$ cntry $2=\&$ state 3 =\&cntry3=\&locn=\&phase=1\&rcv s=\&rcv e=\&lup s=\&lup e> Accessed in: September $8^{\text {th }} 2016$. 322 ChemBlink's website - Material Safety Data Sheet. Available at: $<$ http://www.chemblink.com/MSDS/MSDSFiles/111358-88-4 Sigma-Aldrich.pdf $>$. Accessed in: September $8^{\text {th }} 2016$.

${ }^{323}$ Arnold, L. D.; Cesario, C.; Coate, H.; Crew, A. P.; Dong, H.; Foreman, K.; Honda, A.; Laufer, R.; Li, A-H.; Mulvihill, K. M.; Mulvihill, M. J.; Nigro, A.; Panicker, B.; Steinig, A. G.; Sun, Y.; Weng, Q.; Werner, D. S.; Wyle, M. J.; Zhang, T; Canada. 2005. (WO 2005097800 A1)

324 Tinib-Tools website. Available at: <http://www.tinib-tools.com/products L.html\#L168>. Accessed in: September $9^{\text {th }} 2016$.

${ }^{325}$ Mulvihill, M. J.; Cooke, A.; Rosenfeld-Franklin, M.; Buck, E.; Foreman, K.; Landfair, D.; O'Connor, M.; Pirritt, C.; Sun, Y.; Yao, Y.; Arnold, L. D.; Gibson, N. W.; Ji, Q. S. Discovery of OSI906: a selective and orally efficacious dual inhibitor of the IGF-1 receptor and insulin receptor. Future Medicinal Chemistry 2009, 1, 1153. [CrossRef] [PubMed]

${ }^{326}$ Scagliotti, G. V.; Novello, S. The role of the insulin-like growth factor signaling pathway in non-small cell lung cancer and other solid tumors. Cancer Treatment Reviews 2012, 38, 292. [PubMed] [CrossRef]

${ }^{327}$ Clinical Trials.gov's website - A service of the U.S. National Institutes of Health. Available at: $<$ https://clinicaltrials.gov/ct2/results?term=Linsitinib\&recr=\&type=\&rslt=\&age $v=\& g n d r=\& c o n$ $\mathrm{d}=$ \&intr=\&titles=\&outc=\&spons=\&lead=\&id=\&state1=\&cntry1=\&state2=\&cntry2=\&state3=\&cn try3=\&locn=\&phase=2\&rcv s=\&rcv e=\&lup s=\&lup e $>$. Accessed in: September $~_{\text {th }}^{\text {th }} 2016$.

328 ChemBlink's website - Material Safety Data Sheet. Available at: $<$ http://www.chemblink.com/MSDS/MSDSFiles/867160-71-2 Clear\%20Synth.pdf>. Accessed in: September $9^{\text {th }} 2016$.

${ }^{329}$ Dubreuil, P.; Letard, S.; Ciufolini, M.; Gros, L.; Humbert, M.; Castéran, N.; Borge, L.; Hajem, B.; Lermet, A.; Sippl, W.; Voisset, E.; Arock, M.; Auclair, C.; Leventhal, P. S.; Mansfield, C. D.; Moussy, A.; Hermine, O. Masitinib (AB1010), a potent and selective tyrosine kinase inhibitor targeting KIT. PloS One 2009, 4, e7258. [CrossRef] [PubMed]

${ }^{330}$ Tinib-Tools website. Available at: <http://www.tinib-tools.com/products M.html\#M102> Accessed in: September $9^{\text {th }} 2016$.

${ }^{331}$ Clinical Trials.gov's website - A service of the U.S. National Institutes of Health. Available at: $<$ https://clinicaltrials.gov/ct2/results?term=MASITINIB\&recr=\&type=\&rslt=\&age $v=\& g n d r=\& c$ ond=\&intr=\&titles=\&outc=\&spons=\&lead=\&id=\&state1=\&cntry1=\&state2=\&cntry2=\&state3= \&cntry3=\&locn=\&phase=1\&rcv s=\&rcv e=\&lup s=\&lup e>. Accessed in: September $8^{\text {th }} 2016$. 332 ChemBlink's website - Material Safety Data Sheet. Available at: $<$ http://www.chemblink.com/MSDS/MSDSFiles/790299-79-5 Ark\%20Pharm.pdf >. Accessed in: September $9^{\text {th }} 2016$.

${ }^{333}$ Manfredi, M. G.; Ecsedy, J. A.; Meetze, K. A.; Balani, S. K.; Burenkova, O.; Chen, W.; Galvin, K. M.; Hoar, K. M.; Huck, J. J.; LeRoy, P. J.; Ray, E. T.; Sells, T. B.; Stringer, B.; Stroud, S. G.; Vos, T. J.; Weatherhead, G. S.; Wysong, D. R.; Zhang, M.; Bolen, J. B.; Claiborne, C. F. Antitumor activity of MLN8054, an orally active small-molecule inhibitor of Aurora A kinase. Proceedings of the National Academy of Sciences of the United States of America 2007, 104, 4106. [CrossRef] [PubMed] 
${ }^{334}$ Tinib-Tools website. Available at: <http://www.tinib-tools.com/products M.html\#M051>. Accessed in: September $9^{\text {th }} 2016$.

335 Hoar, K.; Chakravarty, A.; Rabino, C.; Wysong, D.; Bowman, D.; Roy, N.; Ecsedy, J. A. MLN8054, a small-molecule inhibitor of Aurora A, causes spindle pole and chromosome congression defects leading to aneuploidy. Molecular and Cellular Biology 2007, 27, 4513. [CrossRef] [PubMed]

${ }^{336}$ Clinical Trials.gov's website - A service of the U.S. National Institutes of Health. Available at: $<$ https://clinicaltrials.gov/ct2/results?term=MLN8054\&recr=\&type=\&rslt=\&age v=\&gndr=\&co nd=\&intr=\&titles=\&outc=\&spons=\&lead=\&id=\&state1=\&cntry1=\&state2=\&cntry2=\&state3=\&c ntry3=\&locn=\&phase=0\&rcv s=\&rcv e=\&lup s=\&lup e>. Accessed in: September ${ }^{\text {th }} 2016$.

337 ChemBlink's website - Material Safety Data Sheet. Available at: <http://www.chemblink.com/MSDS/MSDSFiles/869363-13-3 Clear\%20Synth.pdf>. Accessed in: September $9^{\text {th }} 2016$.

${ }^{338}$ Askew, B.; Adams, J.; Booker, S.; Chen, G.; DiPietro, L. V.; Elbaum, D.; Germain, J.; GeunsMeyer, S. D.; Habgood, G. J.; Handley, M.; Huang, Q.; Kim, T-S.; Li, A.; Nishimura, N.; Nomak, R.; Patel, V. F.; Riahi, B.; Kim, J. L.; Xi, N.; Yang, K.; Yuan, C. C.; USA. 2005. (US 6878714 B2)

${ }^{339}$ Tinib-Tools website. Available at: <http://www.tinib-tools.com/products M.html\#M052>. Accessed in: September $9^{\text {th }} 2016$.

${ }^{340}$ Polverino, A.; Coxon, A.; Starnes, C.; Diaz, Z.; DeMelfi, T.; Wang, L.; Bready, J.; Estrada, J.; Cattley, R.; Kaufman, S.; Chen, D.; Gan, Y.; Kumar, G.; Meyer, J.; Neervannan, S.; Alva, G.; Talvenheimo, J.; Montestruque, S.; Tasker, A.; Patel, V.; Radinsky, R.; Kendall, R. AMG 706, an oral, multikinase inhibitor that selectively targets vascular endothelial growth factor, plateletderived growth factor, and kit receptors, potently inhibits angiogenesis and induces regression in tumor xenografts. Cancer Research 2006, 66, 8715. [CrossRef] [PubMed]

${ }^{341}$ Clinical Trials.gov's website - A service of the U.S. National Institutes of Health. Available at: $<$ https://clinicaltrials.gov/ct2/results?term=motesanib\&recr=\&type=\&rslt=\&age $v=\& g n d r=\& c$ ond=\&intr $=$ \&titles $=$ \&outc $=\&$ spons $=$ \&lead $=\& i d=\&$ state $1=\&$ cntry $1=\&$ state $2=\&$ cntry $2=\&$ state $3=$ \&cntry3=\&locn=\&phase=2\&rcv s=\&rcv e=\&lup s=\&lup e>. Accessed in: September $8^{\text {th }} 2016$. 342 Selleckchem.com website. Available at: $<$ http://www.selleckchem.com/msds/MSDS S1032.pdf>. Accessed in: September $9^{\text {th }} 2016$.

${ }^{343}$ Hilberg, F.; Solca, F.; Stefanic, M. F.; Baum, A.; Munzert, G.; Van Meel, Jacobus C. A.; 2004. (WO 2004096224 A2)

${ }^{344}$ Rabindran, S. K.; Discafani, C. M.; Rosfjord, E. C.; Baxter, M.; Floyd, M. B.; Golas, J.; Hallett, W. A.; Johnson, B. D.; Nilakantan, R.; Overbeek, E.; Reich, M. F.; Shen, R.; Shi, X.; Tsou, H. R.; Wang, Y. F.; Wissner, A. Antitumor activity of HKI-272, an orally active, irreversible inhibitor of the HER-2 tyrosine kinase. Cancer Research 2004, 64, 3958. [CrossRef] [PubMed]

${ }^{345}$ Tsou HR1, Overbeek-Klumpers EG, Hallett WA, Reich MF, Floyd MB, Johnson BD, Michalak RS, Nilakantan R, Discafani C, Golas J, Rabindran SK, Shen R, Shi X, Wang YF, Upeslacis J, Wissner A. Optimization of 6,7-disubstituted-4-(arylamino)quinoline-3-carbonitriles as orally active, irreversible inhibitors of human epidermal growth factor receptor-2 kinase activity. Journal of Medicinal Chemistry 2005, 48, 1107. [CrossRef] [PubMed]

${ }^{346}$ Clinical Trials.gov's website - A service of the U.S. National Institutes of Health. Available at: $<$ https://clinicaltrials.gov/ct2/results?term=Neratinib\&type=\&rslt=\&recr=\&age $v=\& g n d r=\& c 0$ nd=Cancer\&intr $=\&$ titles $=$ \&outc $=\&$ spons $=\& l e a d=\& i d=\&$ state $1=\&$ cntry $1=\&$ state $2=\&$ cntry $2=\&$ sta te3=\&cntry3=\&locn=\&rcv s=\&rcv e=\&lup s=\&lup e=>. Accessed in: February $4^{\text {th }} 2017$. 
347 Biovision website -- safety data sheet for Neratinib: Available at: $<$ http://www.biovision.com/neratinib-5319.html $>$. Accessed in: August 21 2016.

${ }^{348}$ Clinical Trials.gov's website - A service of the U.S. National Institutes of Health. Available at: $<$ https://clinicaltrials.gov/ct2/show/NCT00878709?term=Neratinib\&phase=2\&rank=1 >.

Accessed in: August $20^{\text {th }} 2016$.

${ }^{349}$ Tinib-Tools website. Available at: $<$ http://www.tinib-tools.com>. Accessed in: August $20^{\text {th }}$ 2016.

${ }^{350}$ Lacy, A. M. Structural and physiological relationships within the to locus in Neurospora crassa. Biochemical and Biophysical Research Communications 1965, 18, 812. [CrossRef]

${ }^{351}$ Verdugo, D. E.; Cancilla, M. T.; Ge, X.; Gray, N. S.; Chang, Y. T.; Schultz, P. G.; Negishi, M.; Leary, J. A.; Bertozzi, C. R. Discovery of estrogen sulfotransferase inhibitors from a purine library screen. Journal of Medicinal Chemistry 2001, 44, 2683. [PubMed]

352 Rockwelllabs website. Available at: $<$ http://www.rockwelllabs.com/SDS/Pyrethroids/LambdaStar.pdf $>$. Accessed in: August $28^{\text {th }}$ 2016.

${ }^{353}$ Clinical Trials.gov's website - A service of the U.S. National Institutes of Health. Available at: $<$ https://clinicaltrials.gov/ct2/show/NCT00701363?term=NG+38\&phase=3\&rank=1>. Accessed in: August $20^{\text {th }} 2016$.

${ }^{354}$ Breitenstein, W.; Furet, P.; Jacob, S.; Manley, P. W.; 2004. (WO 2004005281 A1)

355 O'Hare, T.; Walters, D. K.; Deininger, M. W. N.; Druker, B. J. AMN107: tightening the grip of imatinib. Cancer Cell 2005, 7, 117. [CrossRef] [PubMed]

${ }^{356}$ Weisberg E.; Manley, P. W.; Breitenstein, W.; Brüggen, J.; Cowan-Jacob, S. W.; Ray, A.; Huntly, B.; Fabbro, D.; Fendrich, G.; Hall-Meyers, E.; Kung, A. L.; Mestan, J.; Daley, G. Q.; Callahan, L.; Catley, L.; Cavazza, C.; Azam, M.; Neuberg, D.; Wright, R. D.; Gilliland, D. G.; Griffin, J. D. Characterization of AMN107, a selective inhibitor of native and mutant Bcr-Abl. Cancer Cell 2005, 7, 129. [CrossRef] [PubMed]

357 Biovision website - safety data sheet for Nilotinib: Available at: <http://www.biovision.com/nilotinib-4141.html>. Accessed in: August $21^{\text {st }} 2016$.

${ }^{358}$ Clinical Trials.gov's website - A service of the U.S. National Institutes of Health. Available at: $<$ https://clinicaltrials.gov/ct2/results?term=Nilotinib\&Search=Search $>$. Accessed in: August $20^{\text {th }} 2016$.

${ }^{359}$ Martin, N. M. B.; Smith, G. C. M.; Jackson, S. P.; Loh Jr., V. M.; Cockcroft, X. F.; Matthews, I. T. W.; Menear, K. A.; Kerrigan, F.; Ashworth, A.; UK. 2004. (WO 2004080976 A1)

${ }^{360}$ Menear, K. A.; Adcock, C.; Boulter, R.; Cockcroft, X. L.; Copsey, L.; Cranston, A.; Dillon, K. J.; Drzewiecki, J.; Garman, S.; Gomez, S.; Javaid, H.; Kerrigan, F.; Knights, C.; Lau, A.; Loh, V. M. Jr.; Matthews, I. T.; Moore, S.; O'Connor, M. J.; Smith, G. C.; Martin, N. M. 4-[3-(4cyclopropanecarbonylpiperazine-1-carbonyl)-4-fluorobenzyl]-2H-phthalazin-1-one: a novel bioavailable inhibitor of poly(ADP-ribose) polymerase-1. Journal of Medicinal Chemistry 2008, 51, 6581. [CrossRef] [PubMed]

${ }^{361}$ Weston, V. J.; Oldreive, C. E.; Skowronska, A.; Oscier, D. G.; Pratt, G.; Dyer, M. J.; Smith, G.; Powell, J. E.; Rudzki, Z.; Kearns, P.; Moss, P. A.; Taylor, A. M.; Stankovic, T. The PARP inhibitor olaparib induces significant killing of ATM-deficient lymphoid tumor cells in vitro and in vivo. Blood 2010, 116, 4578. [CrossRef] [PubMed] 
${ }^{362}$ Senra, J. M.; Telfer, B. A.; Cherry, K. E.; McCrudden, C. M.; Hirst, D. G.; O'Connor, M. J.; Wedge, S. R.; Stratford, I. J. Inhibition of PARP-1 by olaparib (AZD2281) increases the radiosensitivity of a lung tumor xenograft. Molecular Cancer Therapeutics 2011, 10, 1949. [CrossRef] [PubMed]

363 Biovision website - safety data sheet for Olaparib: Available at: <http://www.biovision.com/olaparib-4979.html>. Accessed in: August 21 2016.

${ }^{364}$ Clinical Trials.gov's website - A service of the U.S. National Institutes of Health. Available at: $<$ https://clinicaltrials.gov/ct2/show/NCT02476968?term=Olaparib\&phase=3\&rank=1 $>$.

Accessed in: August $20^{\text {th }} 2016$.

${ }^{365}$ Charles, W. P.; Barrie, E.; David, S. L. inhibitors of two enzymes which metabolize cytokinins. Phytochemistry, 1986, 25, 303. [CrossRef] [PubMed]

${ }^{366}$ Veselý, J.; Havlicek, L.; Strnad, M.; Blow, J. J.; Donella-Deana, A.; Pinna, L.; Letham, D. S.; Kato, J.; Detivaud, L.; Leclerc, S. Inhibition of cyclin-dependent kinases by purine analogues. European Journal of Biochemistry 1994, 224, 771. [PubMed]

${ }^{367}$ Abraham, R. T.; Acquarone, M.; Andersen, A.; Asensi, A.; Bellé, R.; Berger, F.; Bergounioux, C.; Brunn, G.; Buquet-Fagot, C.; Fagot, D.; Glab, N.; Goudeau, H.; Goudeau, M.; Guerrier, P.; Houghton, P.; Hendriks, H.; Kloareg, B.; Lippai, M.; Marie, D.; Maro, B.; Meijer, L.; Mester, J.; Mulner-Lorillon, O.; Poulet, S. A.; Schierenberg, E.; Schutte, B.; Vaulot, D.; Verlhac, M. H. Cellular effects of olomoucine, an inhibitor of cyclin-dependent kinases. Biology of the Cell 1995, 83, 105. [CrossRef] [PubMed]

${ }^{368}$ Wandl, S.; Wesierska-Gadek, J.; Is olomoucine, a weak CDK2 inhibitor, able to induce apoptosis in cancer cells?. Annual New York Academy Science 2009, 1171, 242. [CrossRef] [PubMed]

369 Sigma-Aldrich website - Safety Data Sheet of Olomoucine. Available at: $<$ http://www.sigmaaldrich.com/catalog/product/sigma/o0886?lang=pt\&region=BR\&gclid=CJfE 9Muy-84CFVUJkQod3DoECw>. Accessed in: August $29^{\text {st }} 2016$.

${ }^{370}$ Clinical Trials.gov's website - A service of the U.S. National Institutes of Health. Available at: $<$ https://clinicaltrials.gov/ct2/results?term=OLOMOUCINE\&Search=Search>. Accessed in: September $18^{\text {th }} 2016$.

${ }^{371}$ Krystof, V.; Lenobel, R.; Havlícek, L.; Kuzma, M.; Strnad, M. Synthesis and biological activity of olomoucine II. Bioorganic \& Medicinal Chemistry Letters 2002, 12, 3283. [CrossRef] [PubMed]

${ }^{372}$ Krystof, V.; McNael, Walkinshaw, M. D.; Fischer, P. M.; Müller, P.; Vojtesek, B.; Orság, M.; Havlícek, L.; Strnad, M. Antiproliferative activity of olomoucine II, a novel 2,6,9-trisubstituted purine cyclin-dependent kinase inhibitor. Cellular and Molecular Life Sciences 2005, 62, 1763. [CrossRef] [PubMed]

373 Abcam website. Available at: <http://www.abcam.com/olomoucine-ii-ab141238.html>. Accessed in: August $20^{\text {th }} 2016$.

${ }^{374}$ Clinical Trials.gov's website - A service of the U.S. National Institutes of Health. Available at: $<$ https://clinicaltrials.gov/ct2/results?term=OLOMOUCINE+II\&Search=Search>. Accessed in: September $18^{\text {th }} 2016$. 
${ }^{375}$ Boloor, A.; Cheung, M.; Davis, R.; Harris, P. A.; Hinkle, K.; Mook, R. A.; Stafford, J. A.; Veal, J. M.; 2002. (WO 2002059110 A1)

${ }^{376}$ Podar, K.; Tonon, G.; Sattler, M.; Tai, Y. T.; Legouill, S.; Yasui, H.; Ishitsuka, K.; Kumar, S.; Kumar, R.; Pandite, L. N.; Hideshima, T.; Chauhan, D.; Anderson, K. C. The small-molecule VEGF receptor inhibitor pazopanib (GW786034B) targets both tumor and endothelial cells in multiple myeloma. Proceedings of the National Academy of Sciences of the United States of America 2006, 103, 19478. [CrossRef] [PubMed]

377 Biovision website - safety data sheet for Tandutinib: Available at: $<$ http://www.biovision.com/gw-786034-4886.html>. Accessed in: August 21 2016.

${ }^{378}$ Clinical Trials.gov's website - A service of the U.S. National Institutes of Health. Available at: $<$ https://clinicaltrials.gov/ct2/show/NCT01205230?term=Pazopanib\&phase=3\&rank=1 >

Accessed in: August $20^{\text {th }} 2016$.

379 Eck, S. L.; Fry, D. W.; Leopold, J.; USA. 2005. (US 20050222163 A1)

${ }^{380}$ Fry, D. W.; Harvey, P. J.; Keller, P. R.; Elliott, W. L.; Meade, M.; Trachet, E.; Albassam, M.; Zheng, X.; Leopold, W. R.; Pryer, N. K.; Toogood, P. L. Specific inhibition of cyclin-dependent kinase $4 / 6$ by PD 0332991 and associated antitumor activity in human tumor xenografts. Molecular Cancer Therapeutics 2004, 3, 1427. [PubMed]

${ }^{381}$ Toogood, P. L.; Harvey, P. J.; Repine, J. T.; Sheehan, D. J.; VanderWel, S. N.; Zhou, H.; Keller, P. R.; McNamara, D. J.; Sherry, D.; Zhu, T.; Brodfuehrer, J.; Choi, C.; Barvian, M. R.; Fry, D. W. Discovery of a potent and selective inhibitor of cyclin-dependent kinase 4/6. Journal of Medicinal Chemistry 2005, 48, 2388. [CrossRef] [PubMed]

382 Biovision website - safety data sheet for PD-0332991: Available at: $<$ http://www.biovision.com/pd-0332991-isethionate-10151.html $>$. Accessed in: August $21^{\text {st }}$ 2016.

${ }^{383}$ Clinical Trials.gov's website - A service of the U.S. National Institutes of Health. Available at: <https://clinicaltrials.gov/ct2/show/NCT02679755?term=PD-0332991\&phase=3\&rank=1>.

Accessed in: August $20^{\text {th }} 2016$.

${ }^{384}$ Torrance, C. J.; Jackson, P. E.; Montgomery, E.; kinzler, K. W.; Vogelstein, B.; Wissner, A.; Nunes, M.; Frost, P.; Discafani, C. M. Combinatorial chemoprevention of intestinal neoplasia. Nature Medicine 2000, 6, 1024. [CrossRef]

${ }^{385}$ Wissner, A.; Brawner, F. M. B.; Rabindran, S. K.; Nilakantan, R.; Greenberger, L. M.; Shen, R.; Wang, Y. F.; Tsou, H. R. Syntheses and EGFR and HER-2 kinase inhibitory activities of 4anilinoquinoline-3-carbonitriles: analogues of three important 4-anilinoquinazolines currently undergoing clinical evaluation as therapeutic antitumor agents. Bioorganic \& Medicinal Chemistry Letters 2002, 12, 2893. [PubMed]

${ }^{386}$ Clinical Trials.gov's website - A service of the U.S. National Institutes of Health. Available at: $<$ https://clinicaltrials.gov/ct2/results?term=Pelitinib\&type=\&rslt=\&recr=\&age $v=\& g n d r=\& c o n$ $\mathrm{d}=$ =ancer\&intr $=\&$ titles $=\&$ outc $=\&$ spons $=\&$ lead $=\& i d=\&$ state $1=\&$ cntry $1=\&$ state $2=\&$ cntry $2=\&$ stat e3=\&cntry3=\&locn=\&rcv s=\&rcv e=\&lup s=\&lup e=>. Accessed in: February $4^{\text {th }} 2017$.

387 CaymanChem website. Available at: <https://www.caymanchem.com/product/15627>. Accessed in: August $20^{\text {th }} 2016$. 
${ }^{388}$ Clinical Trials.gov's website - A service of the U.S. National Institutes of Health. Available at: <https://clinicaltrials.gov/ct2/show/NCT00067548?term=Pelitinib\&phase=1\&rank=1>. Accessed in: August $20^{\text {th }} 2016$.

${ }^{389}$ Noessner, G.; Kutscher, B.; Engel, J.; Schumacher, W.; Stekar, J.; Hilgard, P. Preparation of new phospholipid derivatives (phosphates containing heterocycle moieties) as drugs. DE 4222910 A1, 1994, Jan 13.

${ }^{390}$ Clinical Trials.gov's website - A service of the U.S. National Institutes of Health. Available at: $<$ https://clinicaltrials.gov/ct2/results?term=Perifosine\&type=\&rslt=\&recr=\&age v=\&gndr=\&co nd=Cancer\&intr=\&titles=\&outc=\&spons=\&lead=\&id=\&state1=\&cntry1=\&state2=\&cntry2=\&sta te3=\&cntry3=\&locn=\&rcv s=\&rcv e=\&lup s=\&lup e=>. Accessed in: February $4^{\text {th }} 2017$.

${ }^{391}$ Hilgard, P.; Klenner, T.; Stekar, J.; Nössner, G.; Kutscher, B.; Engel, J. D-21266, a new heterocyclic alkylphospholipid with antitumour activity. European Journal of Cancer 1997, 33, 442. [PubMed]

${ }^{392}$ Kondapaka, S. B.; Singh, S. S.; Dasmahapatra, G. P.; Sausville, E. A.; Roy, K. K. Perifosine, a novel alkylphospholipid, inhibits protein kinase B activation. Molecular Cancer Therapeutics 2003, 2, 1093. [PubMed]

393 Biovision website - safety data sheet for Perifosine: Available at: $<$ http://www.biovision.com/perifosine-krx-0401-303.html>. Accessed in: August $21^{\text {st }} 2016$.

${ }^{394}$ Clinical Trials.gov's website - A service of the U.S. National Institutes of Health. Available at: $<$ https://clinicaltrials.gov/ct2/show/NCT01097018?term=Perifosine\&phase=2\&rank=2>.

Accessed in: August $20^{\text {th }} 2016$.

395 Fancelli, D.; Berta, D.; Bindi, S. Potent and selective aurora inhibitors identified by the expansion of a novel scaffold for protein kinase inhibition. Journal of Medicinal Chemistry 2005, 48, 3080. [CrossRef] [PubMed]

396 Soncini, C.; Carpinelli, P.; Gianellini, L.; Fancelli, D.; Vianello, P.; Rusconi, L.; Storici, P.; Zugnoni, P.; Pesenti, E.; Croci, V.; Ceruti, R.; Giorgini, M. L.; Cappella, P.; Ballinari, D.; Sola, F.; Varasi, M.; Bravo, R.; Moll, J. PHA-680632, a novel Aurora kinase inhibitor with potent antitumoral activity. Clinical Cancer Research 2006, 12, 4080. [CrossRef] [PubMed]

${ }^{397}$ Selleckchem.com - Inhibitor Expert (Inhibitors, Compound Libraries) website - Safety Data Sheet for PHA-680632. Available at: <http://www.selleckchem.com/msds/MSDS S1454.pdf>. Accessed in: August $28^{\text {th }} 2016$.

${ }^{398}$ Clinical Trials.gov's website - A service of the U.S. National Institutes of Health. Available at: $<$ https://clinicaltrials.gov/ct2/results?term=PHA-680632\&Search=Search>. Accessed in: September $18^{\text {th }} 2016$.

399 Chuckowree, I.; Folkes, A.; Hancox, T.; Shuttleworth, S.; 2007. (WO 2007129161 A2)

${ }^{400}$ Folkes, A. J.; Ahmadi, K.; Alderton, W. K.; Alix, S.; Baker, S. J.; Box, G.; Chuckowree, I. S.; Clarke, P. A.; Depledge, P.; Eccles, S. A.; Friedman, L. S.; Hayes, A.; Hancox, T. C.; Kugendradas, A.; Lensun, L.; Moore, P.; Olivero, A. G.; Pang, J.; Patel, S.; Pergl-Wilson, G. H.; Raynaud, F. I.; Robson, A.; Saghir, N.; Salphati, L.; Sohal, S.; Ultsch, M. H.; Valenti, M.; Wallweber, H. J.; Wan, N. C.; Wiesmann, C.; Workman, P.; Zhyvoloup, A.; Zvelebil, M. J.; Shuttleworth, S. J. The identification of 2-(1H-indazol-4-yl)-6-(4-methanesulfonyl-piperazin-1-ylmethyl)-4-morpholin4-yl-thieno[3,2-d]pyrimidine (GDC-0941) as a potent, selective, orally bioavailable inhibitor of 
class I PI3 kinase for the treatment of cancer. Journal of Medicinal Chemistry 2008, 51, 5522. [CrossRef] [PubMed]

${ }^{401}$ Clinical Trials.gov's website - A service of the U.S. National Institutes of Health. Available at: $<$ https://clinicaltrials.gov/ct2/results?term=Pictilisib\&type=\&rslt=\&recr=\&age $v=\& g n d r=\& c o n$ $\mathrm{d}=$ Cancer\&intr $=\&$ titles $=$ \&outc $=\&$ spons $=\&$ lead $=\& \mathrm{id}=\&$ state $1=\&$ cntry $1=\&$ state $2=\&$ cntry $2=\&$ stat e3=\&cntry3=\&locn=\&rcv s=\&rcv e=\&lup s=\&lup e=>. Accessed in: February $4^{\text {th }} 2017$.

${ }^{402}$ Abcam website. Available at: <http://www.abcam.com/gdc-0941-pictilisib-ab141352.html>. Accessed in: August $20^{\text {th }} 2016$.

${ }^{403}$ Clinical Trials.gov's website - A service of the U.S. National Institutes of Health. Available at: $<$ https://clinicaltrials.gov/ct2/show/NCT01437566?term=Pictilisib\&phase=1\&rank=1>.

Accessed in: August $20^{\text {th }} 2016$.

404 Gray, N. S.; Wodicka, L.; Thunnissen, A. W. H.; Norman, T. C.; Kwon, S.; Espinoza, F. H.; Morgan, D. O.; Barnes, C.; LeClerc, S.; Meijer, L.; Kim, S.; Lockhart, D. J.; Schultz, P. C. Exploiting Chemical Libraries, Structure, and Genomics in the Search for Kinase Inhibitors. Science 1998, 281, 533. [CrossRef] [PubMed]

${ }^{405}$ Villerbu, N.; Gaben, A. M.; Redeuilh, G.; Mester, J. Cellular effects of purvalanol A: a specific inhibitor of cyclin-dependent kinase activities. International Journal of Cancer 2002, 97, 761. [CrossRef] [PubMed]

${ }^{406}$ Lclabs website. Available at: $\langle$ http://www.lclabs.com/products/433/sds $>$. Accessed in: August $20^{\text {th }} 2016$.

${ }^{407}$ Clinical Trials.gov's website - A service of the U.S. National Institutes of Health. Available at: $<$ https://clinicaltrials.gov/ct2/results?term=PURVALANOL+A\&Search=Search>. Accessed in: September $18^{\text {th }} 2016$.

${ }^{408} \mathrm{Ma}, \mathrm{R} . ;$ Fontaine, T. D. In vitro antibiotic activity of crystalline tomatine toward Candida albicans; antagonistic effect of rutin and quercetin. Archives of Biochemistry 1948, 16, 399. [PubMed]

409 Kelly, G. S. Quercetin. Monograph. Alternative Medicine Review: a Journal of Clinical Therapeutic 2011, 16, 172. [PubMed]

${ }^{410}$ Clinical Trials.gov's website - A service of the U.S. National Institutes of Health. Available at: $<$ https://clinicaltrials.gov/ct2/results?term=Quercetin\&type=\&rslt=\&recr=\&age $v=\& g n d r=\& c 0$ nd=Cancer\&intr=\&titles=\&outc=\&spons=\&lead=\&id=\&state1=\&cntry1=\&state2=\&cntry2=\&sta te $3=\&$ cntry3=\&locn=\&rcv s=\&rcv e=\&lup s=\&lup e=>. Accessed in: February $4^{\text {th }} 2017$.

411 Biovision website - safety data sheet for Quercetin: Available at: <http://www.biovision.com/quercetin-dihydrate-4193.html>. Accessed in: August $21^{\text {st }} 2016$.

${ }^{412}$ Clinical Trials.gov's website - A service of the U.S. National Institutes of Health. Available at: $<$ https://clinicaltrials.gov/ct2/show/NCT00913081?term=Quercetin\&phase=3\&rank=1>. Accessed in: August $20^{\text {th }} 2016$.

${ }^{413}$ Vezina, C.; Kudelski, A.; SehgaL, S. N. Rapamycin, a new antifungal antibiotic. The Journal of Antibiotics 1975, 28, 721. [PubMed]

${ }^{414}$ Schenone, S.; Brullo, C.; Musumeci, F.; Radi, M.; Botta, M. ATP-competitive inhibitors of mTOR: an update. Current Medicinal Chemistry 2011, 18, 2995. [CrossRef] [PubMed]

${ }^{415}$ Clinical Trials.gov's website - A service of the U.S. National Institutes of Health. Available at: $<$ https://clinicaltrials.gov/ct2/results?term=Rapamycin\&type=\&rslt=\&recr=\&age $v=\& g n d r=\& c$ ond=Cancer\&intr $=\&$ titles $=\&$ outc $=\&$ spons $=\& l e a d=\& i d=\&$ state $1=\&$ cntry $1=\&$ state $2=\&$ cntry $2=\&$ st 
ate $3=\& c n t r y 3=\& l o c n=\&$ phase $=3 \& r c v \quad s=\& r c v$ e=\&lup $s=\& l u p ~ e=>$. Accessed in: February $4^{\text {th }}$ 2017.

416 Biovision website - safety data sheet for Rapamycin. Available at: $<$ http://www.biovision.com/rapamycin-262.html $>$. Accessed in: August $21^{\text {st }} 2016$.

${ }^{417}$ Clinical Trials.gov's website - A service of the U.S. National Institutes of Health. Available at: <https://clinicaltrials.gov/ct2/show/NCT01046045?term=Rapamycin\&phase=3\&rank=1>.

Accessed in: August $20^{\text {th }} 2016$.

${ }^{418}$ Wilhelm, S.; Dumas, J.; Ladouceur, G.; Lynch, M.; Scott, W. J.; 2004. (WO 2004113274 A2)

${ }^{419}$ Wilhelm, S. M.; Dumas, J.; Adnane, L.; Lynch, M.; Carter, C. A.; Schütz, G.; Thierauch, K. H.; Zopf, D. Regorafenib (BAY 73-4506): a new oral multikinase inhibitor of angiogenic, stromal and oncogenic receptor tyrosine kinases with potent preclinical antitumor activity. International Journal of Cancer 2011, 129, 245. [CrossRef] [PubMed]

${ }^{420}$ Clinical Trials.gov's website - A service of the U.S. National Institutes of Health. Available at: $<$ https://clinicaltrials.gov/ct2/results?term=Regorafenib\&type=\&rslt=\&recr=\&age $v=\& g n d r=\&$ cond=Cancer\&intr $=\&$ titles $=\&$ outc $=\&$ spons $=\&$ lead $=\& i d=\&$ state $1=\&$ cntry $1=\&$ state $2=\&$ cntry $2=\& \mathrm{~s}$ tate3=\&cntry3=\&locn=\&phase=1\&phase=2\&phase=3\&rcv s=\&rcv e=\&lup s=\&lup e=>. Accessed in: February $4^{\text {th }} 2017$.

${ }^{421}$ Biovision website - safety data sheet for Regorafenib. Available at: $<$ http://www.biovision.com/regorafenib-9860.html>. Accessed in: August 21 2016.

${ }^{422}$ Clinical Trials.gov's website - A service of the U.S. National Institutes of Health. Available at: $<$ https://clinicaltrials.gov/ct2/show/NCT02287025?term=Regorafenib\&phase=3\&rank=3>.

Accessed in: August $20^{\text {th }} 2016$.

${ }^{423}$ Planchais, S.; Glab, N.; Trehin, C.; Perennes, C.; Bureau, J.; Meijer, L.; Bergounioux, C. Roscovitine, a novel cyclin-dependent kinase inhibitor, characterizes restriction point and G2/M transition in tobacco BY-2 cell suspension. The Plant Journal 1997, 12, 191. [CrossRef] [PubMed]

${ }^{424}$ Havlícek, L.; Hanus, J.; Veselý, J.; Leclerc, S.; Meijer, L.; Shaw, G.; Strnad, M. Cytokininderived cyclin-dependent kinase inhibitors: synthesis and cdc2 inhibitory activity of olomoucine and related compounds. Journal of Medicinal Chemistry 1997, 40, 408. [CrossRef] [PubMed]

${ }^{425}$ ChemBlink's website - Online Database of Chemicals from Around the World, Available at: <http://www.chemblink.com/MSDS/MSDSFiles/186692-44-4 Clear\%20Synth.pdf>. Accessed in: August $20^{\text {th }} 2016$.

${ }^{426}$ Chemexpress website. Available at: < http://chemexpress.cn/186692-44-4.htm>. Accessed in: August $20^{\text {th }} 2016$.

${ }^{427}$ Clinical Trials.gov's website - A service of the U.S. National Institutes of Health. Available at: https://clinicaltrials.gov/ct2/show/NCT02160730?term=ROSCOVITINE\&phase=1\&rank=2>.

Accessed in: September $18^{\text {th }} 2016$.

428 Sigma-Aldrich website - Safety Data Sheet of $(R)$-Roscovitine. Available at: $<$ http://www.sigmaaldrich.com/catalog/product/sigma/r7772?lang=pt\&region=BR $>$. Accessed in: August $29^{\text {st }} 2016$. 
${ }^{429}$ Clinical Trials.gov's website - A service of the U.S. National Institutes of Health. Available at: $<$ https://clinicaltrials.gov/ct2/show/NCT02160730?term=\%28R\%29-

roscovitine\&phase $=1 \&$ rank $=1>$. Accessed in: August $20^{\text {th }} 2016$.

${ }^{430}$ Wang, S.; McClue, S. J.; Ferguson, J. R.; Hull, J. D.; Stokes, S.; Parsons, S.; Westwooda, R.; Fischera, P. M. Synthesis and configuration of the cyclin-dependent kinase inhibitor roscovitine and its enantiomer. Tetrahedron: Asymmetry 2001, 12, 2891. [CrossRef]

431 Adipogen website. Available at: <http://www.adipogen.com/mr-c0002/-sroscovitine.html>. Accessed in: August $20^{\text {th }} 2016$.

${ }^{432}$ Clinical Trials.gov's website - A service of the U.S. National Institutes of Health. Available at: $<$ https://clinicaltrials.gov/ct2/show/NCT00372073?term=\%28S\%29-

roscovitine\&phase $=1 \&$ rank $=1>$. Accessed in: August $20^{\text {th }} 2016$.

${ }^{433}$ DePinto, W.; Chu, X.; Yin, X.; Smith, M.; Packman, K.; Goelzer, P.; Lovey, A.; Chen, A.; Qian, H.; Hamid, R.; Xiang, Q.; Tovar, C.; Blain, R.; Nevins, T.; Higgins, B.; Luistro, L.; Kolinsky, K.; Felix, B.; Hussain, S.; Heimbrook, D. In vitro and in vivo activity of R547: a potent and selective cyclin-dependent kinase inhibitor currently in phase I clinical trials. Molecular Cancer Therapeutics 2006, 5, 2644. [CrossRef] [PubMed]

434 Apexbt website. Available at: $<$ http://www.apexbt.com/downloader/document/A8642/MSDS.pdf $>$. Accessed in: August $20^{\text {th }}$ 2016.

${ }^{435}$ Clinical Trials.gov's website - A service of the U.S. National Institutes of Health. Available at: $<$ https://clinicaltrials.gov/ct2/show/NCT00400296?term=R547\&phase=0\&rank=1>. Accessed in: August $20^{\text {th }} 2016$.

${ }^{436}$ Caligiuri, M.; Bockovich, N.; Oalmann, C.; Kaplan, F.; Lamphere, L.; Wang, S.; Kluge, A.; Kley, N. Induction of tumor regression by the broad-spectrum cyclin dependent kinase inhibitor, RGB-286638. Proceedings of the American Association for Cancer Research 2006, 47, 3205.

${ }^{437}$ de Bruijn, P.; Moghaddam-Helmantel, I. M.; de Jonge, M. J.; Meyer, T.; Lam, M. H.; Verweij, J.; Wiemer, E. A.; Loos, W. J. Validated bioanalytical method for the quantification of RGB286638, a novel multi-targeted protein kinase inhibitor, in human plasma and urine by liquid chromatography/tandem triple-quadrupole mass spectrometry. Journal of Pharmaceutical and Biomedical Analysis 2009, 50, 977. [CrossRef] [PubMed]

438 Biovision website - safety data sheet for RGB-286638. Available at: <http://www.biovision.com/rgb-286638-free-base-9838.html >. Accessed in: August $21^{\text {st }} 2016$. ${ }^{439}$ Clinical Trials.gov's website - A service of the U.S. National Institutes of Health. Available at: $<$ https://clinicaltrials.gov/ct2/show/NCT01168882?term=RGB-286638\&phase=0\&rank=1>. Accessed in: August $20^{\text {th }} 2016$.

${ }^{440}$ Rodgers, J. D.; Shepard, S.; Maduskuie, T. P.; Wang, H.; Falahatpisheh, N.; Rafalski, M.; Arvanitis, A. G.; Storace, L.; Jalluri, R. K.; Fridman, J. S.; Vaddi, K.; USA 2007. (US 20070135461

A1)

${ }^{441}$ Lin, Q.; Meloni, D.; Pan, Y.; Xia, M.; Rodgers, J.; Shepard, S.; Li, M.; Galya, L.; Metcalf, B.; Yue, T. Y.; Liu, P.; Zho, J. Enantioselective synthesis of Janus kinase inhibitor INCB018424 via an organocatalytic aza-Michael reaction. Organic Letters 2009, 11, 1999. [CrossRef] [PubMed]

442 Biovision website - safety data sheet for Ruxolitinib. Available at: <http://www.biovision.com/ruxolitinib-free-base-5731.html $>$. Accessed in: August $21^{\text {st }} 2016$. 
${ }^{443}$ Clinical Trials.gov's website - A service of the U.S. National Institutes of Health. Available at: $<$ https://clinicaltrials.gov/ct2/show/NCT01558739?term=Ruxolitinib\&phase=3\&rank=2>.

Accessed in: August $20^{\text {th }} 2016$.

${ }^{444}$ Hennequin, L. F. A.; Ple, P.; 2001. (WO 2001094341 A1)

${ }^{445}$ Hennequin LF1, Allen J, Breed J, Curwen J, Fennell M, Green TP, Lambert-van der Brempt C, Morgentin R, Norman RA, Olivier A, Otterbein L, Plé PA, Warin N, Costello G. N-(5-chloro-1,3benzodioxol-4-yl)-7-[2-(4-methylpiperazin-1-yl)ethoxy]-5-(tetrahydro-2 $\mathrm{H}$-pyran-4-

yloxy)quinazolin-4-amine, a novel, highly selective, orally available, dual-specific c-Src/Abl kinase inhibitor. Journal of Medicinal Chemistry 2006, 49, 6465. [CrossRef] [PubMed]

${ }^{446}$ Clinical Trials.gov's website - A service of the U.S. National Institutes of Health. Available at: $<$ https://clinicaltrials.gov/ct2/results?term=Saracatinib\&type=\&rslt=\&recr=\&age $v=\& g n d r=\& c$ ond=Cancer\&intr=\&titles=\&outc=\&spons=\&lead=\&id=\&state $1=\&$ cntry $1=\&$ state $2=\& \mathrm{cntry} 2=\&$ st ate3=\&cntry3=\&locn=\&rcv s=\&rcv e=\&lup s=\&lup e=>. Accessed in: February $4^{\text {th }} 2017$.

447 Biovision website - safety data sheet for Saracatinib. Available at: $<$ http://www.biovision.com/saracatinib-azd0530-283.html $>$. Accessed in: August $21^{\text {st }} 2016$.

${ }^{448}$ Clinical Trials.gov's website - A service of the U.S. National Institutes of Health. Available at: <https://clinicaltrials.gov/ct2/show/NCT01196741?term=Saracatinib\&phase=2\&rank=1>.

Accessed in: August $20^{\text {th }} 2016$.

${ }^{449}$ Adams, J. L.; Gallagher, T. F.; Lee, J. C.; White, J. R.; USA. 1993. (WO 9314081 A1)

${ }^{450}$ Wilson KP1, McCaffrey PG, Hsiao K, Pazhanisamy S, Galullo V, Bemis GW, Fitzgibbon MJ, Caron PR, Murcko MA, Su MS. The structural basis for the specificity of pyridinylimidazole inhibitors of p38 MAP kinase. Chemistry \& Biology 1997, 4, 423. [PubMed]

${ }^{451}$ Menon, M. B.; Kotlyarov, A.; Gaestel, M. SB202190-Induced Cell Type-Specific Vacuole Formation and Defective Autophagy Do Not Depend on p38 MAP Kinase Inhibition. Plos One 2011, 6, 23054. [CrossRef] [PubMed]

452 Biovision website - safety data sheet for SB202190. Available at: $<$ http://www.biovision.com/sb-202190-8026.html $>$. Accessed in: August 21 2016.

${ }^{453}$ Clinical Trials.gov's website - A service of the U.S. National Institutes of Health. Available at: https://clinicaltrials.gov/ct2/results?term=SB202190\&Search=Search>. Accessed in: September $18^{\text {th }} 2016$.

${ }^{454}$ Lee, J. C.; Kassis, S.; Kumar, S.; Badger, A.; Adams, J. L. p38 mitogen-activated protein kinase inhibitors-mechanisms and therapeutic potentials. Pharmacology \& Therapeutics 1999, 82, 389. [PubMed]

${ }^{455}$ Ding, W.; Jiang, Y.; Jiang, Y.; Zhu, T.; Xu, Y.; Jiang, W.; Zhu, W.; Tang, Z.; Ge, Z.; Ma, T.; Tan, Y. Role of SB203580 in the regulation of human esophageal cancer cells under the effection of Diosgenin. International Journal of Clinical and Experimental Medicine 2015, 8, 2476. [PubMed]

456 Biovision website - safety data sheet for SB203580. Available at: <http://www.biovision.com/sb-203580-3901.html>. Accessed in: August 21 2016.

${ }^{457}$ Clinical Trials.gov's website - A service of the U.S. National Institutes of Health. Available at: $<$ https://clinicaltrials.gov/ct2/results?term=SB203580\&Search=Search>. Accessed in: September $18^{\text {th }} 2016$.

458 Guzi, T. J.; Paruch, K.; Dwyer, M. P.; Labroli, M.; Keertikar, K. M. Preparation of pyrazolopyrimidines as cyclin-dependent kinase inhibitors. US 20060128725 A1 Jun 15, 2006. 
${ }^{459}$ Guzi, T. J.; Paruch, K.; Dwyer, M. P.; Labroli, M.; Shanahan, F.; Davis, N.; Taricani, L.; Wiswell, D.; Seghezzi, W.; Penaflor, E.; Bhagwat, B.; Wang, W.; Gu, D.; Hsieh, Y.; Lee, S.; Liu, M.; Parry, D. Targeting the replication checkpoint using $\mathrm{SCH}$ 900776, a potent and functionally selective CHK1 inhibitor identified via high content screening. Molecular cancer Therapeutics 2011, 10, 591. [CrossRef] [PubMed]

${ }^{460}$ Scbt website. Available at: $<$ http://www.scbt.com/datasheet-364611-CASNumber-89149463-6.html >. Accessed in: August $21^{\text {st }} 2016$.

${ }^{461}$ Clinical Trials.gov's website - A service of the U.S. National Institutes of Health. Available at: <https://clinicaltrials.gov/ct2/show/NCT01870596?term=SCH900776\&phase=1\&rank=1>. Accessed in: August $20^{\text {th }} 2016$.

${ }^{462}$ Array. Available at: $<$ http://investor.arraybiopharma.com/phoenix.zhtml?c=123810\&p=irolnewsArticle\&ID=1702337>. Accessed in: August $21^{\text {st }} 2016$.

${ }^{463}$ Huynh, H.; Soo, K. C.; Chow, P. K.; Tran, E. Targeted inhibition of the extracellular signalregulated kinase kinase pathway with AZD6244 (ARRY-142886) in the treatment of hepatocellular carcinoma. Molecular Cancer Therapeutics 2007, 6, 138. [CrossRef] [PubMed] ${ }^{464}$ Clinical Trials.gov's website - A service of the U.S. National Institutes of Health. Available at: $<$ https://clinicaltrials.gov/ct2/results?term=Selumetinib\&type $=$ \&slt=\&recr=\&age $v=\& g n d r=\&$ cond=Cancer\&intr $=\&$ titles $=$ \&outc $=\&$ spons $=\&$ lead $=\& i d=\&$ state $1=\&$ cntry $1=\&$ state $2=\&$ cntry $2=\& \mathrm{~s}$ tate3=\&cntry3=\&locn=\&rcv s=\&rcv e=\&lup s=\&lup e $=>$. Accessed in: February $4^{\text {th }} 2017$. 465 Biovision website - safety data sheet for Selumitinib. Available at: <http://www.biovision.com/azd6244-6172.html>. Accessed in: August $21^{\text {st }} 2016$.

${ }^{466}$ Clinical Trials.gov's website - A service of the U.S. National Institutes of Health. Available at:

$<$ https://clinicaltrials.gov/ct2/results?term=Selumetinib\&recr=\&type=\&rslt=\&age v=\&gndr=\& cond=\&intr=\&titles=\&outc=\&spons=\&lead=\&id=\&state $1=\&$ cntry1 $=$ \&state $2=\&$ cntry2=\&state $3=$ \&cntry3=\&locn=\&phase=2\&rcv s=\&rcv e=\&lup s=\&lup e $>$. Accessed in: August $20^{\text {th }} 2016$.

467 Sunesis website. Available at: <http://ir.sunesis.com/phoenix.zhtml?c=194116\&p=irolnewsArticle\&ID=1507052>. Accessed in: August $20^{\text {th }} 2016$.

${ }^{468}$ Misra, R. N.; Xiao, H. Y.; Kim, K. S.; Lu, S.; Han, W. C.; Barbosa, S. A.; Hunt, J. T.; Rawlins, D. B.; Shan, W.; Ahmed, S. Z.; Qian, L.; Chen, B. C.; Zhao, R.; Bednarz, M. S.; Kellar, K. A.; Mulheron, J. G.; Batorsky, R.; Roongta, U.; Kamath, A.; Marathe, P.; Ranadive, S. A.; Sack, J. S.; Tokarski, J. S.; Pavletich, N. P.; Lee, F. Y.; Webster, K. R.; Kimball, S. D. N-(cycloalkylamino)acyl2-aminothiazole inhibitors of cyclin-dependent kinase 2. N-[5-[[[5-(1,1-dimethylethyl)-2oxazolyl]methyl]thio]-2-thiazolyl]-4-piperidinecarboxamide (BMS-387032), a highly efficacious and selective antitumor agent. Journal of Medicinal Chemistry 2004, 47, 1719. [CrossRef] [PubMed]

${ }^{469}$ Clinical Trials.gov's website - A service of the U.S. National Institutes of Health. Available at: $<$ https://clinicaltrials.gov/ct2/results?term=SNS+\%E2\%80\%93+032\&type=\&rslt=\&recr=\&age v $=\& g n d r=\&$ cond=Cancer\&intr $=\&$ titles $=$ \&outc $=\&$ spons $=\& l e a d=\& i d=\&$ state $1=\&$ cntry $1=\&$ state $2=\&$ cntry2=\&state3=\&cntry3=\&locn=\&rcv s=\&rcv e=\&lup s=\&lup e=>. Accessed in: February $4^{\text {th }}$ 2017.

470 Biovision website - safety data sheet for _SNS-032. Available at: <http://www.biovision.com/sns-032-10189.html>. Accessed in: August 21 2016. 
${ }^{471}$ Clinical Trials.gov's website - A service of the U.S. National Institutes of Health. Available at: $<$ https://clinicaltrials.gov/ct2/show/NCT00977652?term=SNS+032\&phase=1\&rank=1>.

Accessed in: August $20^{\text {th }} 2016$.

${ }^{472}$ Riedl, B.; Dumas, J. S.; Khire, U.; Lowinger, Timothy. B.; Scott, W. J.; Smith, R. A.; Wood, J. E.; Monahan, M.; Natero, R.; Renick, J.; Sibley, R. N.; 2000. (WO 2000042012 A1)

${ }^{473}$ Wilhelm, S. M.; Carter, C.; Tang, L.; Wilkie, D.; McNabola, A.; Rong, H.; Chen, C.; Zhang, X.; Vincent, P.; McHugh, M.; Cao, Y.; Shujath, J.; Gawlak, S.; Eveleigh, D.; Rowley, B.; Liu, L.; Adnane, L.; Lynch, M, Auclair, D.; Taylor, I.; Gedrich, R.; Voznesensky, A.; Riedl, B.; Post, L. E.; Bollag, G.; Trail, P. A. BAY 43-9006 exhibits broad spectrum oral antitumor activity and targets the RAF/MEK/ERK pathway and receptor tyrosine kinases involved in tumor progression and angiogenesis. Cancer Research 2004, 7099. [CrossRef] [PubMed]

474 Biovision website - safety data sheet for Sorafenib. Available at: $<$ http://www.biovision.com/bay-43-9006-307.html>. Accessed in: August 21 2016.

${ }^{475}$ Clinical Trials.gov's website - A service of the U.S. National Institutes of Health. Available at: $<$ https://clinicaltrials.gov/ct2/show/NCT01203787?term=Sorafenib\&phase=3\&rank=1>.

Accessed in: August $20^{\text {th }} 2016$.

${ }^{476}$ Omura, S.; Iwai, Y.; Hirano, A.; Nakagawa, A.; Awaya, J.; Tsuchiya, H.; Takahashi, Y.; Masuma, R. A new alkaloid AM-2282 of Streptomyces origin taxonomy, fermentation, isolation and preliminary characterization. The Journal of Antibiotics 1977, 30, 275. [CrossRef] [PubMed] ${ }^{477}$ Tamaoki, T.; Nomoto, H.; Takahashi, I.; Kato, Y.; Morimoto, M.; Tomita, F. Staurosporine, a potent inhibitor of phospholipid/ $\mathrm{Ca}^{++}$dependent protein kinase. Biochemical and Biophysical Research Communications 1986, 135, 397. [CrossRef] [PubMed]

${ }^{478}$ Scbt website. Available at: <http://www.scbt.com/pt/datasheet-3510-staurosporine.html $>$. Accessed in: August $21^{\text {st }} 2016$.

${ }^{479}$ Clinical Trials.gov's website - A service of the U.S. National Institutes of Health. Available at: $<$ https://clinicaltrials.gov/ct2/show/NCT00651261?term=Staurosporine\&phase=2\&rank=1>. Accessed in: August $20^{\text {th }} 2016$.

${ }^{480}$ Mendel, D. B.; Cherrington, J. M.; Laird, A. D. CCR 20th Anniversary Commentary: Determining a Pharmacokinetic/Pharmacodynamic Relationship or Sunitinib - A Look Back. Clinical Cancer Research 2015, 21, 2415. [CrossRef] [PubMed]

${ }^{481}$ Sun, L.; Liang, C.; Shirazian, S.; Zhou, Y.; Miller, T.; Cui, J.; Fukuda, J. Y.; Chu, J. Y.; Nematalla, A.; Wang, X.; Chen, H.; Sistla, A.; Luu, T. C.; Tang, F.; Wei, J.; Tang, C. Discovery of 5-[5-fluoro-2oxo-1,2- dihydroindol-(3Z)-ylidenemethyl]-2,4-dimethyl-1H-pyrrole-3-carboxylic acid (2diethylaminoethyl)amide, a novel tyrosine kinase inhibitor targeting vascular endothelial and platelet-derived growth factor receptor tyrosine kinase. Journal of Medicinal Chemistry 2003, 46, 1116. [CrossRef] [PubMed]

${ }^{482}$ ChemBlink's website - Online Database of Chemicals from Around the World, Available at: $<$ http://www.chemblink.com/MSDS/MSDSFiles/341031-54-7 Sigma-Aldrich.pdf >. Accessed in: August $20^{\text {th }} 2016$.

${ }^{483}$ Clinical Trials.gov's website - A service of the U.S. National Institutes of Health. Available at: $<$ https://clinicaltrials.gov/ct2/show/NCT00793871?term=Sunitinib+malate\&phase=3\&rank=2>. Accessed in: August $20^{\text {th }} 2016$. 
${ }^{484}$ Yu, J. C.; Lokker, N. A.; Hollenbach, S.; Apatira, M.; Li, J.; Betz, A.; Sedlock, D.; Oda, S.; Nomoto, Y.; Matsuno, K.; Ide, S.-I.; Tsukuda, E.; Giese, N. A. Efficacy of the novel selective platelet-derived growth factor receptor antagonist CT52923 on cellular proliferation, migration, and suppression of neointima following vascular injury. The Journal of Pharmacology and Experimental Therapeutics 2001, 298, 1172. [PubMed]

${ }^{485}$ Kelly, L. M.; Yu, J.; Boulton, C. L.; Apatira, M.; Li, J.; Sullivan, C. M.; Williams, I.; Amaral, S. M.; Curley, D. P.; Duclos, N.; Neuberg, D.; Scarborough, R. M.; Pandey, A.; Hollenbach, S.; Abe, K.; Lokker, N. A.; Gilliland, D. G.; Giese, N. A. CT53518, a novel selective FLT3 antagonist for the treatment of acute myelogenous leukemia (AML). Cancer Cell 2002, 5, 421. [CrossRef] [PubMed]

${ }^{486}$ Pandey, A.; Volkots, D. L.; Seroogy, J. M.; Rose, J. W.; Yu, J.; Lambing, J. L.; Hutchaleelaha, A.; Hollenbach, S. J.; Abe, K.; Giese, N. A.; Scarborough, R. M. Identification of Orally Active, Potent, and Selective 4-Piperazinylquinazolines as Antagonists of the Platelet-Derived Growth Factor Receptor Tyrosine Kinase Family. Journal of Medicinal Chemistry 2002, 45, 3772. [CrossRef] [PubMed]

${ }^{487}$ Clinical Trials.gov's website - A service of the U.S. National Institutes of Health. Available at: $<$ https://clinicaltrials.gov/ct2/results?term=Tandutinib\&type $=\& r s \mid t=\& r e c r=\& a g e ~ v=\& g n d r=\& c$ ond=Cancer\&intr $=\&$ titles $=$ \&outc $=\&$ spons $=\&$ lead $=\& i d=\&$ state $1=\&$ cntry $1=\&$ state $2=\&$ cntry $2=\&$ st ate $=\&$ cntry3=\&locn=\&rcv s=\&rcv e=\&lup s=\&lup e=>. Accessed in: February $4^{\text {th }} 2017$.

${ }^{488}$ Clinical Trials.gov's website - A service of the U.S. National Institutes of Health. Available at: $<$ https://clinicaltrials.gov/ct2/results?term=Tandutinib\&Search=Search $>. \quad$ Accessed in: August $21^{\text {st }} 2016$.

489 Biovision website - safety data sheet for Tandutinib: Available at: $<$ http://www.biovision.com/manuals/2024 MSDS.pdf?osCsid=8630d23jht1vi8su7lbidnsp23 $>$. Accessed in: August $21^{\text {st }} 2016$.

490 Tinib-Tools website. Available at: <http://www.tinib-tools.com/products T.html\#T151>. Accessed in: August $20^{\text {th }} 2016$.

${ }^{491}$ Dumas, J.P.; Joe, T.K.; Kluender, H.C.E.; Lee, W.; Nagarathnam, D.; Sibley, R.N.; Su, N.; Boyer, S.J.; Dixon, J.A.; 2001. (WO 2001023375 A2)

${ }^{492}$ Steeghs, N.; Gelderblom, H.; Wessels, J.; Eskens, F. A. L. M.; Bont, N.; Nortier, J. W. R.; Guchelaar, H.-J. Pharmacogenetics of telatinib, a VEGFR-2 and VEGFR-3 tyrosine kinase inhibitor, used in patients with solid tumors. Investigational New Drugs 2011, 29, 137. [CrossRef] [PubMed]

${ }^{493}$ Clinical Trials.gov's website - A service of the U.S. National Institutes of Health. Available at: $<$ https://clinicaltrials.gov/ct2/show/NCT00952497?term=Telatinib\&rank=1 $>$. Accessed in: August $21^{\text {st }} 2016$.

494 Biovision website -- safety data sheet for Telatinib: Available at:<http://www.biovision.com/manuals/1774 MSDS.pdf?osCsid=18dcsbuc68je99nidiljiOuma5 $>$. Accessed in: August $21^{\text {st }} 2016$.

495 Dancey, J. E.; American Society of Clinical Oncology Educational Book; Perry, M. C., ed.; American Society Clinical Oncology: Alexandria, 2000, pp. 68-75.

${ }^{496}$ Podsypanina, K.; Lee, R. T.; Politis, C.; Hennessy, I.; Crane, A.; Puc, J.; Neshat, M.; Wang, H.; Yang, L.; Gibbons, J.; Frost, P.; Dreisbach, V.; Blenis, J.; Gaciongi, Z.; Fisher, P.; Sawyers, C.; Hedrick-Ellenson, L.; Parsons, R. An inhibitor of mTOR reduces neoplasia and normalizes p70/S6 kinase activity in Pten ${ }^{+/}$mice. Proceedings of the National Academy of Sciences of the United States of America 2001, 98, 10320. [CrossRef] [PubMed]

497 Stock, C.; Zaccagnini, M.; Schulze, M.; Teber, D.; Rassweiler, J. J. Temsirolimus. Recent Results Cancer Research 2010, 184, 189. [CrossRef] [PubMed] 
${ }^{498}$ Clinical Trials.gov's website - A service of the U.S. National Institutes of Health. Available at: $<$ https://clinicaltrials.gov/ct2/results?term=Temsirolimus\&Search=Search $>$. Accessed in: August $21^{\text {st }} 2016$.

499 Biovision website -- safety data sheet for Temsirolimus: Available at: $<$ http://aslb.jp/sites/default/files/MSDS/BioVision/1600 MSDS.pdf $>$. Accessed in: August $21^{\text {st }}$ 2016.

${ }^{500}$ Goh, K. C.; Novotny-Diermayr, V.; Hart, S.; Ong, L. C.; Loh, Y. K.; Cheong, A.; Tan, Y. C.; Hu, C.; Jayaraman, R.; William, A. D.; Sun, E. T.; Dymock, B. W.; Ong, Ethirajulu, K. H.; Burrows, F.; Wood, J. M. TG02, a novel oral multi-kinase inhibitor of CDKs, JAK2 and FLT3 with potent antileukemic properties. Leukemia 2012, 26, 236. [CrossRef] [PubMed]

${ }^{501}$ William, A. D.; Lee, A. C.-H.; Goh, K. C.; Blanchard, S.; Poulsen, A.; Teo, E. L.; Nagaraj, H.; Lee, C. P.; Wang, H.; Williams, M.; Sun, E. T.; Hu, C.; Jayaraman, R.; Pasha, M. K.; Ethirajulu, K.; Wood, J. M.; Dymock, B. W. Discovery of Kinase Spectrum Selective Macrocycle (16E)-14Methyl-20-oxa-5,7,14,26-tetraazatetracyclo[19.3.1.1(2,6).1(8,12)] heptacosa-

1(25),2(26),3,5,8(27),9,11,16,21,23-decaene (SB1317/TG02), a Potent Inhibitor of Cyclin Dependent Kinases (CDKs), Janus Kinase 2 (JAK2), and Fms-like Tyrosine Kinase-3 (FLT3) for the Treatment of Cancer. Journal of Medicinal Chemistry 2012, 55, 169. [CrossRef] [PubMed]

${ }^{502}$ Clinical Trials.gov's website - A service of the U.S. National Institutes of Health. Available at:<https://clinicaltrials.gov/ct2/results?term=TG2\&Search=Search $>$. Accessed in: August $21^{\text {st }}$ 2016.

503 Ebiochemicals website - Safety Data Sheet for TG02. Available at: $<$ http://www.ebiochemicals.com/Wiki/wikiEB000022616.html >. Accessed in: August $21^{\text {st }}$ 2016.

${ }^{504}$ Wernig, G.; Kharas, M. G.; Okabe, R.; Moore, S. A.; Leeman, D. S.; Cullen, D. E.; Gozo, M.; McDowell, E. P.; Levine, R. L.; Doukas, J.; Mak, C. C.; Noronha, G.; Martin, M.; Ko, Y. D.; Lee, B. H.; Soll, R. M.; Tefferi, A.; Hood, J. D.; Gilliland, D. G. Efficacy of TG101348, a selective JAK2 inhibitor, in treatment of a murine model of JAK2V617F-induced polycythemia vera. Cancer Cell 2008, 13, 311. [CrossRef] [PubMed]

${ }^{505}$ Lasho, T. L.; Tefferi, A.; Hood, J. D.; Verstovsek, S.; Gilliland, D. G.; Pardanan, A. TG101348, a JAK2-selective antagonist, inhibits primary hematopoietic cells derived from myeloproliferative disorder patients with JAK2V617F, MPLW515K or JAK2 exon 12 mutations as well as mutation negative patients. Leukemia 2008, 22, 1790. [CrossRef] [PubMed]

${ }^{506}$ Clinical Trials.gov's website - A service of the U.S. National Institutes of Health. Available at: $<$ https://clinicaltrials.gov/ct2/results?term $=$ TG101348\&Search=Search $>. \quad$ Accessed in: August $21^{\text {st }} 2016$.

507 Selleckchem.com - Inhibitor Expert (Inhibitors, Compound Libraries) website - Safety Data Sheet for TG101348. Available at: <http://www.selleckchem.com/msds/MSDS S2736.pdf>. Accessed in: August $21^{\text {st }} 2016$.

508 Businesswire webste. Available at: <http://www.businesswire.com/news/home/20080414006428/en/AVEO-PharmaceuticalsTriple-VEGF-Receptor-Inhibitor-Shows $>$. Accessed in: August, $28^{\text {th }} 2016$.

${ }^{509}$ Eskens, F. A. L. M.; Jonge, M. J. A.; Bhargava, P.; Isoe, T.; Cotreau, M. M.; Esteves, B.; Hayashi, K.; Burger, H.; Thomeer, M.; Doorn, L. V.; Verweij, J. Biologic and Clinical Activity of Tivozanib (AV-951, KRN-951), a Selective Inhibitor of VEGF Receptor-1, -2, and -3 Tyrosine Kinases, in a 4-Week-On, 2-Week-Off Schedule in Patients with Advanced Solid Tumors. Clinical Cancer Research 2011, 17, 7156. [CrossRef] [PubMed] 
${ }^{510}$ Clinical Trials.gov's website - A service of the U.S. National Institutes of Health. Available at: $<$ https://clinicaltrials.gov/ct2/results?term=Tivozanib\&Search=Search $>$. Accessed in: August $21^{\text {st }} 2016$.

${ }^{511}$ Selleckchem.com - Inhibitor Expert (Inhibitors, Compound Libraries) website - Safety Data Sheet for Tivozanib. Available at: <http://www.selleckchem.com/msds/MSDS S1207.pdf>. Accessed in: August $21^{\text {st }} 2016$.

512 Abe, H.; Kikuchi, S.; Hayakawa, K.; lida, T.; Nagahashi, N.; Maeda, K.; Sakamoto, J.; Matsumoto, N.; Miura, T.; Matsumura, K.; Seki, N.; Inaba, T.; Kawasaki, H.; Yamaguchi, T.; Kakefuda, R.; Nanayama, T.; Kurachi, H.; Hori, Y.; Yoshida, T.; Kakegawa, J.; Watanabe, Y.; Gilmartin, A. G.; Richter, M. C.; Moss, K. G.; Laquerre, S. G. Discovery of a Highly Potent and Selective MEK Inhibitor: GSK1120212 (JTP-74057 DMSO Solvate). American Chemical Society Medicinal Chemistry Letters 2011, 2, 320. [CrossRef] [PubMed]

${ }^{513}$ Gilmartin, A. G.; Bleam, M. R.; Groy, A.; Moss, K. G.; Minthorn, E. A.; Kulkarni, S. G.; Rominger, C. M.; Erskine, S.; Fisher, K. E.; Yang, J.; Zappacosta, F.; Annan, R.; Sutton, D.; Laquerre, S. G. GSK1120212 (JTP-74057) Is an Inhibitor of MEK Activity and Activation with Favorable Pharmacokinetic Properties for Sustained in Vivo Pathway Inhibition. Clinical Cancer Research 2011, 17, 989. [CrossRef] [PubMed]

${ }^{514}$ Kim, K. B.; Kefford, R.; Pavlick, A. C.; Infante, J. R.; Ribas, A.; Sosman, J. A.; Fecher, L. A.; Millward, M.; McArthur, G. A.; Hwu, P.; Gonzalez, R; Ott, P. A.; Long, G. V.; Gardner, O. S.; Ouellet, D.; Xu, Y.; DeMarini, D. J.; Le, N. T.; Patel, K.; Lewis, K. D. Phase II Study of the MEK1/MEK2 Inhibitor Trametinib in Patients with Metastatic BRAF-Mutant Cutaneous Melanoma Previously Treated with or Without a BRAF Inhibiton. Journal of Clinical Oncology 2013, 31, 482. [CrossRef] [PubMed]

${ }^{515}$ Clinical Trials.gov's website - A service of the U.S. National Institutes of Health. Available at:<https://clinicaltrials.gov/ct2/results?term=Trametinib\&Search=Search>. Accessed in: August $21^{\text {st }} 2016$.

${ }^{516}$ Selleckchem.com - Inhibitor Expert (Inhibitors, Compound Libraries) website - Safety Data Sheet for Trametinib. Available at: <http://www.selleckchem.com/msds/MSDS S2673.pdf>. Accessed in: August $21^{\text {st }} 2016$.

${ }^{517}$ Gazit, A.; Osherov, N.; Posner, I.; Yaish, P.; Poradosu, E.; Gilon, C.; Levitzki, A. Tyrphostins. II. Heterocyclic and $\alpha$-substituted benzylidenemalononitrile tyrphostins as potent inhibitors of EGF receptor and ErbB2/neu tyrosine kinases. Journal of Medicinal Chemistry 1991, 34, 1896.

${ }^{518}$ Meydan, N.; Grunberger, T.; Dadi, H.; Shahar, M.; Arpaia, E.; Lapidot, Z.; Leeder, J. S.; Freedman, M.; Cohen, A.; Gazit, A.; Levitzki, A.; Fifman, C. M. Inhibition of acute lymphoblastic leukaemia by a Jak-2 inhibitor. Nature 1996, 379, 645. [CrossRef] [PubMed]

${ }^{519}$ Clinical Trials.gov's website - A service of the U.S. National Institutes of Health. Available at: $<$ https://clinicaltrials.gov/ct2/results?term=TYRPHOSTIN+AG+490\&Search=Search>. Accessed in: September $18^{\text {th }} 2016$.

520 Biovision website -- safety data sheet for Tyrphostin AG 490. Available at: $<$ http://www.biovision.com/manuals/1570 MSDS.pdf >. Accessed in: August $21^{\text {st }} 2016$.

${ }^{521}$ Barker, A. J.; Canada. 1993. (CA 2086968 A1)

522 Osherov, N.; Levitzki, A. Epidermal-Growth-Factor-Dependent Activation of the Src-Family Kinases. European Journal of Biochemistry 1994, 225, 1047. [CrossRef] [PubMed]

${ }^{523}$ Vos, J. D.; Jourdan, M.; Tarte, K.; Jasmin, C.; Klein, B. JAK2 tyrosine kinase inhibitor tyrphostin AG490 downregulates the mitogen-activated protein kinase (MAPK) and signal transducer and activator of transcription (STAT) pathways and induces apoptosis in myeloma cells. British Journal of Haematology 2000, 109, 823. [CrossRef] [PubMed] 
${ }^{524}$ Clinical Trials.gov's website - A service of the U.S. National Institutes of Health. Available at: $<$ https://clinicaltrials.gov/ct2/results?term=TYRPHOSTIN+AG+1478\&Search=Search>. Accessed in: September $18^{\text {th }} 2016$.

${ }^{525}$ ThermoFisher Scientific website - Safety Data Sheet for Tyrphostin AG 1478. Available at: $<$ https://tools.thermofisher.com/content/sfs/manuals/PHZ1034 Rev\%203.0.pdf >. Accessed in: August $21^{\text {st }} 2016$.

${ }^{526}$ Middleton, W. J.; Engelhardt, V. A.; Fisher, B. S. Cyanocarbon Chemistry. VIII. Heterocyclic Compounds from Tetracyanoethylene. Journal of the American Chemical Society 1958, 80, 2822. [CrossRef]

${ }^{527}$ Duncia, J. V.; Santella, J. B.; Higley, C. A.; Pitts, W. J.; Wityak, J.; Frietze, W. E.; Rankin, F. W.; Sun, J.; Earl, R. A.; Tabaka, A. C.; Teleha, C. A.; Blom, K. F.; Favata, M. F.; Manos, E. J.; Daulerio, A. J.; Stradley, D. A.; Horiuchi, K.; Copeland, R. A.; Scherle, P. A.; Trzaskos, J. M.; Magolda, R. L.; Trainor, G. L.; Wexler, R. R.; Hobbs, F. W.; Olson, R. E. MEK inhibitors: The chemistry and biological activity of U0126, its analogs, and cyclization products. Bioorganic \& Medicinal Chemistry Letters 1998, 8, 2839. [CrossRef] [PubMed]

${ }^{528}$ Davies, S. P.; Reddy, H.; Caivano, M.; Cohen, P. Specificity and mechanism of action of some commonly used protein kinase inhibitors. Biochemical Journal 2000, 351, 95. [CrossRef] [PubMed]

${ }^{529}$ Clinical Trials.gov's website - A service of the U.S. National Institutes of Health. Available at: $<$ https://clinicaltrials.gov/ct2/results?term $=U+0126 \&$ type $=\& \mathrm{rs} / \mathrm{t}=\& \mathrm{recr}=$ \&age $\mathrm{v}=$ \&gndr $=\&$ cond $=$ Cancer\&intr $=\&$ titles $=\&$ outc $=\&$ spons $=\& l e a d=\& i d=\&$ state $1=\&$ cntry $1=\&$ state $2=\&$ cntry $2=\&$ state 3=\&cntry3=\&locn=\&rcv s=\&rcv e=\&lup s=\&lup e=>. Accessed in: February $4^{\text {th }} 2017$.

${ }^{530}$ Clinical Trials.gov's website $-A$ service of the U.S. National Institutes of Health. Available at: $<$ https://clinicaltrials.gov/ct2/results?term=U+0126\&Search=Search $>$. Accessed in: August $21^{\text {st }}$ 2016.

531 ThermoFisher Scientific website - Safety Data Sheet for U0126. Available at: $<$ https://tools.thermofisher.com/content/sfs/manuals/U0126 man.pdf $>$. Accessed in: August $21^{\text {st }} 2016$.

${ }^{532}$ Tinib-Tools website. Available at: <http://www.tinib-tools.com/products U.html>. Accessed in: August $20^{\text {th }} 2016$.

${ }^{533}$ Hennequin, L. F.; Stokes, E. S. E.; Thomas, A. P.; Johnstone, C.; Plé, P. A.; Ogilvie, D. J.; Dukes, M.; Wedge, S. R.; Kendrew, J.; Curwen, J. O. Novel 4-Anilinoquinazolines with C-7 Basic Side Chains: Design and Structure Activity Relationship of a Series of Potent, Orally Active, VEGF Receptor Tyrosine Kinase Inhibitors. Journal of Medicinal Chemistry 2002, 45, 1300. [CrossRef] [PubMed]

${ }^{534}$ Wedge, S. R.; Ogilvie, D. J.; Dukes, M.; Kendrew, J.; Chester, R.; Jackson, J. A.; Boffey, S. J.; Valentine, P. J.; Curwen, J. O.; Musgrove, H. L.; Graham, G. A.; Hughes, G. D.; Thomas, A. P.; Stokes, E. S. E.; Curry, B.; Richmond, G. H. P.; Wadsworth, P. F.; Bigley, A. L.; Hennequin, L. F. ZD6474 Inhibits Vascular Endothelial Growth Factor Signaling, Angiogenesis, and Tumor Growth following Oral Administration. Cancer Research 2002, 62, 4645. [PubMed]

${ }^{535}$ Clinical Trials.gov's website - A service of the U.S. National Institutes of Health. Available at: $<$ https://clinicaltrials.gov/ct2/results?term=Vandetanib\&type=\&rslt=\&recr=\&age $v=\& g n d r=\& C$ ond=Cancer\&intr $=\&$ titles $=\&$ outc $=\&$ spons $=\&$ lead $=\& i d=\&$ state $1=\&$ cntry $1=\&$ state $2=\&$ cntry $2=\&$ st ate3=\&cntry3=\&locn=\&rcv s=\&rcv e=\&lup s=\&lup e=>. Accessed in: February $4^{\text {th }} 2017$.

${ }^{536}$ Clinical Trials.gov's website - A service of the U.S. National Institutes of Health. Available at: $<$ https://clinicaltrials.gov/ct2/results?term=vandetanib\&Search=Search>. Accessed in: August $21^{\text {st }} 2016$. 
${ }^{537}$ Selleckchem.com - Inhibitor Expert (Inhibitors, Compound Libraries) website - Safety Data Sheet for Vandetanib. Available at: <http://www.selleckchem.com/msds/MSDS S1046.pdf>. Accessed in: August $21^{\text {st }} 2016$.

538 Tinib-Tools website. Available at: <http://www.tinib-tools.com/products V.html\#V153>. Accessed in: August $20^{\text {th }} 2016$.

${ }^{539}$ Wood, J. M.; Bold, G.; Buchdunger, E.; Cozens, R.; Ferrari, S.; Frei, J.; Hofmann, F.; Mestan, J.; Mett, H.; O’Reilly, T.; Persohn, E.; Rösel, J.; Schnell, C.; Stover, D.; Theuer, A.; Towbin, H.; Wenger, F.; Woods-Cook, K.; Menrad, A.; Siemeister, G.; Schirner, M.; Thierauch, K.; Schneider, M. R.; Drevs, J.; Martiny-Baron, G.; Totzke, F.; Marme, D. PTK787/ZK 222584, a novel and potent inhibitor of vascular endothelial growth factor receptor tyrosine kinases, impairs vascular endothelial growth factor-induced responses and tumor growth after oral administration. Cancer Research 2000, 60, 2178. [PubMed]

${ }^{540}$ Bold, G.; Altmann, K.; Frei, J.; Lang, M.; Manley, P. W.; Traxler, P.; Wietfeld, B.; Brüggen, J.; Buchdunger, E.; Cozens, R.; Ferrari, S.; Furet, P.; Hofmann, F.; Martiny-Baron, G.; Mestan, J.; Rösel, J.; Sills, M.; Stover, D.; Acemoglu, F.; Boss, E.; Emmenegger, R.; Lässer, L.; Masso, E.; Roth, R.; Schlachter, C.; Vetterli, W.; Wyss, D.; Wood, J. M. New Anilinophthalazines as Potent and Orally Well Absorbed Inhibitors of the VEGF Receptor Tyrosine Kinases Useful as Antagonists of Tumor-Driven Angiogenesis. Journal of Medicinal Chemistry 2000, 43, 2310. [CrossRef] [PubMed]

${ }^{541}$ Clinical Trials.gov's website - A service of the U.S. National Institutes of Health. Available at: $<$ https://clinicaltrials.gov/ct2/results?term=Vatalanib\&type=\&rslt=\&recr=\&age $\mathrm{v}=$ \&gndr $=\&$ co nd=Cancer\&intr $=\&$ titles $=$ \&outc $=\&$ spons $=\& l e a d=\& i d=\&$ state $1=\&$ cntry $1=\&$ state $2=\&$ cntry $2=\&$ sta te3=\&cntry3=\&locn=\&rcv s=\&rcv e=\&lup s=\&lup e=>. Accessed in: February $4^{\text {th }} 2017$.

542 Clinical Trials.gov's website - A service of the U.S. National Institutes of Health. Available at: $<$ https://clinicaltrials.gov/ct2/results?term=Vatalanib+\&Search=Search $>$. Accessed in: August $21^{\text {st }} 2016$.

${ }^{543}$ Apollo Scientific Limited website - safety data sheet of Vatalanib (dihydrochloride): Available at: <http://www.apolloscientific.co.uk/downloads/msds/BIFK0044 msds.pdf>. Accessed in: August 21st 2016.

${ }^{544}$ Reaper, P. M.; Griffiths, M. R.; Long, J. M.; Charrier, J.-D.; MacCormick, S.; Charlton, P. A.; Golec, J. M. C.; Pollard, J. R. Selective killing of ATM- or p53-deficient cancer cells through inhibition of ATR. Nature Chemical Biology 2011, 7, 428. [CrossRef] [PubMed]

${ }^{545}$ Prevo, R.; Fokas, E.; Reaper, P. M.; Charlton, P. A.; Pollard, J. R.; McKenna, W. G.; Muschel, R. J.; Brunne, T. B. The novel ATR inhibitor VE-821 increases sensitivity of pancreatic cancer cells to radiation and chemotherapy. Cancer Biology and Therapy 2012, 13, 1072. [CrossRef] [PubMed]

${ }^{546}$ Pires, I. M.; Olcina, M. M.; Anbalagan, S.; Pollard, J. R.; Reaper, P. M.; Charlton, P. A.; McKenna, W. G.; Hammond, E. M. Targeting radiation-resistant hypoxic tumour cells through ATR inhibition. British Journal of Cancer 2012, 107, 291. [CrossRef] [PubMed]

${ }^{547}$ Reaper, P. M.; Griffiths, M. R.; Long, J. M.; Charrier, J.; MacCormick, S.; Charlton, P. A.; Golec, J. M. C.; Pollard, J. R. Selective killing of ATM- or p53-deficient cancer cells through inhibition of ATR. Nature Chemical Biology 2011, 7, 428. [CrossRef] [PubMed]

${ }^{548}$ Clinical Trials.gov's website - A service of the U.S. National Institutes of Health. Available at: $<$ https://clinicaltrials.gov/ct2/show/NCT00153101?term=VE+-+821\&rank=1>. Accessed in: August $21^{\text {st }} 2016$.

${ }^{549}$ Selleckchem.com - Inhibitor Expert (Inhibitors, Compound Libraries) website - Safety Data Sheet for VE-821. Available at: <http://www.selleckchem.com/msds/MSDS S8007.pdf>. Accessed in: August $21^{\text {st }} 2016$. 
${ }^{550}$ Plexxikon website. Available at < http://www.plexxikon.com/view.cfm/91/press-releases $>$. Accessed in: August, $28^{\text {th }} 2016$.

${ }^{551}$ Smalley, K. S. PLX-4032, a small-molecule B-Raf inhibitor for the potential treatment of malignant melanoma. Current Opinion Investigation Drugs 2010, 11, 699. [PubMed]

${ }^{552}$ Yang, H.; Higgins, B.; Kolinsky, K.; Packman, K.; Go, Z.; Iyer, R.; Kolis, S.; Zhao, S.; Lee, R.; Grippo, J. F.; Schostack, K.; Simcox, M. E.; Heimbrook, D.; Bollag, G.; Su, F. RG7204 (PLX4032), a selective BRAFV600E inhibitor, displays potent antitumor activity in preclinical melanoma models. Cancer Research 2010, 70, 5518. [CrossRef] [PubMed]

${ }^{553}$ Clinical Trials.gov's website - A service of the U.S. National Institutes of Health. Available at: $<$ https://clinicaltrials.gov/ct2/results?term=Vemurafenib\&Search=Search>. Accessed in: August $21^{\text {st }} 2016$.

${ }^{554}$ Apollo Scientific Limited website - safety data sheet of Vemurafenib: Available at: $<$ http://www.apolloscientific.co.uk/downloads/msds/BIFK0039 msds.pdf>. Accessed in: August $21^{\text {st }} 2016$.

555 Vertex Website. Available at $<$ http://investors.vrtx.com/releasedetail.cfm?ReleaselD=233089 $>$. Accessed at August $28^{\text {th }}$ 2016.

${ }^{556}$ Harrington, E. A.; Bebbington, D.; Moore, J.; Rasmussen, R. K.; Ajose-Adeogun, A. O.; Nakayama, T.; Graham, J. A.; Demur, C.; Hercend, T.; Diu-Hercend, A.; Su, M.; Golec, J. M. C.; Miller, K. M. VX-680, a potent and selective small-molecule inhibitor of the Aurora kinases, suppresses tumor growth in vivo. Nature Medicine 2004, 10, 262. [CrossRef] [PubMed]

${ }^{557}$ Giles, F. J.; Cortes, J.; Jones, D.; Bergstrom, D.; Kantarjian, H.; Freedman, S. J. MK-0457, a novel kinase inhibitor, is active in patients with chronic myeloid leukemia or acute lymphocytic leukemia with the T315I BCR-ABL mutation. Blood Journal 2007, 109, 500. [CrossRef] [PubMed] ${ }^{558}$ Cheetham, P. G. M. T.; Charlton, A.; Golec, J. M. C.; Pollard, J. R. Structural basis for potent inhibition of the Aurora kinases and a T315I multi-drug resistant mutant form of Abl kinase by VX-680. Cancer Letters 2007, 251, 323. [CrossRef] [PubMed]

${ }^{559}$ Clinical Trials.gov's website - A service of the U.S. National Institutes of Health. Available at: $<$ https://clinicaltrials.gov/ct2/results?term=VX-

680\&type=\&rslt=\&recr=\&age $v=\& g n d r=\&$ cond $=$ Cancer\&intr=\&titles=\&outc=\&spons=\&lead=\&i $\mathrm{d}=$ \&state1=\&cntry1=\&state2=\&cntry2=\&state3=\&cntry3=\&locn=\&rcv s=\&rcv e=\&lup s=\&lup $\mathrm{e}=>$. Accessed in: February $4^{\text {th }} 2017$.

$\frac{\mathrm{e}}{560}$ Clinical Trials.gov's website $-\mathrm{A}$ service of the U.S. National Institutes of Health. Available at: $<$ https://clinicaltrials.gov/ct2/results?term=VX-680\&Search=Search $>$. Accessed in: August $20^{\text {th }}$ 2016.

${ }^{561}$ Selleckchem.com - Inhibitor Expert (Inhibitors, Compound Libraries) website - Safety Data Sheet for VX-680. Available at: <http://www.selleckchem.com/msds/MSDS S1048.pdf>. Accessed in: August 20 ${ }^{\text {th }}$ 2016,

${ }^{562}$ Osborne, C. K.; Schiff, R.; Shou, J. P38 MAPK pathway predicts endocrine-resistant growth of human breast cancer and provides a novel diagnostic and treatment target. Patent WO 2003000189 A2, Jan 3, 2003.

${ }^{563}$ Zhao, J.; Zhang, Z.; Du, W. Mutation of the retinoblastoma tumor suppressor gene sensitizes cancers to mitotic inhibitor induced cell death. American Journal of Cancer Research 2014, 4, 42. [PubMed]

${ }^{564}$ Clinical Trials.gov's website - A service of the U.S. National Institutes of Health. Available at: $<$ https://clinicaltrials.gov/ct2/show/NCT00205478?term=VX-702\&rank=2>. Accessed in: August $20^{\text {th }} 2016$. 
565 Cellagen Technology website - Safety Data Sheet. Available at: $<$ https://www.cellagentech.com/content/product files/VX-702 Product specification.pdf $>$. Accessed in: August $20^{\text {th }} 2016$.

${ }^{566}$ Ayral-Kaloustian, S.; Bursavich, M. G.; Cole, D. C.; Curran, K. J.; Kaplan, J.; Lefever, M.; Malwitz, D.; Nowak, P. W.; Richard, D. J.; Verheijen, J.; Yu, K.; Zask, A.; 2008. (WO 2008115974 A2)

${ }^{567}$ Yu, K.; Toral-Barza, L.; Shi, C.; Zhang, W.; Lucas, J.; Shor, B.; Kim, J.; Verheijen, J.; Curran, K.; Malwitz, D. J.; Cole, D. C.; Ellingboe, J.; Ayral-Kaloustian, S.; Mansour, T. S.; Gibbons, J. J.; Abraham, R. T.; Nowak, P.; Zask, A. Biochemical, cellular, and in vivo activity of novel ATPcompetitive and selective inhibitors of the mammalian target of rapamycin. Cancer Research 2009, 69, 6232. [CrossRef] [PubMed]

${ }^{568}$ Clinical Trials.gov's website - A service of the U.S. National Institutes of Health. Available at:

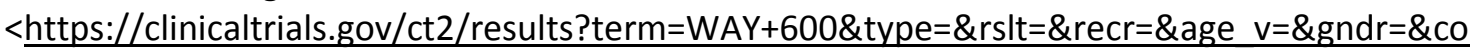
nd=Cancer\&intr=\&titles=\&outc=\&spons=\&lead=\&id=\&state1=\&cntry1=\&state2=\&cntry2=\&sta te3=\&cntry3=\&locn=\&rcv s=\&rcv e=\&lup s=\&lup e=>. Accessed in: February $4^{\text {th }} 2017$.

${ }^{569}$ Clinical Trials.gov's website - A service of the U.S. National Institutes of Health. Available at: $<$ https://clinicaltrials.gov/ct2/results?term $=W A Y+-+600 \& S e a r c h=S e a r c h>$. Accessed in: August $21^{\text {st }} 2016$.

${ }^{570}$ Selleckchem.com - Inhibitor Expert (Inhibitors, Compound Libraries) website - Safety Data Sheet for WAY-600. Available at: <http://www.selleckchem.com/msds/MSDS S2689.pdf>. Accessed in: August $20^{\text {th }} 2016$.

${ }^{571}$ Tinib-Tools website. Available at: <http://www.tinib-tools.com/products W.html\#W092>. Accessed in: August $20^{\text {th }} 2016$.

${ }^{572}$ Brian, P. W.; Curtis, P. J.; Hemming, H. G.; Norris, G. F. L. Differential rhizosphere effects of three pea cultivars on physiologic races of Fusarium oxysporum $f$. pisi. Transactions of the British Mycological Society 1957, 40, 365. [CrossRef]

573 MacMillan, J.; Vanstone, A. E.; Yeboah, S. K. Fungal Products. Part II. Structure and Stereochemistry of the Acid $\mathrm{C}_{18} \mathrm{H}_{16} \mathrm{O}_{5}$, a Degradation Product of Wortmannin. Journal of Chemical Society, Perkin Transactions 1 1972, 2898. [CrossRef]

574 Wymann, M. P.; Bulgarelli-Leva, G.; Zvelebil, M. J.; Pirola, L.; Vanhaesebroeck, B.; Warterfield, M. D.; Panayotou, G. Wortmannin Inactivates Phosphoinositide 3-Kinase by Covalent Modification of Lys-802, a Residue Involved in the Phosphate Transfer Reaction. Molecular and Cellular Biology 1996, 16, 1722. [CrossRef] [PubMed]

${ }^{575} \mathrm{Ui}, \mathrm{M}$.; Okada, T.; Hazeki, K.; Hazeki, O. Wortmannin as a unique probe for an intracellular signalling protein, phosphoinositide 3-kinase. Trends in Biochemical Sciences 1995, 20, 303. [CrossRef] [PubMed]

${ }^{576}$ Boehle, A. S.; Kurdow, R.; Boenicke, L.; Schniewind, B.; Faendrich, F.; Dohrmann, P.; Kalthoff, H. Wortmannin inhibits growth of human non-small-cell lung cancer in vitro and in vivo. Langenbeck's Archives of Surgery 2002, 387, 234.

${ }^{577}$ Clinical Trials.gov's website - A service of the U.S. National Institutes of Health. Available at: $<$ https://clinicaltrials.gov/ct2/show/NCT00534261?term=Wortmannin\&rank=1>. Accessed in: August $20^{\text {th }} 2016$.

578 Tocris a biothecne brand website - safety datasheet of Wortmannin. Available at: $<$ https://www.tocris.com/literature/1232 sds.pdf?1471725250>. Accessed in: August $20^{\text {th }}$ 2016.

${ }^{579}$ Shor, B.; Wu, J.; Shakey, Q.; Toral-Barza, L.; Shi, C.; Follettie, M.; Yu, K. Requirement of the mTOR Kinase for the Regulation of Maf1 Phosphorylation and Control of RNA Polymerase IIIdependent Transcription in Cancer Cells. The Journal of Biological Chemistry 2010, 285, 15380. [CrossRef] [PubMed] 
${ }^{580}$ Yu, K.; Shi, C.; Toral-Barza, L.; Lucas, J.; Shor, B.; Kim, J.E.; Zhang, W.; Mahoney, R.; Gaydos, C.; Tardio, L. Kim, S. K.; Conant, R.; Curran, K.; Kaplan, J.; Verheijen, J.; Ayral-Kaloustian, S.; Mansour, T. S.; Abraham, R. T.; Zask, A.; Gibbons, J. J. Beyond Rapalog Therapy: Preclinical Pharmacology and Antitumor Activity of WYE-125132, an ATP-Competitive and Specific Inhibitor of mTORC1 and mTORC2. Cancer Research 2010, 70, 621. [CrossRef] [PubMed]

${ }^{581}$ Clinical Trials.gov's website - A service of the U.S. National Institutes of Health. Available at: $<$ https://clinicaltrials.gov/ct2/results?term=WYE\&Search=Search $>$. Accessed in: August $21^{\text {st }}$ 2016.

582 Abcam website - material safety data sheet for WYE-125132. Available at: $<$ http://www.abcam.com/wye-125132-wye-132-ab143866.html >. Accessed in: August $20^{\text {th }}$ 2016.

${ }^{583}$ Zhou, W.; Ercan, D.; Chen, L.; Yun, C.; Li, D.; Capelletti, M.; Cortot, A.; Chirieac, L.; lacob, R.; Padera, R.; Engen, J.; Wong, K.; Eck, M.; Gray, N.; Jänne, P. Novel mutant-selective EGFR kinase inhibitors against EGFR. T790M. Nature 2009, 462, 1070. [CrossRef] [PubMed]

${ }^{584}$ Clinical Trials.gov's website - A service of the U.S. National Institutes of Health. Available at: $<$ https://clinicaltrials.gov/ct2/results?term=wZ3146\&Search=Search>. Accessed in: September $18^{\text {th }} 2016$.

${ }^{585}$ Selleckchem.com - Inhibitor Expert (Inhibitors, Compound Libraries) website - Safety Data Sheet for WZ3146. Available at: <http://www.selleckchem.com/msds/MSDS S1170.pdf>. Accessed in: August $20^{\text {th }} 2016$.

${ }^{586}$ Capot Chemical Co., Ltd. website - material safety data sheet of WZ8040. Available at: $<$ http://www.capotchem.com/MSDS/msds 22456.pdf> Accessed in: August $20^{\text {th }} 2016$.

${ }^{587}$ Ditchfield, C.; Johnson, V.; Tighe, A.; Ellston, R.; Haworth, C.; Johnson, T.; Mortlock, A.; Keen, N.; Taylor, S.; Aurora B couples chromosome alignment with anaphase by targeting BubR1, Mad2, and Cenp-E to kinetochores. The Journal of Cell Biology 2003, 161, 267. [CrossRef] [PubMed]

${ }^{588}$ Li, M.; Jung, A.; Ganswindt, U.; Marini, P.; Friedl, A.; Daniel, P.; Lauber, K.; Jendrossek, V.; Belka, C. Aurora kinase inhibitor ZM447439 induces apoptosis via mitochondrial pathways. Biochemical Pharmacology 2010, 79, 122. [CrossRef] [PubMed]

${ }^{589}$ Tocris website - Safety Data sheet for ZM44743. Available at: <https://www.tocris.com/>. Accessed in: August $20^{\text {th }} 2016$.

590 Tinib-Tools website. Available at: <http://www.tinib-tools.com/products Z.html\#Z143>. Accessed in: August $20^{\text {th }} 2016$.

${ }^{591}$ Yaguchi, S.; Izumisawa, Y.; Sato, M.; Nakagane, T.; Koshimizu, I.; Sakita, K.; Kato, M.; Yoshioka, K.; Sakato, M.; Kawashima, S. In vitro cytotoxicity of imidazolyl-1,3,5-triazine derivatives. Biological \& Pharmaceutical Bulletin 1997, 20, 698. [CrossRef] [PubMed]

592 Yaguchi, S.; Fukui, Y.; Koshimizu, I.; Yoshimi, H.; Matsuno, T.; Gouda, H.; Hirono, S.; Yamazaki, K.; Yamori, T. Antitumor Activity of ZSTK474, a New Phosphatidylinositol 3-Kinase Inhibitor. Journal of the National Cancer Institute 2006, 98, 545. [CrossRef] [PubMed]

${ }^{593}$ Kong, D.; T. Yamori, ZSTK474 is an ATP competitive Inhibitor of Class I Phosphatidylinositol 3-Kinase Isoforms. Cancer Science 2007, 98, 1638. [CrossRef] [PubMed]

${ }^{594}$ Toyama, S.; Tamura, N.; Haruta, K.; Karakida, T.; Mori, S.; Watanabe, T.; Yamori, T.; Takasaki, Y. Inhibitory Effects of ZSTK474, a Novel Phosphoinositide 3-Kinase Inhibitor, on Osteoclasts and Collagen-induced Arthritis in Mice. Arthritis Research \& Therapy 2010, 31, 1189. [CrossRef] [PubMed]

${ }^{595}$ Selleckchem.com - Inhibitor Expert (Inhibitors, Compound Libraries) website - Safety Data Sheet for ZSTK474. Available at: <http://www.selleckchem.com/msds/MSDS S1072.pdf>. Accessed in: August $20^{\text {th }} 2016$. 
Costa, D. C. S. et al.

${ }^{596}$ Clinical Trials.gov's website - A service of the U.S. National Institutes of Health. Available at: $<$ https://clinicaltrials.gov/ct2/show/study/NCT01280487?view=results $>$. Accessed in: August $20^{\text {th }} 2016$. 